Portland State University

PDXScholar

Spring 6-5-2017

\title{
Middle School Teacher Beliefs about Classroom Diversity and their Influence on Differentiated Instructional Practices
}

Marcus Fredrick-Lynn Wenzel

Portland State University

Follow this and additional works at: https://pdxscholar.library.pdx.edu/open_access_etds

Part of the Curriculum and Instruction Commons, Educational Methods Commons, and the Junior High, Intermediate, Middle School Education and Teaching Commons Let us know how access to this document benefits you.

\section{Recommended Citation}

Wenzel, Marcus Fredrick-Lynn, "Middle School Teacher Beliefs about Classroom Diversity and their Influence on Differentiated Instructional Practices" (2017). Dissertations and Theses. Paper 3612. https://doi.org/10.15760/etd.5504

This Dissertation is brought to you for free and open access. It has been accepted for inclusion in Dissertations and Theses by an authorized administrator of PDXScholar. Please contact us if we can make this document more accessible: pdxscholar@pdx.edu. 
Middle School Teacher Beliefs about Classroom Diversity and Their Influence on Differentiated Instructional Practices

by

Marcus Fredrick-Lynn Wenzel

A dissertation submitted in partial fulfillment of the requirements for the degree of

Doctor of Education

in

Educational Leadership: Curriculum and Instruction

Dissertation Committee:

Dannelle D. Stevens, Chair

Micki M. Caskey

Ulrich H. Hardt

Matthew Carlson

Portland State University

2017 


\begin{abstract}
Diversity across U.S. classrooms is on the rise which is leading to renewed calls for teachers to meet individual learning needs. Studies indicate the failure to address individual learning needs can lead to higher rates of student disengagement, off-task behaviors, and diminished learning outcomes. Differentiated instruction is an approach to teaching that meets the growing diversity of individual learning needs by considering students' readiness, interest, and learning styles. Differentiated instructional approaches help teachers meet individual learning needs by allowing them to modify instruction as needed. However, despite the apparent benefits of differentiated instruction, teachers are hesitant to abandon other educational models. Research has shown beliefs about student learning influence teachers classroom practices. If teachers do not possess beliefs supporting differentiated classroom practices, then calls for additional implementation may go unheeded. Thus it is important to examine teacher beliefs that may help or hinder implementation of differentiated instructional practices. The purpose of this study was to explore teacher beliefs connected to teaching, learning, and differentiated instruction in diverse classrooms. This study used qualitative case study methodologies to interview, survey, and observe the beliefs and practices of four white, female, veteran middle level educators operating in diverse classroom settings. Data analysis led to the identification of revealed the following themes: (a) differentiated instruction is considered essential, (b) teachers' diversity definitions influenced their differentiated instructional strategies, (c) the classroom environment influences teachers self-efficacy, and (d) professional development sessions support differentiated instructional practices. Conclusions drawn
\end{abstract}


from this study may be used to help improve teacher practices-and ultimately learner outcomes - by informing teacher preparation and professional development, state and local educational policies, and curricular reform efforts. 


\section{Dedication}

This is dedicated to my wife, Alicia. I do not need any qualitative research methods to prove I am the luckiest guy in the whole world. 


\title{
Acknowledgements
}

\author{
Dr. Dannelle D. Stevens \\ Dr. Micki M. Caskey \\ Dr. Ulrich H. Hardt \\ Dr. Matthew Carlson \\ Dr. Susan J. Lenski \\ Dr. Swapna Mukhopadhyay \\ Dr. Ken Carano \\ Dr. Greg Zobel \\ Dr. Mark Girod \\ Jason Foltz- Oregon Education Association \\ Donna Webb \\ Haven \\ Lynn \& Martha \\ Joyce Stein
}


Table of Contents

Abstract............................................................

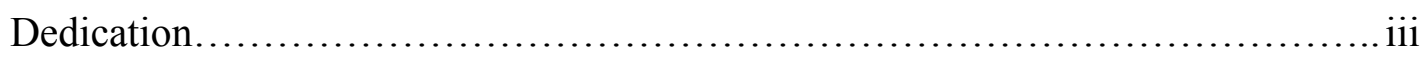

Acknowledgements................................................. iv

List of Tables...................................................... viii

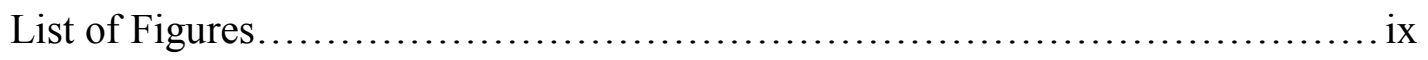

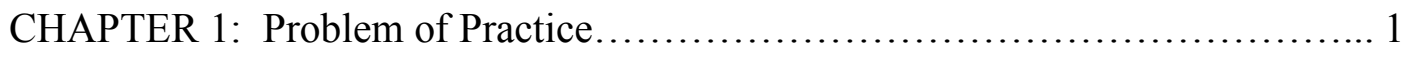

Introduction to the Problem...................................... 1

Background of the Research Problem............................. 6

Statement of the Research Problem.............................. 15

Significance of the Research Problem............................. 16

Presentation of the Research Question and Methods................... 19

Definitions of Key Concepts................................. 21

CHAPTER 2: Literature Review........................................ 24

Theoretical Framework: Social Cognitive Theory.................... 24

Conceptual Framework: Teacher Beliefs and Practices................. 28

Review of the Research Literature

Adaptive Teaching Competency.............................. 33

Foundations of Teachers' Beliefs........................... 35

Teachers Beliefs about Diverse Learners..................... 40

Differentiated Instruction............................... 47

Association between Teachers' Beliefs and DI Practices......... 52 
Critiques of Differentiated Instruction...................... 55

Influence of Classroom Diversity........................ 57

Review of the Methodological Literature

Measuring Teacher Beliefs............................... 62

Selection of Research Methods.............................. 63

CHAPTER 3: Methodology.......................................... 67

Research Paradigms............................................. 67

Research Methods............................................... 70

Context and Participants....................................... 71

Procedures...................................................... 78

Instruments \& Measures............................................ 79

Data Collection \& Analysis......................................... 83

Trustworthiness \& Researcher Bias................................... 87

Limitations.................................................. 88

CHAPTER 4: Data and Analysis......................................... 92

Analysis of Data................................................ 92

Presentation of Data............................................... 95

Interpretation of Findings..................................... 130

CHAPTER 5: Discussion and Conclusions.................................. 148

Synthesis of Findings........................................... 149

Situated in Larger Context........................................ 155

Recommendations............................................. 156 
References............................................................... 161

Appendices.......................................................... 187

Appendix A. Semi-Structured Interview Questions................... 187

Appendix B. Teacher Cultural Beliefs Scale......................... 188

Appendix C. Semi-Structured Interview 2 Questions.....................189

Appendix D. Classroom Differentiated Instructional Observation Codes....190 


\section{List of Tables}

Table 1. Gaps between Recommended Practices and Teachers' Interpretations..... 54

Table 2. Qualitative Instruments Selected and Constructs Measured............... 75

Table 3. Results from the Teacher Cultural Belief Scale...........................134 


\section{List of Figures}

Figure 1. Model of Triadic Reciprocal Determination of Social Cognitive Theory. 25

Figure 2. Framework for the Analysis of Teacher Beliefs and Practices............ 30

Figure 3. Differentiated Instructional Practices............................. 48

Figure 4. Belief Constructs...........................................60

Figure 5. Research Questions and Selected Methods........................... 64

Figure 6. Thematic Network Analysis....................................... 85 


\section{Chapter 1: Problem of Practice}

Today's student population is rapidly becoming more culturally, linguistically, ethnically, and economically diverse (Capps, Fix, Murray, Ost, Passel, \& Herwantoro, 2005; Tomlinson, 2014). A significant challenge facing educators in the United States today is how to address this growing diversity while also navigating the requirements of standards-based reforms (Dixon, Yssel, McConnell, \& Hardin, 2014; Lee \& Picanco, 2013; Morgan, 2014; Robinson, Maldonado, \& Whaley, 2014; Sherman, 2009;

Tomlinson, 2014). The rise in student diversity increases pressures on teachers to reduce gaps in learning outcomes between different populations of their students as measured by Common Core State Standards (CCSS).

In many cases, these pressures originated with policy and administrative responses to the No Child Left Behind Act (NCLB) implemented in 2001. This education initiative was intended to raise educational achievement and close achievement gaps (U.S. Department of Education, 2002), but schools and districts faced penalties when they failed to meet Average Yearly Progress (AYP) as measured by a yearly standardized assessment. NCLB also led to a number of unintended consequences. These included adopting curricula that failed to foster meaningful learning among learners, standardized teaching practices that mimicked testing formats, and inordinate academic pressures on English language learners (ELLs), students with disabilities (SWDs), and other low-scoring students (Darling-Hammond, 2007; McTighe \& Brown, 2010).

Teacher pressures have intensified with the adoption of the CCSS, a more rigorous set of academic standards. Teachers must teach more challenging concepts and 
content to more diverse student populations and meet the specific learning needs of students but have few supports or guidance for doing so. "The Standards set gradespecific standards but do not define the intervention methods or materials necessary to support students who are well below or well above grade-level expectations" (Common Core State Standards Initiative, 2012, para. 3). This means although the standards specify academic goals for students, teachers are not provided with strategies or tools to meet the needs of all types of learners. In sum, a primary task for teachers is to meet required standards-driven accountability mandates while remaining responsive to the needs of diverse learners (McTighe \& Brown, 2010). On the surface, these tasks may seem like reasonable ones, but reconciling how to simultaneously meet the needs of diverse learners and of rigorous academic standards continues to be a challenge for teachers.

While some students have flourished under the new accountability policies, others have not. According to The Nations Report Card (NAEP, 2013) eighth grade math and reading scores show significant disparities between African-American, Latino, and students from poverty as compared to White and Asian students. The disparities between these two groups were equivalent to a three year difference in learning outcomes. In addition to the differences between these groups, research indicates significant achievement gaps for students with special needs. Thurlow, Moen, and Altman (2006) found approximately 70 percent of students with Individual Education Plans (IEPs) did not meet proficiency levels on state mandated reading and math tests. 
Making matters worse, according to Sullivan, Klingbeil, and Norman (2013) found lower scoring students were also more likely to experience disproportionate levels of exclusionary school discipline (i.e., higher suspension rates). Consequently, students who struggle in middle school are more likely to drop out of high school than students who do not (Balfanz, Herzog, \& Mac Iver, 2007). Ultimately, by the end of middle school, certain groups of students are being left behind.

These inequalities have placed considerable stress on middle level teachers to increase their students' learning outcomes or academic achievement despite an everwidening diverse student population. While middle school classrooms have always featured a diverse mix of cognitive levels, life experiences, and developmental stages, the teachers in those rooms are under increasing pressure to meet young adolescents' varied social, emotional, and developmental needs by supporting classroom diversity (National Middle School Association, 2010). Yet while student diversity and academic achievement expectations keep rising, teachers feel pressure to find effective instructional practices and create learning environments that meet rising and shifting expectations.

This pressure comes from the highest levels of government: a Council of Foreign Relations study cited poor high school graduation rates, large performance gaps between middle and lower class students, and the general perception that public school graduates are not adequately prepared for careers in the $21^{\text {st }}$ century (Klein \& Rice, 2012). Hyperbole aside, the important role middle schools can play during adolescent development necessitates middle level teachers revisit their instructional and managerial 
practices used to address individual learning needs so students can succeed academically and be prepared for their futures.

Santamaria (2009) claimed the best classroom teachers pay attention to academic, cultural, linguistic, and socioeconomic diversity. Research demonstrates that when students are in responsive classrooms where they are viewed as individuals and their learning is supported, their attitudes and academic success improves (Ryan \& Cooper, 2007). One practice involves differentiated instructional interventions targeted towards middle school students (Brighton, 2003; Little, McCoach, \& Reis, 2014; Moon, Tomlinson, \& Callahan, 1995). Differentiated instruction calls for teachers to address a broad range of student readiness levels, interests, and modes of learning. According to Tomlinson (2014), differentiated instruction is a philosophy of teaching that enables teachers "to reach out effectively to students who span the spectrum of learning readiness, personal interests, and culturally shaped ways of seeing and speaking about and experiencing the world" (p. 1). In short, differentiated instruction supports students who learn in different ways, at different rates, and possess different talents and interests. However, successfully employing differentiated instructional practices suggests middle school teachers possess a particular set of beliefs (Wenzel \& Roberts, 2014). Some researchers maintain teacher beliefs influence teacher practices (Buehl \& Beck, 2015; Pajares, 1992; Woolfolk-Hoy, Davis, \& Pape, 2006). Teacher beliefs can influence classroom practices by serving to filter, frame, and guide teachers' experiences, decisions, and actions (Fives \& Buehl, 2012). As Bandura (1997) explained, "People’s level of motivation, affective states, and actions are based more on what they believe than 
on what is objectively true" (p. 2). If so, then educators need to reassess the popular assumption that solutions to educational achievement for diverse students can be mandated without also addressing underlying teacher beliefs about classroom diversity.

More than 10 years ago, Tomlinson et al. (2003) hypothesized the interest in differentiated instruction was due to the rising level of classroom diversity that "teachers... can no longer ignore" (p. 121). Since then, a growing body of scholarship supports the use of differentiated instruction to meet diverse student needs (Hood, 2012; Little et al., 2014; Parker, 2011; Subban, 2006; Tomlinson, 2014). Differentiated instructional practices would seem a good fit for the current realities of diverse classrooms and accountability mandates. However, despite the appeal of differentiated instruction, many teachers have not adjusted their classroom practices (Brighton, 2003; Fairbanks et al., 2009; Sherman, 2009).

Wormelli (2007) concluded the most important teacher characteristic for successful differentiation is their "mind set." Although most teachers generally accept the necessity of addressing individual learner's needs, many teachers believe they are inadequately prepared to plan and implement differentiated instruction (Archambault et al., 1993; Joseph, 2013; Lalvani, 2013; Reis, Gentry, \& Maxfield, 1998; Reis et al., 2004; Rochkind, Ott, Immerwahr, Doble, \& Johnson, 2007; Smit \& Humpert, 2012; Tomlinson et al., 2003). In other words, rather than viewing classroom diversity as an opportunity to expand their adaptive teaching knowledge, some teachers may view classroom diversity as problematic. Then teachers may see incorporating this diversity into lesson planning and instruction as an arduous, time-consuming task. Teachers could overlook or 
minimize this aspect of their content pedagogy. Thus teachers' beliefs about adopting differentiated instruction should be considered. This is important because years after differentiated instruction was first proposed to handle the realities of diverse student needs, it is safe to say widespread adoption of differentiated instruction is still scattered and incomplete.

From my research and own observations, I believe the extent teachers adopt differentiated instructional approaches in their classrooms is related to a combination of two teacher belief factors: (a) efficacy with adaptive pedagogical content knowledge, and (b) expectations with classroom diversity. If so, then it is important to understand the specific knowledge and beliefs that help or hinder differentiated instructional practices. By exploring middle school teachers' beliefs and their relationship to differentiated approaches, we may understand and implement more effective instruction to meet the diverse needs of all students in rich academic environments.

\section{Background of the Problem}

When it comes to the topic of teaching increasingly diverse student populations, most of us will readily agree there are challenges. Where this agreement usually ends, however, is on the question of what to do about it.

On the one hand, some believe reform efforts should target achievement gaps by focusing on stronger curriculum mandates, increasing accountability, or expanding options for school choices (Common Core State Standards Initiative, 2012; Figlio \& Loeb, 2011; Hanushek, 2011; Kim \& Axelrod, 2005; National Commission on Excellence in Education, 1983; Rivkin, Hanushek \& Kain, 2005, U.S. Department of 
Education, 2002). From this perspective, wielding the proper balance of penalties and rewards is approach to the belief "too many of our neediest children are being left behind" (U.S. Department of Education, 2002, p. 1). In short, schools needed to increase academic performance across all student populations.

On the other hand, there are those who contend educational reforms should focus on correcting existing social inequalities which tend to replicate themselves in classroom performances (Berliner \& Biddle, 1995; Giroux, 2012; Kohn, 2000; Kozol, 1991; Ladson-Billings, 2011; Luke, 2010; McInerney, 2007; Milner, 2010). Rather than using achievement gaps to explain disparities in students' learning outcomes, proponents believe students in many public schools lack opportunities to be successful because educational systems, processes, and institutions are not structurally designed to do so (Milner, 2010).

Though I grant both perspectives have merits, based on my training and experience as a K-12 teacher, I maintain they are not particularly useful for classroom teachers with more immediate goals to meet all student learning needs. So, while I agree that high curricular standards, evidence-based practices, and educational innovations have their place in school reform, I do not believe these approaches alone will raise achievement without also addressing broader social, cultural, and economic factors facing students today. Further, while I recognize the destructive influence of what Milner (2010) termed the "opportunity gap" across diverse student populations, most teachers over the years generally have resisted calls to drive systematic social change (Apple, 2006, Gay, 2015; Grimaldi, 2010; Lumby, 2013). Instead, many teachers engage in what 
Trent, Kea, and Oh (2008) dubbed "distancing strategies" to avoid acknowledging sensitive issues (e.g., empowerment for the disenfranchised) with their students (p. 333). It would seem schools are as ill-equipped to address wider social inequalities since Counts (1932) suggested, “...our schools, instead of directing the course of change, are themselves driven by the very forces that are transforming the rest of the social order" (p.1). Counts was saying that teachers were subject to the same cultural norms and stereotypes as the societies that produced them and it was unrealistic to expect schools to act as social change agents.

In short, I maintain both extremes are unhelpful to teachers seeking to teach diverse student populations and address individual learning needs. Based on my training and experience, I believe teachers face personal and professional mandates to improve the learning outcomes for all of their students by walking a line somewhere in the middle of both perspectives. The question remains: How do teachers effectively distribute their time, resources, and energies for maximum benefit to all students? Answers to these questions could acknowledge and address the growing cultural, socioeconomic, and academic diversity present in middle level classrooms. The next section elaborates upon this growing classroom diversity.

Growing classroom diversity. To begin, shifting immigration trends have changed the cultural demographics in US classrooms. From just six percent of students in 1970, the children of immigrants now make up nearly 20 percent of the US school population (Capps et al., 2005). Nationally, rates of students identified as English Language Learners (ELLs) rose to over 9 percent of the total population. In 2014, these 
increases resulted in a milestone of sorts for public schools: a majority of students identified themselves as something other than white (U.S. Department of Education, 2014).

Second, socio-economic disparities are growing as well. The numbers of students experiencing homelessness in 2010 jumped $40 \%$ in two years. Additionally, $38 \%$ of all school-aged children have some experience with poverty (Miller, 2011). These same children account for nearly $70 \%$ of all children who failed to complete high school (Hernandez, 2011). These students bring their own needs to the classroom.

Finally, the inclusion movement for students with disabilities (SWDs) is now well established (Osgood, 2005). More than $80 \%$ of all students with disabilities receive the majority of their education in general education classes (U.S. Department of Education, 2014). Consequently, teachers face a wider range of academic, social, emotional, physical, and sensory needs than in the past.

Increasing student diversity is significant in light of educational policy shifts that favor heterogeneous classroom groupings (George, 2010; Osgood, 2005; Rubin, 2006). Whereas schools in the past might have addressed student differences through tracking (students assigned to separate classes on the basis of ability) or ability grouping (students assigned to more or less permanent separate groups within the same classroom), many modern classrooms deemphasize these approaches in the name of educational equity (Rubin, 2006). For example, differentiated instruction calls for flexible grouping requiring continual reshuffling of students. Thus, teachers who in the past might have 
relied upon school organizational structures to address classroom diversity now must address learner variance on their own in the classroom.

The upshot of all this is, while the students who sit together in a classroom may share similar ages, they would seem to share few other cultural, socio-economic, or cognitive characteristics. As such, current wisdom calls for teachers to adjust curriculum, materials and support to ensure each student has equity of access to high quality learning (Darling-Hammond, 2007; Tomlinson et al., 2003). In short, it seems teachers no longer have the choice to overlook diversity in the classroom.

Any curricular and instructional adjustments require long-term teacher buy-in to be successful (Richardson, 1996; Tomlinson, 1995). Conversely, some teacher beliefs might challenge differentiated instructional implementation. In the next section, I look at two areas of teacher beliefs which may hinder teacher buy-in, including pedagogical content knowledge and classroom diversity.

Teachers' pedagogical content knowledge. Studies have shown that teachers tend to teach the way they were taught (Cuban, 1983; Oleson \& Hora, 2014). Despite technological advancements, policy mandates, and curricular reforms, teaching practices seemingly have changed little in many classrooms. More than three decades ago, Cuban (1983) noted the longevity of a traditional set of teaching practices familiar to many teachers today:

These practices (teaching the whole group, reliance upon textbook, rows of desks, question-answer framework for carrying on dialogue, etc.) persisted over time, in 
different settings, in spite of changes in teacher education and the knowledge that students bring to school and major social and cultural movements (p. 165).

While I admit schools have made gains towards meeting individual student needs since Cuban's (1983) observation, the reliance on standardized teaching practices continues in many classrooms (Tomlinson, 2014). In spite of recent National Council for the Accreditation of Teacher Education (NCATE) recommendations to include differentiated instruction (National Council for Accreditation of Teacher Education, 2010), some teachers have not embraced differentiated instruction. Why? I maintain one factor is a lack of familiarity with DI approaches. Let us take a quick look at how differentiated instruction is taught and the resulting influence on teacher beliefs.

Shulman's (1986) definition of pedagogical content knowledge acknowledged teachers must possess "many ways of representing and formulating the subject to make it comprehensive to others" (p. 9). The ability to represent content in a variety of forms is a crucial skill when employing differentiated instructional approaches. However, while increasing pedagogical content knowledge is a longstanding goal for most teacher education and professional development programs, training teacher candidates and practicing teachers to employ differentiated instruction remains a challenge.

Years ago, Tomlinson (1995) noted teachers were seldom trained to differentiate instruction in their teaching programs. More recently, Farkas and Duffet (2010) found $81 \%$ of college of education professors acknowledged the difficulties of tailoring instruction to individual learners in their own classrooms. As a result, while some teacher education programs might include references to differentiated instruction, Santangelo and 
Tomlinson (2012) found teacher candidates often do not transfer these differentiated instructional approaches into their own classroom practices. It is a safe assumption to conclude teacher education programs can do more to model and emphasize differentiated instructional practices.

What about practicing teachers? Practicing teachers seem as hesitant as teacher candidates to incorporate differentiated instruction. Rochkind et al. (2007) found 84\% of teachers struggled to implement differentiated instructional practices. This sizable majority suggests current efforts to train teachers to differentiate are fraught with difficulty. Teachers' pedagogical content knowledge seems to influence their ability to differentiate instruction. Hardre and Sullivan (2008) found the majority of teachers in 19 high schools lacked the strategies and knowledge to implement differentiated instruction. Further, typical one-time professional development sessions featuring outside consultants often do not provide the level of operationalization to allow teachers to try differentiated instruction when they return to their classrooms (Dixon et al., 2014). Even Tomlinson (2014) admitted, "It can be difficult to implement and plan for effectively differentiated classrooms because we see few examples of good ones" (p. 5). In short, practicing teachers hesitate to differentiate because they may not know how.

Teaching is a complex activity that requires teachers to juggle multiple responsibilities simultaneously (Atjonen, Korkeakoski, \& Mehtalainen, 2011; Brante, 2009). Inevitably, differentiated instruction increases the amount of pedagogical decisions teachers must make. To diagnose and differentiate instruction to meet student needs successfully, teachers need to consider students' prior experiences, current 
interests, plus cognitive and motivational preconditions (Nuthall, 2005). Yet, these diagnoses are invariably influenced by teachers' personal and professional beliefs about their students. Teacher beliefs about their students could be related to their instructional decisions and could limit their flexibility acknowledging and addressing cultural diversity. The next section looks at teacher beliefs about cultural diversity.

Teachers' cultural diversity beliefs. There are several areas of consensus in the research on teacher beliefs about cultural diversity, including the importance of addressing cultural diversity in the classroom and teachers' confidence to deal with individual student needs. The next section explores three cultural diversity beliefs that contribute to teachers' adoption of differentiated instruction in the classroom.

First, the general consensus of belief research indicates many teachers believe the best way to deal with cultural, ethnic, and racial diversity is to avoid addressing it at all (Gay, 2015; Milner, 2010; White, 2011). While colorblind practices may initially seem desirable for public school teachers, Schofield (2010) cautioned these practices "make it unlikely...that the challenge ...of providing all its students with an engaging and effective education will be met” (p. 276). Indeed, Gay (2004) and Tyler, Boykin, and Walton (2006) found teachers preferred behaviors associated with majority culture students, teachers' perceptions of learning outcomes were mediated by their own cultural backgrounds, and students' experiences in class were far from culturally neutral. If so, then teacher beliefs that downplay or negate cultural diversity could hinder the implementation of DI. 
A second consensus of teachers' beliefs about diversity suggests a lack of confidence to meet student needs (Gay, 2015, Milner, 2010; White, 2011). In their study of high school physical education teachers, Anunah and Hodge (2005) found educators held wavering, but generally positive, beliefs about working with special needs students, yet lacked confidence in their pedagogical knowledge to do so. The researchers called this phenomena troubled confidence (p. 50). However, it is worth noting that Anunah and Hodge (2005) also found teachers' personal and professional beliefs could mediate the level of influence troubled confidence held over their classroom practices. MacFarlane and Woolfson (2013) reported similar findings: in short, teachers who exhibited more positive beliefs and teaching self-efficacy were more likely to engage with differentiated instruction.

A third area of agreement about teacher cultural beliefs regards the consistency of teachers' beliefs with idealized societal values such as equality, positive benefits of cultural assimilation, receptivity to selected immigration, and the tendency to blame marginalized groups for their own social conditions. Causey, Thomas, and Armento (2000) noted many teacher candidates believed strongly in optimistic individualism (i.e., hard work and individual efforts will conquer any obstacles), absolute democracy (regardless of background, all students will react similarly to good pedagogical practices), and nä̈ve egalitarianism (all students are created equally and should share equal access to resources and opportunities) during their teacher education programs (pp. 33-34). 
Thus, it stands to reason some teachers could believe that achievement gaps of some cultural, ethnic, or social groups are individual problems that can be remedied by a combination of personal interest, motivation, and hard work. As teacher beliefs are often identified as predictors or precursors to classroom behaviors, these types of beliefs could potentially hinder the adoption of differentiated instructional practices. Ullucci (2007) claimed teacher beliefs formed the "foundation of the child/educator relationship" (p. 2). If so, then the beliefs and expectations teachers hold about their diverse students will impact their interactions with these students. These beliefs matter: differentiated classroom practices are partially shaped by the beliefs teachers have regarding the students in their classrooms.

\section{Statement of the Research Problem}

While it is widely believed that differentiated instructional approaches hold the key to meeting individual student needs, teacher practices in the classroom continue to be dominated by “one-size-fits-all” planning, management, and instructional choices. These choices are largely influenced by teachers' knowledge and beliefs about differentiated instruction and the diverse student populations they serve. Therefore, understanding the teacher beliefs that influence differentiated instructional practices is critical.

Researchers have much to learn about the specific beliefs of teachers that best promote student growth (Fives \& Buehl, 2015; Rubie-Davies, Flint, \& McDonald, 2012). Hattie's (2013) synthesis of over 800 studies related to student achievement led him to conclude that individualized learning is superior to any one particular instructional 
method or script. Yet there are still knowledge gaps about teacher beliefs and practices addressing diverse classroom compositions, particularly among practicing teachers (Gay, 2015).

The purpose of this study was to explore teacher beliefs about differentiated instruction in a culturally diverse, rural middle school to gain a greater understanding of the complex relationship between teacher beliefs and teacher practices, especially situated within the context of middle-level classrooms. Conclusions drawn from this study may be used to help improve teacher practices- and ultimately learner outcomesby informing teacher preparation and professional development, state and local educational policies, and curricular reform efforts.

\section{Significance of the Research Problem}

Teachers' beliefs about classroom diversity could negatively influence their ability to create classroom environments supporting differentiated instruction. In the next section, I explain why more complex understandings of individual learning needs, equity issues, and changing student demographics have placed increased urgency on teachers to adopt beliefs that embrace differentiated instructional practices in their classrooms. Student achievement could benefit if educators could identify beliefs linked to successful instructional practices with diverse learners (Gay, 2015, Milner, 2006)

Importance of middle school differentiated instruction. While a case could be made for adopting differentiated instructional practices for grade levels, teaching practices explicitly addressing classroom diversity are embedded into the philosophy of middle level education (Anfara, Mertens, \& Caskey, 2007; National Middle School 
Association [NMSA], 1995; NMSA, 2010). Due to their unique developmental and geographical contexts, middle schools are ideally suited for differentiated instructional practices.

First, middle school students possess a wide range of physical, intellectual, moral/ethical, emotional/psychological, and social developmental levels during adolescence (Anfara et al., 2007). This range of developmental stages has been associated with declines in student motivation and performance (Eccles \& Midgley, 1989). However, middle level students' perceptions of teachers who regarded them positively by promoting individual effort and improvement were linked to increases in affective and learning outcomes (Roeser \& Eccles, 1998). As stated previously, differentiated instructional philosophy emphasizes teachers' ability to create studentcentered climates (Tomlinson, 2014). This study sought to explore and understand teacher beliefs that can help or hinder this ability.

Second, middle schools are typically larger than pre K-5 or K-8 schools. Because their student bodies are gathered from wider geographic areas, middle schools tend to be more ethnically and economically heterogeneous (Holas \& Huston, 2012). For the first time, many students are interacting with larger numbers of classmates who may be different from their elementary peer groups. Acknowledging and addressing these differences are necessary and positive steps for middle level educators and students alike.

Student demographics and issues of equity. Traditional methods of meeting individual student needs, including homogenous classroom groupings and remedial courses, have failed to help many struggling students or challenge advanced learners, 
creating conditions ".... where a standardized learning plan swallows some learners, pinches others, and fails to inspire most" (Tomlinson, 2014, p.39). In other words, some teachers aim for the middle and try to accommodate the rest of their students.

This traditional process which labels and sorts students based upon learning needs seems to have an influence on teacher beliefs. Teacher expectations are believed to affect learning outcomes (Frome, Lasater, \& Cooney 2005). For example, Gamoran, Nystrand, Berends, and LePore (1995) found diminished teacher's expectations for students who lag behind traditional grade-level norms. This belief is supported by social-cognitive perspectives arguing beliefs can affect classroom behaviors in significant ways (Good \& Brophy, 1997). As the purpose of this study was to explore and describe the beliefs behind the managerial and instructional choices teachers make in diverse classrooms, understanding these equity issues is important.

Successfully functioning diverse classrooms, consisting of students gathered from across racial, socio-economic, cultural, and academic levels are attractive "real-life laboratories" for the development of a wide range of "interpersonal and social knowledge, skills and attitudes essential to success in adult life" (George, 2010, p. 186). In other words, because positive engagement with a range of diverse populations is assumed for successful functioning in a democratic society, diverse classrooms seem to provide environments more consistent with the goals of democratic society and the recognition of humanity's essential diversity (George, 2010).

Yet, Zeichner and Melnick's (1996) conclusion remains relevant. They concluded: 
Research has also shown that many teacher education students come to their preparation programs viewing student diversity as a problem rather than a resource.... These students generally have very little knowledge about different ethnic groups in the United States, their cultures, their histories, their participation in and contributions to life in the United States... and often have negative attitudes about cultural groups other than their own. (p. 137)

Even when possessing positive attitudes, teachers report that differentiation is still challenging in classrooms that lack supportive environments (Biddle \& Berliner, 1995; Hardre \& Sullivan, 2008; Rochkind et al., 2007; Rubie-Davies, 2007). For example, large class sizes, particularly those with diverse classroom compositions, as well as the lack of effective curricular, behavioral, and personal resources to handle them both, can pose formidable challenges for teachers who seek to improve educational outcomes for all of their students. Indeed, Biddle and Berliner's (1995) 20 year old claim rings true: educational opportunities are not distributed equally in American schools. This study sought to identify those factors influencing the implementation of differentiated instructional practices with diverse classrooms.

\section{Presentation of Methods and Research Questions}

To support this study, a theoretical framework supporting these best practices within a larger system of school reform that addresses basic issues of educational equity was needed. The qualitative methods that explored and supported this theoretical framework are introduced in the next section. 
Methods. Significant gaps still exist in the research body of knowledge exploring teacher beliefs and differentiated instruction, particularly concerning diverse student populations in middle school (Gay, 2015; Lucas, Villegas, \& Martin, 2015). While they might be hidden away under other headings (i.e., multicultural education, culturally responsive teaching, or social justice), Gay (2015) reported few cultural diversity studies include the perspectives of practicing teachers. Further, few studies have explored teachers' perceptions of themselves as culturally diverse others. I believe a qualitative approach was suited to exploring the complex influences of these beliefs on differentiated instructional practices.

Maxwell (2013) asserted that intensive, long-term involvement and rich data are two ways to address validity concerns in qualitative research. As such, this qualitative case study used a combination of personal interviews, classroom observations, surveys, and artifacts to explore the relationship between teacher beliefs and practices.

Research questions. The purpose of this study was to explore teacher beliefs about differentiated instruction in a culturally diverse, rural middle school. In this study, I investigated the following research questions:

1. What are middle school educators' beliefs about differentiated teaching and learning in diverse classes?

2. How do middle school teachers implement their beliefs about differentiated teaching and learning?

3. What factors influence middle school teachers' adoption of differentiated instruction in their classrooms? 
This study sought to gain a greater understanding of the complex relationship between teacher beliefs and teacher practices situated within the context of middle-level classrooms. In particular, this study attempted to address a gap in the current literature neglecting the role experienced veteran teachers' diversity beliefs play in shaping the instructional and socio-emotional climate of their classrooms.

\section{Definitions of Key Concepts}

The following section introduces and defines the key terms behind this study.

Teacher beliefs. A psychological construct that reflects the attitudes, values, and perspectives of educators towards their own performance (teacher efficacy), students' performances (teacher expectations), the structure of their lessons (goal orientations), and the nature of knowledge (epistemological beliefs).

Differentiated instruction. An educational orientation that seeks to meet individual student readiness, interests and learning profiles through a teacher-created educational environment that individualizes content delivery, classroom processes, student products, and the classroom climate (Tomlinson, 2014). During the past century, the conceptual field for differentiated instruction has included individualized instruction (Slavin, Madden, \& Leavey, 1982), adaptive instruction (Wang, 1980), inclusive education (Osgood, 2005), personalized instruction (Enyedy, 2014; Kardan \& Conati, 2013), and differentiated instruction (Santangelo \& Tomlinson, 2012; Tomlinson, 2006; Tomlinson, 2014; Tomlinson \& Imbeau, 2010).

Adaptive teacher competency (ATC). A conceptual model of teachers' knowledge necessary to adopt and use differentiated instructional practices, including 
beliefs, self-efficacy, and resulting planning and teaching practices (Bruhwiler \& Blatchford, 2011). ATC frameworks are built around four different teacher dimensions: (a) high levels of subject knowledge, (b) diagnoses of student learning, (c) methods of instruction, and (d) classroom management (Wang, 1980). Furthermore, high ATC teachers are able to account for students' cognitive, motivational, and behavioral aspects, as well as contextual influences.

Classroom diversity. A sociological construct that acknowledges the variety of student differences within a single classroom, including the range of cognitive abilities of the class (student variance), number of assigned students (class size), and heterogeneous characteristics of the student body (cultural diversity). Milner (2010) further defined diversity as including, but not limited to, aspects of "race, ethnicity, gender, sexual orientation, language, religion, ability, and socio-economic background" (p. 5). In short, classroom diversity can have many different meanings depending on context.

Classroom environment. A social construct resulting from the outcome of teacher practices and classroom context, classroom environments include levels of teacher support, quantity and quality of student-teacher interactions and relationships, types of performance goals, and range of student engagement (i.e., climate).

Case study. A case study is a research method that typically involves a single individual group or an important example. The study tends to involve a comprehensive exploration of a bounded phenomenon or case (e.g., the beliefs of teachers from a single middle school about differentiated instruction). Yin (2003) defined the case study method as "an empirical inquiry that investigates a contemporary phenomenon within its 
real life context, and in which multiple sources of evidence are used" (p. 13). In other words, a quality case study should present an in-depth understanding of a current issue within the environment in which the issue occurs. 


\section{Chapter 2: Literature Review}

In the first chapter, I introduced the problem some middle level educators have implementing differentiated instructional practices in their classrooms. I made the case for using teachers' beliefs about teaching and learning as a way to address this problem. To support my case, the purpose of this study was to explore teacher beliefs about differentiated instruction in a culturally diverse, rural middle school. My research questions included:

1. What are middle school educators' beliefs about differentiated teaching and learning in diverse classes?

2. How do teachers implement their beliefs about differentiated teaching and learning?

3. What factors influence teachers' implementation of differentiated instruction in their classrooms?

In this chapter, I provide the supporting literature review. First, I introduce and defend my rationale for using social cognitive theory (SCT) as a way to explore the relationship between teacher beliefs and practices. Next, I introduce a conceptual framework to explain the relationships between teacher beliefs and differentiated instruction. Then, I review the literature germane to teachers' beliefs and differentiated instruction. Finally, I conclude the chapter with a critique of the methodological literature measuring teacher beliefs and an introduction of my research methods.

\section{Theoretical Framework: Social Cognitive Theory}


Social cognitive theory provides a model for understanding, predicting, and changing human behavior. I used two key constructs of social cognitive theory, reciprocal determinism and self-efficacy, to help guide this study. Both constructs were helpful to explore the internal and external variables that influence teacher practices in the classroom. In social cognitive theory, causal processes are seen through the lens of reciprocal determinism, which provides a basic analytical framework to understanding the interplay of factors. The next section discusses reciprocal determinism.

Reciprocal determinism. According to Bandura's (1986) social cognitive theory (SCT), human behavior occurs through the interaction of personal, behavioral, and environmental factors. These three factors mutually influence each other in a process called reciprocal determinism. Reciprocal determinism is a back-and-forth process where each factor influences (and is in turn influenced by) the other two factors to shape human behavior, as illustrated in Figure 1.

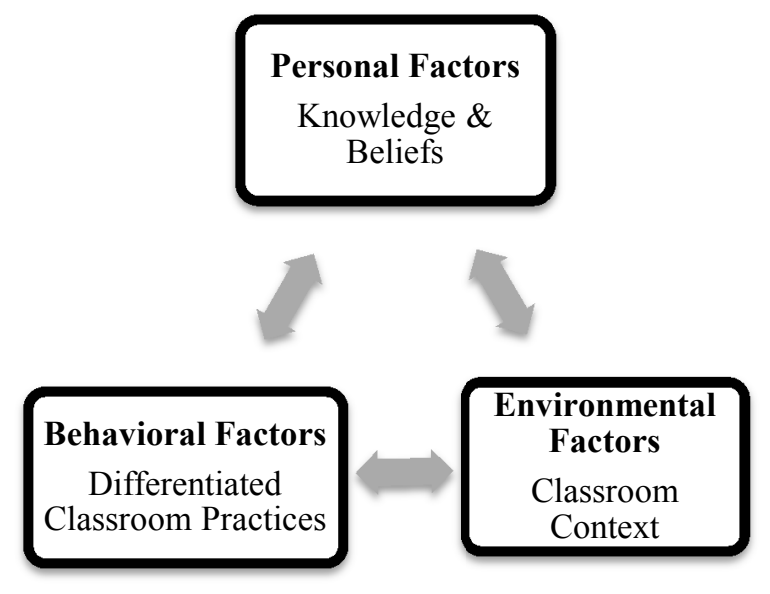

Figure 1. Example using the model of triadic reciprocal determination of social cognitive theory. Adapted from "On the functional properties of perceived self-efficacy revisited," by A. Bandura, 2012, Journal of Management, 38(1), p. 12 
This process of reciprocal determinism among connected factors makes social cognitive theory an attractive choice for my teacher belief study. While teachers generally lack much control selecting their classroom environment (e.g., class sizes, cognitive abilities, socio-economic status), they do have some agency how they choose to interpret and react to this environment. While determinism implies a lack of free will on the part of people to choose their own behaviors, Bandura (1997) was careful to claim that freedom and determinism can co-exist. He argued his reciprocal determinism only leads to a certain probability of outcomes, as opposed to stricter definitions of determinism that maintain people's behaviors are entirely controlled by external causes. The upshot of Bandura's construct is that people operating in the same environmental contexts can make different choices and regulate their behaviors and beliefs differently.

The line between determinism and free will is largely determined by a person's level of personal autonomy, which Bandura (1997) termed "cognitive self-reflection" to include reflective thought, repeated use of one's knowledge and skills, and other "tools of self-influence" to exercise their freedom of choice (p. 7). This study used teacher beliefs to explore this line between determinism and free will to better understand decisions when implementing differentiated pedagogy.

In sum, while environmental factors influence human behaviors, ultimately many classroom instructional and managerial practices depend upon the personal factors teachers possess. Self-efficacy makes up a significant portion of teachers' beliefs. The next section introduces self-efficacy beliefs as they relate to differentiated instructional practices. 
Self-efficacy beliefs. According to Bandura (1997) people's internal factors, including self-efficacy beliefs, largely influence the extent to which people exercise control over their own behaviors (i.e., agency). Self-efficacy refers to "people's judgments of their capabilities to organize and execute courses of action required to attain designated types of performance" (Bandura, 1986, p. 191). In other words, self-efficacy refers to a person's belief in their capacity to perform a specific task successfully. Selfefficacy reflects confidence in one's ability to control personal, behavioral, and environmental factors. Additionally, self-efficacy has a collective component. Goddard, Hoy, and Hoy (2000) found collective self-efficacy found to be positively associated with student achievement in reading and mathematics. An example of collective teacher efficacy could be found in the combined beliefs of a school staff about their collaborative efforts to positively influence students' learning outcomes.

Teacher efficacy is an important subset of teacher beliefs with significant influence on expectations, goal orientations, and epistemological beliefs. To begin, Caprara, Barbaranelli, Steca, and Malone (2006) suggested high levels of teacher efficacy are related to higher job satisfaction and student achievement. Thoonen, Sleegers, Oort, Peetsma and Geijsel (2011) also argued for the association between teacher efficacy and motivation. Extending this argument, Villegas (2007) stated teachers' efficacy beliefs significantly impacted expectations held for student learning and achievement. Further, these beliefs "lead teachers to treat students differently resulting in positive or negative performance, aspirations, and self-concepts" (p. 374). In other words, teacher efficacy significantly influences teacher beliefs and practice, for better or worse. 
Examples of negative influences can be seen with low levels of efficacy. Dixon et al. (2014) described teachers' self-efficacy doubts about implementing differentiated instruction, claiming "the effort required may be just too overwhelming for them" to overcome (p. 115). In other words, teachers may feel they lack the time to make lesson adjustments, lack confidence in their own content knowledge, or focus on all the ways the lesson may fail. Conversely, when teachers are highly efficacious in their beliefs to teach students well, they may be more likely to differentiate.

In summary, social cognitive theory not only provides a model for predicting human behaviors, but also is a theory of learning and change. Bandura (1986) described the personal, behavioral, and environmental factors. However, my specific problem of practice needed a framework connecting Bandura's concepts to the numerous variables influencing differentiated instruction. In the next section, I explain my conceptual framework.

\section{Conceptual Framework: Teacher Beliefs and Practices}

Miles and Huberman (1994) defined a conceptual framework as a visual or written product that "explains, either graphically or in narrative form, the main things to be studied- the key factors, concepts, or variables- the presumed relationships among them" (p. 18). This study looked at the presumed relationship between two "things": teacher beliefs and differentiated instructional practices.

At first glance, this task might be accomplished using a simple conceptual framework with only two variables. However, a simple deterministic relationship does not always exist between the beliefs espoused by teachers and the practices they employ 
in their classroom. Calderhead (1996) and Fives and Buehl (2012) have suggested that there are as many studies questioning a direct relationship between beliefs and practices as there are supporting it. I argue the relationship between beliefs and practices is mediated by other variables, including teacher knowledge, contextual influences, and student learning outcomes. It is important to include these other variables in any conceptual framework to acknowledge the complex situated nature of classroom teaching and learning.

It is the purpose of this section to introduce my conceptual framework to take apart the construct of teacher beliefs related to differentiated instruction. As no one single framework exists, this deconstruction required a multi-dimensional model to adequately explain the relationships between constructs. To construct this framework, I pulled elements from adaptive teacher competency frameworks (Bruhwiler \& Blatchford, 2011) and differentiated instruction (Tomlinson, 2014).

To begin, most research indicates teacher beliefs are closely related to teacher knowledge. In spite of past efforts to separate beliefs from knowledge by Nespor (1987), Pajares (1992), and Richardson (1996), the "messy construct" of teacher beliefs still exists. More recently, Levin, He, and Allen (2013) acknowledged the close relationship between teacher knowledge and beliefs, particularly influencing classroom teacher behaviors. If so, then any framework exploring teacher beliefs and practices needs to situate teaching knowledge as an intermediating variable. This study's framework used Adaptive Teaching Competency (ATC) to measure the knowledge of teachers to meet individual students' diverse learning needs as shown in Figure 2. 
Context of community and school

$\downarrow$
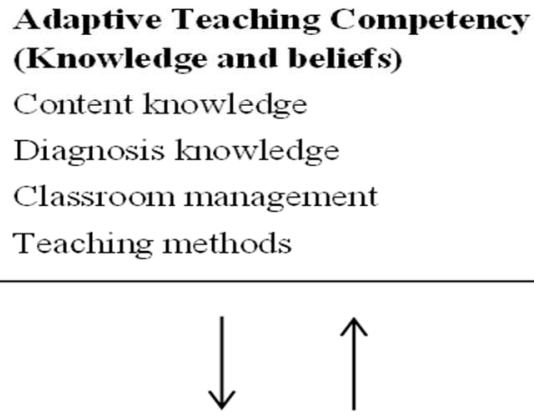

\section{Teacher Beliefs}

Beliefs about the nature of teaching and learning

Beliefs about cultural diversity

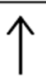

\section{Student Learning Outcomes}

Student academic achievement

Affective domain competencies (e.g. social, emotional, problem-solving competencies)

Figure 2. Framework for the analysis of teacher beliefs and practices. Adapted from
Classroom Diversity

e.g. class size, cognitive abilities of

class, SES, ethuicity heterogeneity

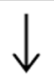

Differentiated Classroom Practices

Content

Process

Product

e.g. climate, teacher-student

relationship, student engagement

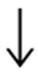

Classroom Environment

"Multilevel supply-use model of student learning," by Bruhwiler, C., \& Blatchford, P. (2011). Effects of class size and adaptive teaching competency on classroom processes and academic outcomes. Learning and Instruction, 21(1), p, 97.

The concept of ATC describes the subject knowledge, diagnosis, teaching methods and classroom management strategies supporting differentiated instruction (Vogt \& Rogalla, 2009). To illustrate, Subban (2006) noted that differentiation forces teachers to shift their focus from simple curriculum coverage towards catering to individual student needs. This shift requires teachers possess the necessary competence to do so. Professional competence includes teachers' pedagogical content knowledge, professional beliefs, work related motivation, and self-regulation (Kunter, Klusmann, 
Baumert, Richter, Voss, \& Hachfield, 2012). In other words, competence involves knowing how to achieve results and feeling effective in doing so. Using this study's framework, I recognize the influence ATC holds over successful implementation of differentiated instructional practices.

Some researchers overlook or downplay the influence of context on teachers' beliefs and classroom practices (Chingos, 2011; Rivkin et al., 2005). Yet, teacher beliefs and practices do not operate independently from other contextual influences. Levin (2014) argued "attending to context is paramount to understanding the development of beliefs because teachers' beliefs and actions cannot be separated from situations in which they occur, including the larger social, political, and economic climate as well as the immediate school context" (p. 51). In other words, beliefs cannot be studied in isolation from the many influences that contribute to their creation and maintenance, including classroom diversity, classroom environments, and student learning outcomes. Bruhwiler and Blatchford (2011) suggested reduced emphases on these contextual influences could lead to direct models of teaching and learning potentially assuming a causal onedirectional relationship between teachers and students. Omitting or even minimizing the influence of context seems to ignore a key tenant of social cognitive theory which assumes a reciprocal relationship between environmental, behavioral, and personal factors.

In addition to teacher knowledge, research frameworks should also acknowledge the influence of the highly complex contexts in which teaching and learning processes occur. For example, Muis (2004) contended that beliefs need to be evaluated in context. 
She suggested individual contexts help shape individual understandings of what more or less "availing" teacher beliefs are "positively related to quality learning and achievement" (p. 324). In other words, as separate school environments define and evaluate student learning outcomes differently, seemingly less desirable beliefs in one context could be more effective for teachers in different context.

In summary, the primary purpose of this conceptual framework was to explain the relationship between teacher beliefs and differentiated instructional practices. To do so, the framework acknowledges the influences by classroom diversity, classroom environments, and student learning outcomes on teacher beliefs and practices. The next section presents the supporting literature review behind these concepts.

\section{Review of the Research Literature}

In the following literature review, I examine the research and ideas associated with the constructs from this study's conceptual framework investigating teacher beliefs and differentiated instructional practices. Taylor and Synder (2012) stated the purpose of a literature review is to "synthesize significant findings, identify areas of concern, and questions yet to be explored, and potentially provoke the status quo, challenging the field to question or rethink what is often unquestioned" (p. 37). With this purpose in mind, I begin by introducing adaptive teaching competency and teacher belief research, particularly ones where classroom diversity is noteworthy. I used a generous definition of classroom diversity to include studies describing heterogeneous classroom contexts differently. Next, I define and examine the murky world of differentiated instruction. Because schools have understood and operationalized individualized instructional 
practices in numerous ways over the years, I relied primarily on studies explicitly using the term "differentiated instruction." While they provided valuable context, I tended to downplay or omit studies that used competing terms like individualized instruction, adaptive instruction, and personalized instruction. Finally, I scrutinize the link between teacher beliefs and differentiated instruction. Following a neglected area of research as suggested by Gay (2015), I favored studies that used practicing teacher participants, as opposed to teacher candidates whose voices appeared more frequently in the literature.

\section{Adaptive Teaching Competency}

Calls to differentiate instruction are nothing new (Grittner, 1975; Gutek, 1986;

Kliebard, 2004). Examining instructional practices over 90 years ago, Washburne (1925) observed, "Mass methods are still in use, although they have been shown to be not only unintelligent, because impossible of specific direction, but actually brutalizing in their effect upon both pupil and teacher" (p. 1). While Washburne's tone may seem antiquated today, his sentiment supporting differentiated instruction does not. Adaptive teaching competency (ATC), the characteristic of teachers to know how to achieve results with a range of diverse students and feeling effective to do so successfully, has its roots in teacher competency work (Wang, 1980) and teachers' pedagogical content knowledge (Shulman,1987). In the next section, I explore the origins and definition of ATC.

Adaptive teaching competency has its beginnings in work by Wang (1980) who argued for alternative instructional strategies and resources to meet individual learning needs. Wang called this approach adaptive instruction. Significant characteristics for adaptive instruction include the active diagnosis and monitoring of student learning 
progress, the teaching of self-management skills, and providing organizational supports. While the term adaptive instruction has few adherents today, Wang's use of pedagogy to address classroom diversity was picked up by later researchers such as Shulman (1987). In his seminal work, Shulman (1987) asked scholars to explore the decisionmaking processes of teachers regarding the content they taught. Shulman argued that research should focus on teachers' competence at the intersection of content and pedagogy. In other words, what are the abilities of teachers to transform content knowledge into pedagogically powerful experiences for their students? To explore the answer, Shulman claimed pedagogical abilities should include some combination of the following processes: a) preparation of the materials including processes of critical interpretation, (b) representation of the ideas in the form of new analogies, metaphors, etc., (c) instructional selections from among an array of teaching methods and models, (d) adaptation of these selections to the general characteristics of the children to be taught, and (e) tailoring these adaptations to the specific youngsters in the classroom (p. 15). While Shulman did not use the term differentiated instruction, his ideas behind the transformation at the heart of pedagogical reasoning share many similarities with differentiated instructional philosophies. Shulman's framing of pedagogical content knowledge and teacher competence was adopted by later generations of educational scholars, such as Vogt and Rogalla (2009).

Vogt and Rogalla (2009) took elements of Shulman's (1987) pedagogical content knowledge and Wang's (1980) concept of teaching competencies to create Adaptive Teaching Competency (ATC), a framework consisting of four dimensions: subject 
knowledge, diagnosis, teaching methods, and classroom management. A teacher with high ATC demonstrates the following competencies:

- requirements of the subject knowledge are fulfilled;

- the diverse pre-conditions and learning processes of students are diagnosed as well as situated nature of relevant themes;

- the benefits of diverse teaching methods are effectively used;

- individual students and the whole class are supported in learning processes and activities through effective classroom management.

ATC would seem to be an important competency for teachers wishing to adopt differentiated instructional practices in their classrooms, making ATC an attractive lens for this study to explore how teacher beliefs about classroom diversity manifest themselves in differentiated instructional and managerial strategies. However, researchers suggest supportive teacher beliefs are also essential to adopting differentiated instructional practices (Brighton, 2003; Dixon et al., 2014; Santangelo \& Tomlinson, 2012). In the next section, I investigate literature exploring teacher belief research including foundational studies and classroom diversity.

\section{Foundations of Teacher Beliefs}

Where do teacher beliefs come from? He and Levin (2008) attributed the sources of teacher candidates' beliefs to family backgrounds, past experiences in public education, and teacher education coursework. In a more recent study, Levin et al. (2013) concluded teacher beliefs originate from numerous sources, including teaching experience, implicit teaching philosophy, personal values, stereotypes, and other 
professional colleagues. In short, researchers suggest beliefs stem from a variety of sources.

Research on teacher beliefs stretches back over 50 years to the first Handbook of Research on Teaching (Gage, 1963). Prior to this publication, the dominance of behavioral theory in the literature discouraged research into cognitive constructs like beliefs. However, in the 60 years since the publication of the first Handbook, interest in teachers' beliefs has grown and evolved through various theoretical perspectives, including teacher personalities, affective and motivational domains, conceptual change models, and ecological perspectives. In this section, I present and question key research reviews exploring these changing perspectives.

Teacher belief research began with the exploration of teachers' personalities and epistemological orientations in the 1960s and 1970s. While the first Handbook (Gage, 1963) did not explicitly mention beliefs, in the chapter “The Teacher's Personality and Characteristics," Getzels and Jackson (1963) reviewed the Minnesota Teacher Attitude Inventory (MTAI) which held relevance for teacher belief research. Intended for teacher selection processes, the MTAI asked candidates to use a Likert scale to rate statements like "Children should be seen and not heard" and "boastful child[ren are] usually overconfident of [their] ability" (Cook, Leeds, \& Callis, 1951, p. 508). In writing their review of the MTAI, Getzels and Jackson claimed that the MTAI failed to live up to its promise to clarify the relationship between teachers' personalities and their teaching effectiveness. They pointed to issues including vague definitions, lack of transparency, and inadequate methodology still troubling teacher belief research today. 
During the 1980s and 1990s as teacher belief research expanded, scholars placed greater emphasis on clarifying teacher belief constructs. In particular, researchers and theorists shifted towards understanding the distinctions between beliefs and knowledge. Nespor (1987) used evaluative and affective components in an effort to tackle the nuanced differences between knowledge and beliefs. Wondering "how teachers learn and use what they learn," Nespor saw beliefs as a better way for teachers to handle "illstructured problems" and "entangled domains" than academic theory or empirically based research (p.32). Ultimately, Nespor concluded scholars still had much to learn about the nature of beliefs, their development, and how to nurture them. This conclusion was upheld in Fives and Buehls' (2012) review of teacher belief research.

Two important reviews of teacher research were published in 1992, marking a purposeful shift away from the clarification of constructs toward conceptual change models for teachers. First, Kagan (1992) acknowledged the difficulty of separating knowledge from beliefs, concluding “most of a teachers' professional knowledge can be regarded more accurately as belief' (p. 73). Kagan placed knowledge within a special domain of beliefs having objective proof or consensus behind them. In her analysis of 25 teacher belief studies, Kagan concluded teacher's knowledge is primarily influenced by classroom diversity, academic content, and personal beliefs. Again, Fives and Buehl (2012) echoed similar conclusions as Kagan regarding the nature of teachers' beliefs in their more recent review of the literature.

In the second important teacher belief publication, Pajares (1992) attempted to clear up the confusion around teacher beliefs with the hope that teacher beliefs could 
become "the single most important construct in educational research" (p. 329). Pajares believed strongly that beliefs were the most accurate indicators of individual decisions and behaviors, echoing other psychologist's arguments (Bandura, 1986). However, Pajares also pointed to the proliferation of belief constructs and to the fuzzy demarcation between knowledge and beliefs as an issue confounding teacher belief research. To illustrate the confusion, Pajares listed all of the different "aliases" assigned by scholars to describe teacher beliefs:

...attitudes, values, judgments, axioms, opinions, ideology, perceptions, conceptions, conceptual systems, preconceptions, dispositions, implicit theories, explicit theories, personal theories, internal mental processes, action strategies, rules of practice, practical principles, perspectives, dispositions, implicit theories, explicit theories, personal theories, internal mental processes, action strategies, rules of practice, practical principles, perspectives, repertoires of understanding, and social strategies. (p. 309)

Pajares (1992) argued belief constructs do not offer themselves up easily up to empirical investigation. "Beliefs cannot be directly observed or measured, but must be inferred from what people say, intend, and do" (p. 316). In other words, to study beliefs, researchers must not stop with self-report questionnaires (a common practice), but use a variety of methodologies including interviews, observations, and other practices to discover the consistencies and inconsistencies of teachers reported and actual beliefs and practices. Finally, Pajares cautioned that "little will be accomplished" if researchers do not connect teachers' beliefs with teachers' knowledge and practices and student 
outcomes (p. 327). This study's conceptual framework reflects Pajares' warning and includes both knowledge and beliefs components.

More recently, teacher belief research is characterized by a growing use of ecological frameworks to guide their studies. Use of ecological perspectives indicates an acknowledgement by teacher belief scholars of the many influences and contexts that impact teachers' beliefs, including personal experiences, diversity of classroom context, community and school contexts, and broader cultural values. For example, WoolfolkHoy, Davis, and Pape (2006) chose to organize their seminal review of teacher belief literature using Bronfenbrenner's (1986) ecological framework. Bronfenbrenner's framework is helpful for providing a visual representation of the multiple contexts influencing teacher beliefs. Woolfolk et al. (2006) called for "designs and methodologies that enable us to address the 'whole' of teachers' mental lives" (p. 73). In other words, researchers need to recognize the contextual nature of teachers' beliefs. A contemporary review of teacher belief research literature comes from Fives and Buehl (2012), who referenced the complexity of teacher beliefs also using Bronfenbrenner's (1986) ecological framework. Fives and Buehl noted the great range of teacher belief conceptualizations and called for an integrated approach to investigating the internal and external influences on beliefs. Characterizing the definitions of teachers' beliefs to include their (a) implicit or explicit nature, (b) stability over time, (c) situated or generalized nature, (d) relationship to knowledge, and (e) existence as an individual proposition or as part of a larger system, Fives and Buehl concluded different beliefs may operate in different ways as filters, guides, or frames on teacher practices. In other 
words, beliefs influence how teachers interpret new information and experiences. Answering Nespor's (1987) call to uncover how teachers learn and use what they learn, Fives and Buehl concluded teachers' beliefs "shape what and how they learn about teaching” (p. 479). Ultimately, Fives and Buehl recognized the contextual relationship between teacher beliefs, practices, and student outcomes.

Teacher belief research has progressed through a series of theoretical perspectives. Beginning with explorations of teacher personalities in the 1960 s, belief research has investigated distinctions between knowledge and beliefs, conceptual change models, and is presently concerned with contextual factors and the influence these factors hold over the creation and development of teacher beliefs. In short, understanding context is important to understanding teacher beliefs. So which contextual factors seem to hold the most influence on teacher beliefs? One significant factor is the growing level of classroom diversity teachers must regularly face. In the next section, I explore the research on teacher beliefs about their students.

\section{Teachers' Beliefs about Diverse Learners}

There is a growing interest in teachers' beliefs about diverse learners. Perhaps corresponding with a rising acknowledgement of classroom diversity, researchers are starting to explore the relationships between teacher beliefs about their students and their subsequent classroom practices. As previously noted by Fives and Buehl (2012), the beliefs teachers hold about their students' ability to learn and engage with the curriculum help to filter, frame, and guide teachers' planning and instructional choices. This area of belief research is salient to differentiated instructional implementation, which requires 
teachers to proactively acknowledge, diagnose, and address individual learner needs. This section looks at three primary fields of teacher belief research towards classroom diversity, including cultural diversity, English Language Learners (ELLs), and inclusion of students with disabilities (SWDs).

To begin, while the amount of teacher belief research investigating diversity topics has increased since the 1990s, Gay (2015) noticed certain perspectives on diversity are still largely absent from the literature, including the voices of practicing teachers. I have argued the absence of these voices from cultural diversity research could possibly lead to oversimplified, misleading, or inaccurate conclusions on the importance of addressing diversity issues in the classroom. Yet a search of the available literature revealed some inconsistencies about teachers' beliefs and cultural diversity. In the next section, I share studies that explored three of these inconsistencies.

First, while teachers may believe the best way to deal with cultural, ethnic, or racial diversity is to ignore it, Tyler et al. (2006) suggested teachers respond differently to culturally themed behaviors like eye contact, personal space, or family expectations. In a quantitative study of 62 elementary school teachers, Tyler et al. concluded that teachers and students expressed definite cultural preferences for teaching and learning. These cultural preferences manifested themselves in lower rates of achievement for minority students taught by majority teachers, which suggest that the values teachers place on learning outcomes should not be considered culturally context free.

Second, teachers' fear of making mistakes with diversity issues has led them to adopt context neutral beliefs in the classroom. McIntyre (1997) suggested teachers 
worried about insulting diverse students and being labeled racists. In this study, McIntyre examined a group of 13 middle and upper middle class female teachers to create "white talk," a construct to explain the strategies majority white teachers minimize their individual and collective responsibilities for addressing racial and cultural issues in the classroom. McIntyre explained these talk strategies included "derailing the conversation, evading questions, dismissing counterarguments, withdrawing from the discussion, remaining silent, interrupting speakers and topics, and colluding with each other to create a "culture of niceness"” (p. 46). In other words, these strategies revealed how majority white culture insulates itself from cultural diversity issues.

Causey et al. (2000) noted a third area of incongruence with teacher candidates' long-term belief change as instructional leaders teaching diverse students. Participants in this case study kept autobiographical narratives, diversity plans, reflection journals, and post-experience essays. A longitudinal component to the study reviewed these artifacts three years after the study and found most teachers had returned to their prior diversity beliefs. Researchers acknowledged the difficulty of changing longstanding beliefs with only one intervention. Instead, Causey et al. recommended programs pay ongoing attention to classroom diversity issues to provide the best chance for teachers to use more culturally differentiated practices.

Teacher candidates' expressed egalitarian beliefs which supposedly promote cultural diversity (by treating all students equally) sound admirable in practice. But, as noted by Causey et al. (2000), if these beliefs proved enduring, they could lead practicing teachers to "deny the privileges they may enjoy because of their skin color and social 
class, and to discount or minimize the effects of past and present discrimination" in schools and society (p. 34). In other words, the egalitarian viewpoint's ability to overlook cultural diversity issues comes from a position of privilege rather than equity. The upshot is seemingly beneficial beliefs can hinder acknowledgement of classroom diversity realities.

A second way that diversity manifests itself in the classroom is through the growth of English Language Learners (ELL) in the classroom. In their nationwide study of ELL programs, Calderón, Slavin, and Sánchez (2011) noted the wide disparities of learning outcomes between ELL students and English-proficient students. If teacher beliefs influence their judgements of their students' ability to learn, students operating outside of mainstream linguistic norms could negatively influence these beliefs, particularly in the area of teacher expectations.

Why do teacher expectations matter with ELL students? Rosenthal and Jacobson's (1968) Pygmalion experiment demonstrated when teachers expected their students to achieve at a high level, the students did so. This phenomenon became known as the self-fulfilling prophecy effect. More recently, Rubie-Davies (2010) examined the relationship between teacher expectations and student achievement and also concluded teacher expectations are important to student learning. It would seem differing teacher beliefs and attributes can contribute to a range of instructional and socio-emotional climates in the classroom. It is safe to say that teacher expectations hold significant influence over student learning outcomes. 
The self-fulfilling prophecy effect can further be seen in a study of Dutch teachers' expectations for their majority Dutch students versus those of Moroccan and Turkish immigrants. In this quantitative study of teacher prejudices, Van den Bergh, Denessen, Hornstra, Voeten, and Holland (2010) used self-reporting and surveys to explore the teachers' implicit beliefs and classroom expectations for their students. While their self-report method did not reveal any relationship between beliefs and expectations, the survey did reveal teachers held different expectations for students based on race, socio-economics, and ethnicity. Researchers concluded teachers' range of expectations contributed significantly to a disparity of learning outcomes between native and non-native speakers.

A third area of teacher belief research towards diverse students involves populations with special needs or disabilities (SWDs). These students may have special academic, social, emotional, physical, or sensory needs. As a result of the inclusion movement, the majority of SWDs now spend their days in general education classrooms (Osgood, 2005). Inclusion is generally defined as providing SWDs placement in general education classrooms and access to general education curricula, as opposed to the older term mainstreaming, which does not imply the same level of curricular access (Kiely, Brownell, Lauterbach, \& Benedict, 2015).

Similar to findings on culturally diverse and ELL students, research scholars suggest teacher beliefs can also help or hinder successful inclusion efforts. Teachers generally report positive beliefs about the general principles of inclusion while also struggling with the realities of inclusive practices in their classrooms (MacFarlane \& 
Woolfson, 2013). Let us look at three important studies exploring teacher beliefs and SWD inclusion.

To begin, Soodak, Podell, and Lehman (1998) surveyed 188 general education teachers regarding their beliefs about the inclusion of SWDs in their classrooms. They identified two general realms of responses: hostility/receptivity and anxiety/calmness. Results from their quantitative study indicated supportive teacher beliefs and frequent differentiated instructional practices were associated with higher rates of receptivity towards inclusion efforts. Further, Soodak et al. also noted that high teacher efficacy beliefs and supportive classroom environments contributed to less inclusion anxiety. Based on their results, Soodak et al. suggested teacher beliefs be considered in conjunction with classroom diversity (including the unique compositions of SWDs) when evaluating overall inclusion efforts.

Next, Jordan and Stanovich (2003) concluded teachers' positive beliefs about SWDs were related to effective teaching practices. Using interviews to investigate teacher beliefs, Jordan and Stanovich placed responses along a continuum of beliefs about the nature of students' needs and rating the teachers' role in teaching them from pathognomonic to interventionist beliefs. Teachers holding pathognomonic beliefs were more inclined to disengage from teaching SWDs, handing over teaching responsibilities to specialists with training. Teachers holding interventionist beliefs were more likely to take responsibility for teaching all students and make the necessary instructional accommodations. The researchers concluded teachers' beliefs about SWDs were connected to their larger epistemological theories about teaching and learning. 
Finally, Ernst and Rogers' (2009) study developed a measurement of teacher knowledge and beliefs towards inclusion strategies. They explored the difference in beliefs between elementary and secondary teachers, observing elementary teachers had more positive attitudes towards inclusion than secondary teachers. The authors noted elementary teachers often work with the same group of students all day and are better able to differentiate instruction, while secondary teachers may meet several different groups of students throughout the day inhibiting differentiated classroom practices. One other finding from Ernst and Rogers' study is noteworthy: teachers with professional development or experience in inclusive classrooms reported more positive beliefs towards inclusion than those who did not. This finding by Ernst and Rogers is interesting, as it sheds further light on the complex relationship between teacher knowledge and beliefs by echoing similar findings on the value of professional development and success with adopting differentiated instructional practices.

Research on teacher beliefs towards classroom diversity suggests a complex and conflicted relationship. This literature places teacher beliefs at the heart of the studentteacher relationship. Further, these beliefs have significant influence on teacher expectations, instructional practices, and subsequent learning outcomes. Finally, teachers report the same bias, prejudices, and negative beliefs towards classroom diversity as their predominant culture.

In sum, culturally diverse students, English language learners and students with special needs all contribute to the contextual influences that mediate the relationship between teacher beliefs and differentiated instructional practices. Why is differentiated 
instruction seen by some to be an effective instructional approach to help diverse learners improve their learning outcomes? In the next section, I look at the seminal research supporting differentiated instruction.

\section{Differentiated Instruction}

Differentiated instruction is one instructional approach to address increasing classroom diversity. Morgan (2014) defined differentiated instruction as "a way of recognizing and teaching according to different student talents and learning styles (p. 34). Subban (2006) proposed a rationale for differentiated instruction based upon current cognitive research, Gardner's (1983) theory of multiple intelligences, and Vygotsky's (1978) concept of the zone of proximal development. In other words, differentiated instruction understands not all students are the same.

A review of the literature indicates research on differentiated instruction is popular; an EBSCO Host search using the term "differentiated instruction" produced 671 results. However, in spite of the scholarly attention, Tomlinson (2014), a leading proponent of differentiated instruction, noted widespread misperceptions of differentiated instruction still exist. Therefore, I clarify the basic concepts of differentiated instructional practices with the figure below (Figure 3). 


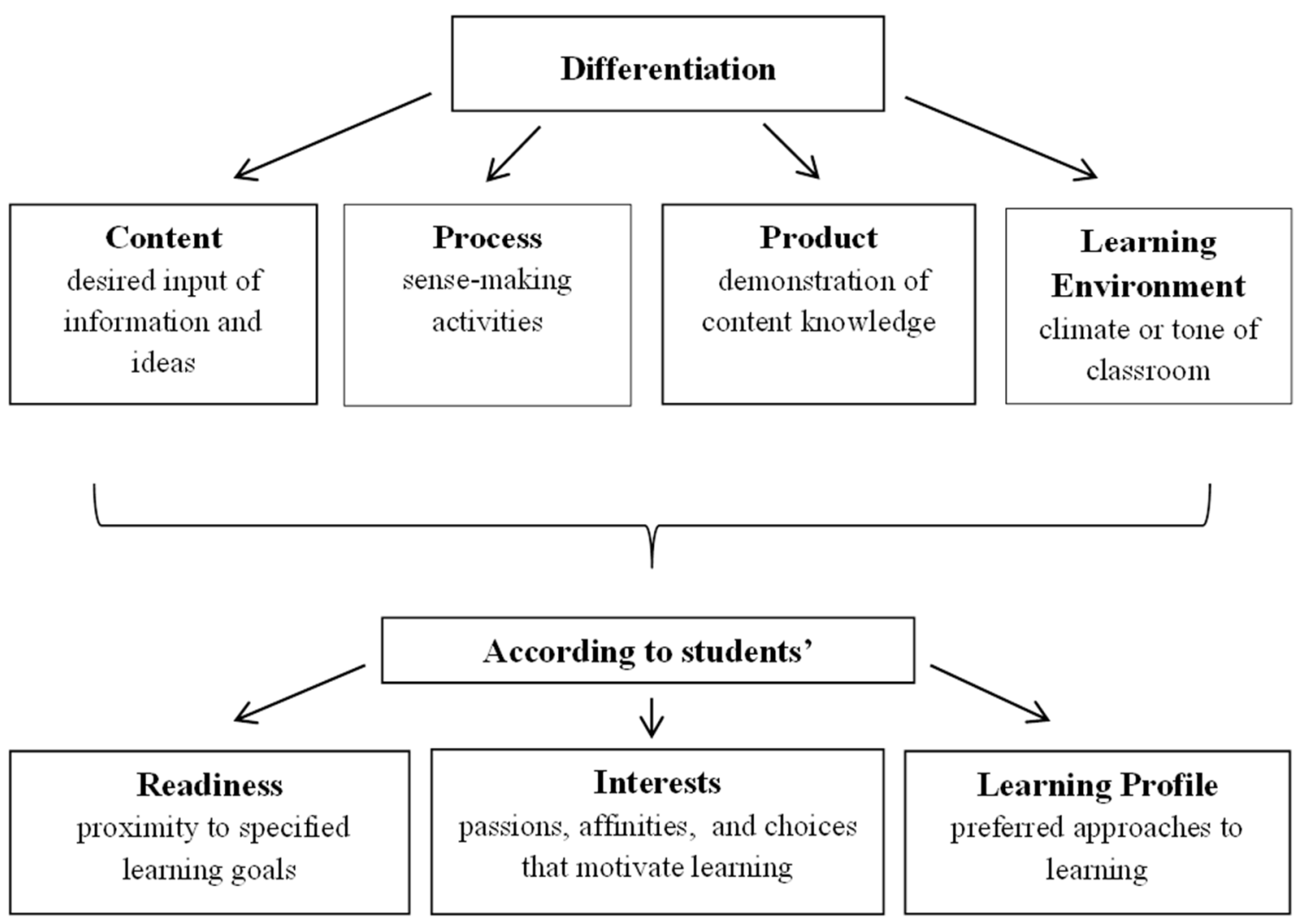

Figure 3. "Differentiated instructional practices," by C. Tomlinson, (2008), The Differentiated Classroom, p. 20. Copyright 2014 by the Association for Supervision and Curriculum Development.

According to Tomlinson (2014), differentiation occurs when teachers use diagnostic assessment data to modify the content, process, product, and the learning environment. Content is defined as what teachers want students to learn from a particular unit of study. Process includes those learning activities designed to ensure that students understand those essential components of content, while products are those student 
creations that demonstrate and enhance knowledge of the content. Finally, the learning environment acknowledges the role of classroom climate.

Tomlinson (2014) further defined differentiated instruction as a philosophy of teaching based on the assumption that students learn best when their teachers take into account individual differences in readiness levels, interests, and learning profiles. Readiness is a student's entry point with respect to the desired curricular knowledge, understanding, or skills. Student interests refer to a "learner's affinity, curiosity, or passion for a particular topic or skill” (p. 19). Learning profiles pertain to the ways in which a student learns, and is partially shaped by gender, culture, and learning styles. In another example of differentiated instructional thinking, Chamberlin and Powers (2010) listed several core principles of differentiated instruction. First, they argued teachers should understand and explain essential student knowledge and skills, which ties assessment to curriculum and instruction. Second, teachers should acknowledge student differences. Third, students should contribute to meaningful work. Fourth, teachers and students should operate in a cooperative classroom environment. Fifth, teachers should employ class grouping and whole class discussion methods flexibly. Sixth, differentiated instruction is proactive (rather than reactive), addressing learning variance from the beginning. Lastly, the physical environment (e.g. time, space, and resources) should be used flexibly to suit the various needs of students. Chamberlain and Powers suggested those teachers who follow these principles are effective practitioners. 
But is differentiated instruction effective? What of the scholarly support for differentiated instruction itself? Here the record is less clear. While the amount of theoretical support and classroom applications for differentiated instructional practices is large, Sherman (2009) argued much literature consists merely of supporting testimonials. Smit and Humpert (2012) agreed, stating differentiated instruction "has not been deeply researched" (p. 1152). Admittedly, after a review of the literature, this perspective seems to hold some validity, yet a few studies suggest positive learning outcomes resulting from differentiated instructional practices. In the next section, I look at four differentiated instructional studies used with students of varied academic performance, students of color, and English language learners.

First, McAdamis (2001) found differentiated instruction was linked to improvements on test scores of low-scoring students in the Rockwood School District (Missouri). Further, teachers indicated students were more motivated and engaged when using differentiated instruction. McAdamis observed the intensive effort to implement school-wide differentiated instructional philosophies, including peer coaching, study groups, and workshops. However, McAdamis also noted the training sessions, mentoring, and professional development efforts took place over a five year span. This study suggests differentiated instructional practices can improve with low academic achievement, but requires significant structural support and sustained cooperation from school faculty and staff.

More recently, Little, McCoach, and Reis (2014) noted the positive effects of a differentiated reading intervention at four middle schools for advanced readers. In their 
cluster-randomized study, students were randomly assigned to treatment groups using differentiated instruction or to control groups using traditional approaches (e.g. lecture, direct instruction, etc.). Students in the treatment groups outperformed control-group students in reading fluency and comprehension despite the reduced amount of wholegroup and small-group instruction in the differentiated group. While Little et al. (2014) were particularly interested in the needs of advanced readers as opposed to the lowscoring students of McAdamis (2001) study, taken together these studies suggest differentiated instructional practices are suitable for a wide range of academic variance.

Second, in a study exploring differentiated instructional practices used in a postsecondary introductory mathematics course, Hood (2012) found differentiated instructional practices were successful with students of color in raising mathematics achievement. Hood concluded the gains in learning outcomes, self-efficacy levels, and positive student behaviors partially resulted from the use of differentiated instructional practices. This study supports the view that differentiated instructional approaches can be used to help bridge ethnic differences between teachers and students.

Third, Parker (2011) explored the relationship between standards-based differentiated instructional strategies and the achievement of elementary English language learners (ELLs) in five elementary schools in grades 3, 4, and 5. In her mixedmethods study, Parker found a significant relationship of differentiated instruction and the improved literacy performance of ELLs. Additionally, Parker noted teachers' desire for additional professional development to evaluate ELL learning, which is consistent with other studies findings about teacher beliefs, differentiated instruction, and 
professional development. However, it is important to note that the qualitative portion of Parker's study involved a focus group consisting of only two teachers: reliance on small sample sizes is a common critique of differentiated instructional scholarship.

Results from these studies suggest differentiated instructional practices are related to positive student learning outcomes. Yet, as this study proposes to explore, teacher beliefs can influence the implementation of differentiated instructional practices in the classroom. In the next section, I present literature exploring the association of teachers' beliefs and differentiated instructional practices.

\section{Associations between Teachers' Beliefs and Differentiated Instructional Practices}

The possible relationship between teacher beliefs and practices has received a great deal of scholarly attention (Calderhead, 1996; Pajares, 1992; Richardson, 1996). However, there is evidence that teachers' espoused beliefs do not always support their actual classroom practices (Brighton, 2003; Liu, 2011). Buehl and Beck (2015) maintained this incongruity should not discount belief research, but rather encourage further exploration into the relationship between beliefs and practices as well as the contextual factors that may help or hinder this relationship. This section explores a small segment of belief literature exploring the associations between specific teacher beliefs and differentiated instructional practices.

In an early effort to understand the factors which helped or hindered differentiated instructional adoption, Tomlinson (1995) examined the teachers in one middle school mandated by district policy to implement it. Many teachers were initially opposed to modifying their instructional approaches, and Tomlinson noted the negative 
impact on some teachers' levels of self-efficacy. On the other hand, Tomlinson found teachers who generally embraced change were more willing to differentiate instruction than those who resisted any reforms. Tomlinson concluded further research was needed to explore teacher resistance to differentiated instructional approaches, as well as classroom management and classroom environment. Yet in this study, Tomlinson used the term "beliefs" only twice. However, once was to conclude "the idea that people are more likely to act their way into belief than believe their way into acting" (pp. 85-86). In other words, experiencing success with a classroom practice was more likely to bring about a change in related teacher behaviors than efforts trying to convince the teacher that the practice will be beneficial. In short, practice influences belief.

Guskey (1986) is one of the better known advocates for shaping teachers' beliefs by having them engage in specific actions and practices. This perspective finds support in the literature acknowledging successful differentiated instruction requires intensive long-term professional development and faculty commitment. Teachers do not always know how to address diverse classrooms or change behaviors in order to do so.

In another early study, Moon et al. (1995) investigated the degree to which middle school teachers addressed classroom diversity using differentiated instructional practices. Their results were discouraging. Moon et al. revealed few teachers planned for student interest, learning profiles, or cultural differences during lesson planning or classroom instruction. Further, their study revealed teacher modifications were generally limited in scope and situated in only a few flexible classrooms that allowed teachers more easily to accommodate student variance. Regarding academic needs of students, Moon et al. 
(1995) found "neither principals nor teachers ranked advanced/gifted learners as first" (p. ix). Overall, this study suggested an urgent need for teachers to undergo professional training and long-term development to switch over to differentiated instruction.

More recently, Brighton (2003) linked attributed teachers' willingness to change to four factors: (a) their personal histories, (b) the level of content knowledge teachers possess, (c) their pedagogical content knowledge, and (d) teachers' efficacy and individual beliefs about their competence relative to content, their students, and the specific intervention involved. Significantly, Brighton argued gaps existed between teachers' expressed beliefs about differentiated instruction and their actual classroom practices. These gaps are summarized in Table 1.

Table 1

Gaps between Recommended Practices and Teachers Beliefs

Recommendation for practice $\quad$ Teachers beliefs hindering recommendations

Teachers should strive to create studentcentered classrooms

Teachers should assume the role of facilitator in the classroom.

Teachers should teach for success for all learners in the classroom.

Teachers should be focused on clear goals and objectives for each learning task

Teachers should provide options for students that reinforce multiple learning modes and individual preferences.
The role of the teacher is to entertain

Teaching is talking, listening is learning

When faced with an academic challenge, students will resist and shut down.

Equity and fairness necessitates that all students do the same thing the same way

Teachers cannot depend on students to opt for a harder task; that is not fair to penalize them with lower grades when other peers selected easier tasks.

Note: Adapted from “The Effects of Middle School Teachers' Beliefs on Classroom

Practices," by Brighton, C, 2003, Journal for the Education of the Gifted, 27, p. 177-206. 
More recent evidence that teachers' beliefs are disconnected from their practices was provided by Liu (2011). In a study of 1,340 teachers, Liu found although $79 \%$ of teachers surveyed espoused learner-centered beliefs, a majority of them reported using lecture methods instead of more constructivist approaches. This research suggests reform effort focus on closing these gaps between beliefs and practices.

The research exploring the association between teachers' beliefs and differentiated instructional practices reveals a persuasive belief about the roles of teachers and students which could possibly inhibit the adoption of differentiated instruction. This literature suggests changing teachers' pre-existing beliefs requires long-term professional development, intensive coaching, and purposeful collaboration to successfully implement differentiated instruction. Policy mandates requiring differentiated instruction does not seem to be as effective, leading to criticisms. What are some critiques of differentiated instruction? The next section addresses that question.

\section{Critiques of Differentiated Instruction}

Differentiated instructional philosophies and practices are not universally embraced. Some of the literature questions the theoretical support for differentiated instruction (Rohrer \& Pashler, 2012; Sherman, 2009). Other critiques highlight the challenges rooted in teacher beliefs hindering differentiated instructional implementation in the classroom (Archambault et al., 1993; Joseph, 2013; Lalvani, 2013; Reis, Gentry, \& Maxfield, 1998; Reis et al., 2004; Rochkind et al., 2007; Tomlinson et al., 2003). In this section, I present two studies exploring both perspectives. 
First, Tomlinson (1995) has made the claim successful differentiation must plan and implement instruction based on a thorough diagnosis of student learning styles. Yet, Rohrer and Pashler (2012) questioned the legitimacy of learning style theories which figure prominently in differentiated instructional literature. They claimed the majority of studies supporting do not employ appropriate methodological designs, and the data provides no evidence for teachers to use style-based instruction. Contradicting Tomlinson's claim, the authors concluded "there presently is no empirical justification for tailoring instruction to students' supposedly different learning styles" (p. 636). In short, Rohrer and Pashler concluded supporting scholarship for learning styles was weak. However, the authors' preference for double-blind empirical designs seems to have biased them against qualitative designs using more holistic analytical designs. These qualitative designs are more favored by differentiated instruction researchers.

Second, Joseph (2013) found every one of his 379 teacher participants reported obstacles to differentiating instruction. In a study of primary and secondary teachers, Joseph found $58 \%$ of participants were familiar with the philosophies behind differentiated instruction, yet the majority of teachers still did not differentiate content or product for their students. Obstacles cited by teachers in Joseph's study including limited time and resources, plus a lack of knowledge how to differentiate for content and products.

Joseph's participants' perceived lack of adaptive teaching competencies was a common theme among critical studies. Thus, studies found teachers often continued to use practices that contradicted differentiated instructional philosophies (Blozowich, 2001; 
Brighton, 2003). For example, Blozowich (2001) found some teachers used a variety of instructional strategies in the classroom, but still tracked students into more or less permanent academic groups in the classroom. Blozowich recommended ongoing professional development and active dialogue as part of a professional learning community to address the tendency to track students academically.

Finally, other teachers had concerns about managing their classroom environment when differentiating instruction. Robinson et al. (2014) explained in their multiple case study the fears of teachers included losing control of students, learning different instructional strategies, too many ideas and subjects running simultaneously, and the lack of time to plan and implement differentiated instruction.

As early as 1995 differentiation "had become a buzzword" (Sherman, 2009, p. 47). However, adoption is still scattered and incomplete. Research consensus indicates school reform cannot be sustained without long term commitment by teachers, administrators, and community partners. However, successful commitment requires stakeholders address classroom diversity context, a significant influence on teacher beliefs. The next section examines the role of classroom diversity on teacher beliefs and differentiated instructional practices.

\section{Influence of Classroom Diversity}

Rubie-Davies (2010) maintained teacher beliefs, by framing classroom instructional decisions and classroom practices, become related to the social and emotional aspects of the classroom and thus influence the classroom climate. On the other hand, Milesi and Gamoran (2006) argued some classroom contexts (like class size) 
were not as important as quality teacher behaviors; yet, they too conceded classroom diversity hampered researchers' ability to make any widespread generalizations about context or diversity. They concluded the "variety in these patterns of findings makes it important to assess the effects of class size for students who differ by race/ethnic, economic, and academic backgrounds in the nation as a whole" (p. 293). In other words, classroom diversity underpins other classroom contexts. Because classroom diversity can hold sway over teacher beliefs, this section presents literature exploring this influence.

One school of thought maintains diverse classrooms can offer many benefits for students. Researchers studying university-aged populations suggested increased levels of student diversity can enhance students' perspectives, increase critical thinking, and raise the level of intellectual engagement (Antonio et al., 2004; Gurin, Nagda, \& Lopez, 2004; Milem \& Umbach, 2003 ). Other research with younger populations suggested higher levels of classroom diversity can lead to diminished prejudicial attitudes, increased tolerance of individual differences, and higher senses of self-worth among students (Damico \& Sparks, 1986; Juvonen, Nishina, \& Graham, 2006; Salend \& Duhaney, 1999; Turner, Hewstone \& Voci, 2007). According to this view, classroom diversity can be an educational benefit when addressed properly by teachers. Yet, researchers also acknowledged components of classroom diversity can result in additional challenges for teachers wishing to implement differentiated instructional practices. In the next section, I introduce studies investigating the influence of two diversity contexts: class sizes and student behavior. 
First, Bruhwiler and Blatchford (2011) concluded large class sizes can reduce effectiveness of certain teacher behaviors in the classroom. Expanding on this conclusion, Dee and West (2011) argued large class sizes are linked to increased off-task student behaviors. Another study concluded larger class sizes resulted in reduced student involvement (Englehart, 2006). Additionally, the quality and quantity of teacher-student interactions dwindled in larger classes (Blatchford, Basset, \& Brown, 2011). These studies support the widespread teacher belief regarding the negative influence of larger class sizes.

Second, some researchers have connected student behaviors to teacher efficacy. For some time, student achievement was linked to teacher competency (Friedman \& Farber, 1992). However, other studies demonstrated types of student behavior, engagement, and interactions influenced their academic achievement (Axelson \& Flick, 2011; McCroskey, Richmond, \& McCroskey, 2002; Weaver, 2006). Finally, researchers suggested high teacher self-efficacy is necessary for the successful functioning of a diverse inclusive classroom (Chan, 2008; MacFarlane \& Woolfson, 2013; Sharma, Loreman, \& Forlin, 2012; Soodak, Podell, \& Lehman, 1998). The converse understanding of this body of research suggests lower student achievement could lower teachers' competency and efficacy levels. The upshot of this section is to highlight the significance classroom diversity contexts play in teachers' beliefs and decision-making processes. This significance can be seen in the study below which combined these contextual challenges together. 
Rubie-Davies, Flint and Macdonald (2012) found teacher beliefs, teacher characteristics, and school contexts all influence instructional practices and classroom environments. They proposed that teacher beliefs were not likely to exist in isolation, but were moderated by school contexts and personal characteristics. Rubie-Davies et al. (2012) examined the relationships between teacher epistemology, teachers' class level expectations, goal orientations, and teacher efficacy (See Figure 4.)

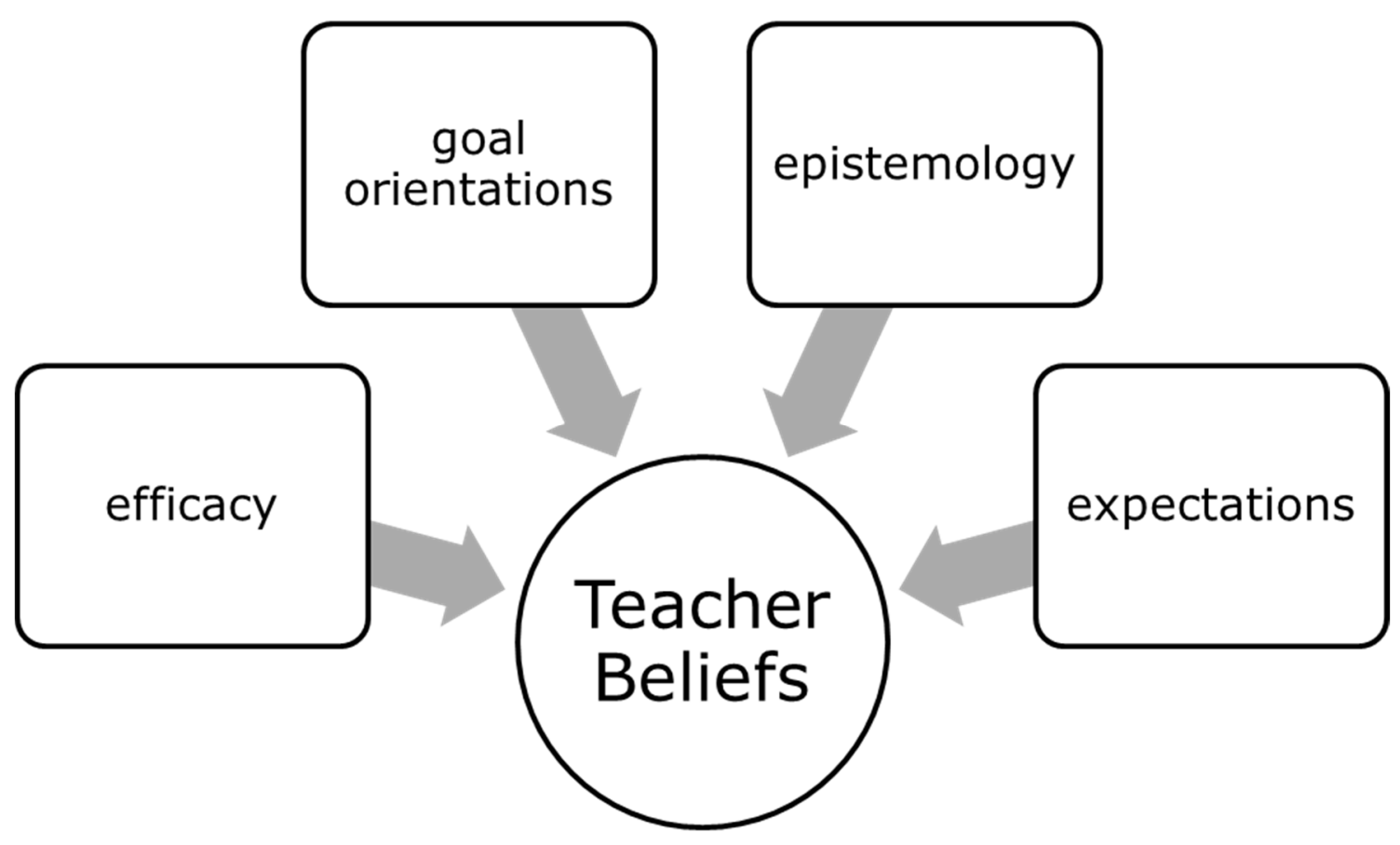

Figure 4. Belief constructs. Adapted from Rubie-Davies, C., Flint, A., \& McDonald, L. (2012). Teacher beliefs, teacher characteristics and school contextual factors: What are the relationships? British Journal of Educational Psychology, 82(2), 270-288.

Broadly speaking, Rubie-Davies et al. (2012) argued teacher efficacy relates to what the teacher believes they can do to get the students there, teacher expectations are related to where the teacher believes the students will get to, and teacher goal orientation 
relates to how they believe lessons and assessment should be structured in order for students to reach their goals. The researchers investigated whether any contextual factors (i.e., school socio-economic level and class level) could predict any of these teacher psychological variables.

Rubie-Davies et al. (2012) used a quantitative approach to study 68 teachers teaching upper elementary and middle schools. They employed three different data collection methods: a teacher-beliefs questionnaire (consisting of teacher efficacy and teacher goal orientation items), a teacher expectation survey, and a measurement of student achievement. First, to measure teacher efficacy, the teacher beliefs questionnaire used the Teachers' Sense of Efficacy Scale (TSES) developed by Tschannen-Moran and Hoy (2001). Second, to measure teacher expectations, the researchers used an assessment tool developed and used in New Zealand to measure students writing, mathematics, and reading comprehension. Third, to measure teacher goal orientations (mastery and performance approaches to instruction), the researchers employed two subscales from the Patterns of Adaptive Learning Scales (Midgley et. al, 2000). RubieDavies et al. (2012) used a series of linear regressions to determine the relationship between teacher expectations, teacher efficacy, and teacher goal orientations. Ultimately, Rubie-Davies et al. concluded that teacher beliefs, teacher characteristics, and classroom contexts were related to both the instructional and socio-emotional climate in the classroom.

Creating a student-centered climate is a tenant of differentiated instructional philosophy (Tomlinson, 2014). Yet, scholars are just beginning to investigate the 
complex relationship teacher beliefs have with classroom diversity and classroom practices. Much remains to be explored. How do researchers measure teacher beliefs?

In the next section, I review the literature on different methodological approaches to studying teacher beliefs pertinent to this study.

\section{Review of the Methodological Literature}

One could argue the large amount of scholarship has muddied, rather than clarified, our understandings of teacher beliefs. That challenge has not stopped researchers from further exploration into teacher beliefs. As noted earlier, Nespor (1987) claimed teacher beliefs are better predictors than knowledge for understanding classroom behaviors, yet also admitting the difficulty untangling beliefs and knowledge. To avoid Nespor's entangled domain, the next section will introduce how recent scholars have attempted to isolate and measure teacher beliefs away from any potential methodological entanglements.

Measuring teacher beliefs. In this paper, I use methodology as a broad term to refer to the general logic and approaches for a study, while the term methods refers to specific techniques used to collect data (Bogdan \& Biklen, 2007). Teacher belief studies rely heavily on two methods of collecting data: self-reports and observation. Self-report, including questionnaires and verbal reports, gets the most use in teacher belief research to describe or quantify beliefs that guide teaching and learning. Observation involves collecting and analyzing teaching and learning artifacts that purport to be manifestations of teacher beliefs. Observation examples include performance observations, analysis of self-reflective writing, evaluations of teaching portfolios, and examination of classroom 
artifacts. Whatever the source, data gathered from belief measures should be subject to quantitative or qualitative scrutiny (Hoffman \& Seidel, 2014).

This scrutiny is important because both widely used methods can raise measurement concerns. Self-reports and observations can be subject to response bias. First, Kagan (1992) found some participants unable or unwilling to accurately report their own beliefs. Second, Fives and Buehl (2012) and Woolfolk et al. (2006) noted the common incongruity between self-reported espoused beliefs and demonstrated enacted beliefs. If this is true, then it stands to reason that precise measurement of beliefs is complicated and objective measurements are still evolving.

Selection of research methods. I believe a qualitative approach was best suited to answering my research questions (see Figure 4). Corbin and Strauss (2008) stated, "Qualitative research allows researchers to get at the inner experience of participants, to determine how meanings are formed through and in culture, and to discover, rather than test variables" (p. 12). I proposed a qualitative case study approach because my goal was to understand middle school teachers' beliefs about teaching and learning in diverse classrooms. With this purpose, qualitative approaches that seem to provide rich descriptions are pragmatically well-suited to explore my three research questions on teacher beliefs (see Figure 5). 
1. What are middle school educators' beliefs about diffferentiated teaching and learning in large classes?

semi-structured interviews

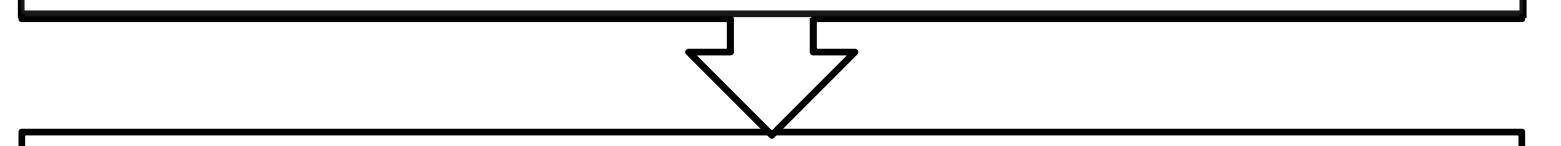

2. How do teacher implement their beliefs about differentaited teaching and learning?

classroom observation

3. What factors influence teachers' adoption of differentiated instruction in their classrooms?

semi-structured interviews

Figure 5. Research questions and selected methods to answer them.

I chose a case study design because Merriam (1988) suggested case study designs are useful to explain variables that are not easily extracted from the surrounding contexts. Teacher beliefs cannot be directly observed and measured; researchers must tease them out from what teachers say, intend, and do (Pajares, 1992). I argue case study methodology is a good fit for teacher belief studies, as the majority of the study occurred in the natural setting of the classroom.

Two studies have had major influence on the measurement of teacher beliefs. First, Gibson and Dembo's (1984) seminal work used a 30-item Teacher Efficacy Scale (TES) to measure general and personal teaching efficacy. Second, Tschannen-Moran and Hoy (2001) used the Teachers' Sense of Efficacy Scale (TSES) to measure self-efficacy for instructional strategies, classroom management, and student engagement. Like this study, some belief researchers make use of both measurement tools. 
For example, Dixon et al. (2014) used both measures (TSES and TES) because they argued both subscales related to areas of differentiation. In particular, they argued the Instructional Strategy subscale of the TSES was the best predictor of differentiation. Questions of this subscale included:

Item 1: To what extent can you use a variety of assessment strategies?

Item 2: To what extent can you provide an alternative explanation or example when students are confused?

Item 4: How well can you implement alternative strategies in your classroom? Item 6: How much can you do to adjust your lessons to the proper level for individual students?

Item 7: To what extent can you gauge student comprehension of what you have taught?

Item 8: How well can you provide appropriate challenges for very capable students? (Tschannen-Moran \& Hoy, 2001, p. 800).

While the TSES scale was originally designed by Tschannen-Moran and Hoy (2001) to be used with Likert-type response formats with nine possible choices, I adapted these questions for use in a semi-structured interview format, which I will discuss further in the next chapter. Additionally, Dixon et al. (2014) administered the TES in their study. While Gibson and Dembo's instrument was designed to measure teacher efficacy, two of items were related to differentiation. These items included:

Item 12: When a student is having difficulty with an assignment, I am usually able to adjust it to his/her level. 
Item 29: If one of my students could not do a class assignment, I would be able to accurately assess whether the assignment was at the correct level of difficulty (Gibson \& Dembo, 1984, p. 573).

Using several different methods to include different subscales related to differentiation seem to be important in teacher belief studies to address validity concerns. To avoid potential methodological issues, it was important to use a variety of strategies to explore and describe teacher beliefs and differentiation. In the next chapter, I elaborate upon this study's methods and methodologies. 


\section{Chapter Three: Methodology}

Increasing classroom diversity calls for teachers to use differentiated teaching strategies to address a variety of learning needs. However, addressing students' varying needs is not a simple practice. Thus, the purpose of this study was to explore and describe veteran middle school teachers' beliefs about their diverse students and to explain how these beliefs influence their differentiated instructional practices. Guiding this study were the following research questions:

1. What are middle school educators' beliefs about differentiated teaching and learning in diverse classes?

2. How do teachers implement their beliefs about differentiated teaching and learning?

3. What factors influence teachers' adoption of differentiated instruction in their classrooms?

This chapter contains a description and rationale for the research methodology proposed for this study. First, I orient my study within a constructivist paradigm and

justify a qualitative case study approach. Next, I present the research plan, including participants, context, procedures, and data collection and analysis. Finally, I conclude this chapter with a look at trustworthiness and researcher bias issues.

\section{Research Paradigms}

Guba and Lincoln (1989) defined inquiry paradigms as basic belief systems based on responses to ontological, epistemological and methodological assumptions. Operating 
within these three sets of assumptions are fundamental questions about the nature of the world:

1. Ontological- What is the form and nature of reality?

2. Epistemological- What is the relationship between the knower and what can be known?

3. Methodological- How can the knower go about finding out? (p. 108).

The responses to these questions shape how researchers view knowledge. Guba and Lincoln argued inquiry paradigms and subsequent analyses are human constructions resulting from conscious decisions made by the researcher. Therefore, the purpose of this section is to persuade the reader that my choice of a constructivist paradigm for my research design was appropriate to the research question and purpose.

Qualitative researchers assume there are multiple realities. Therefore, I begin by addressing the ontological question: "What is the form and nature of reality?" Guba and Lincoln (1994) took a relativist position to describe the situated nature of reality in a constructivist paradigm — this means they established this position by placing reality within the mental constructs of individuals or groups operating in specific contexts. Further, Stake (1995) argued for the essential role of the researcher in constructivism, stating "most contemporary qualitative researchers nourish the belief that knowledge is constructed rather than discovered" (p. 99). In other words, according to this constructivist framework, knowledge construction begins with a personal assignment of meaning to a stimulus; this meaning then mixes with preexisting perspectives and generalizations to form an interpretation of reality. 
Second, I answer the epistemological question, which seeks to explore the relationship between the knower and what can be known. Operating from a constructivist framework, Guba and Lincoln (1985) believed truth is shaped by individual beliefs. Additionally, this knowledge creation is partly a social construction, derived around a common consensus regarding the true nature of reality (Pajares, 1992). In short, the knowledge that emerges from this study is partly my own creation because of my own beliefs.

Third, from a methodological perspective, which explores how the knower can go about understanding, qualitative studies are well suited to understand the meanings participants' construct for an event, the context in which participants act, and the influence of those contexts on the participants (Maxwell, 2013). Using a case study rationale (Yin, 2003), this study attempted to illustrate the contemporary phenomena of differentiated instruction in diverse classes. As such, context is highly pertinent to this study. Further, as contextual variables can be challenging to isolate methodologically, the comprehensive nature of the data collection and analysis strategies needed for case study designs lends itself well to a study of this nature. Ultimately, as Stake (1995) observed, the case is "a specific, a complex, functioning thing" (p. 2). Consequently, there is not a direct link between teacher beliefs and differentiated instructional practices; mediating factors like adaptive teaching competencies and classroom contexts require vigorous interpretation from participant and researcher alike.

One of the greatest strengths of qualitative research lies in its ability to provide "process, understanding, and interpretation," and in creating a thick, descriptive account 
of a bounded phenomenon (Merriam, 1988, p. 21). The classroom environment is a highly complex construct that does not easily reveal the specific influences of individual elements (e.g., class size, ethnic diversity, socio-economic status) on learning outcomes (Englehart, 2011). Furthermore, while teacher characteristics (i.e., knowledge and beliefs) are generally accepted to hold significant influence on learning outcomes, there is no widespread consensus on which teacher characteristics are most effective at increasing learning outcomes (Hanushek, 2011; Harris \& Sass, 2011). I maintain teacher beliefs can be used as a lens to observe teacher characteristics and differentiated classroom processes. Hence, I selected a qualitative design for this study and the guiding research questions to further understand the complex relationship of teacher beliefs and differentiated instructional practices. In the next section, I explain the research design for this study.

\section{Research Methods}

Due to the contextual nature of this phenomenon, I used a case study approach. Case studies are empirical designs that investigate a phenomenon in its natural context (Yin, 2003). Moreover, case study design is especially useful when the boundaries of participants are not easily distinguished from the natural context. This qualitative study incorporated a multiple case study design with a holistic analysis (Stake, 1995). In other words, I selected this design to emphasize the participants' perspectives in the natural setting of their school environments. These natural settings included the participants' classrooms, planning periods, and faculty lunchtimes in order to gain a richer understanding of the contexts in which the participants worked. 
While a misconception in case study methodology maintains that theoretical propositions are not necessary before beginning data collection, Yin (2003) argued theory development is "an essential step" (p. 29). In this study, I created the theoretical framework through a review of the literature on teacher beliefs, differentiated instruction, and classroom diversity, refining it further during and after data collection.

To understand the participants' perspectives, I used life history approaches in my narrative inquiry research. A focus on narrative inquiry is grounded on the idea that people understand and give meaning to their lives through stories (Andrews, Squire, \& Tambokou, 2008; Vogt, Gardner, Haeffele, 2012). In addition, life history helps highlight the social contexts that shape identity, while personal narratives emphasize beliefs and ways of experiencing real world context. My life history approach focused on individual teachers' personal experiences with classroom diversity and differentiated instruction-Clandinin and Connelley (2000) referred to these stories as "field texts." To understand the participants' personal experiences with differentiated instructional practices I made their narratives explicit with this design. Narrative inquiry allowed the participants to explain "how" and "why" they attach meaning to their beliefs and to describe their experiences with differentiated instruction. In the next section I discuss the rationale for the characteristics of the participants in this case study.

\section{Context and Participants}

For this study, I decided to gather research at a middle school. Anfara et al. (2007) reached back over 100 years to give credit to Hall (1904) for recognizing the unique developmental characteristics of adolescents. In subsequent years, middle school 
reform has called for developmentally appropriate practices to meet the needs of their students (NMSA, 1995; NMSA, 2010). Anfara et al. (2007) defined developmentally responsive practices as meeting adolescents' unique physical, intellectual, moral, emotional, and social needs. However, Anfara et al. also worried the implementation of developmentally responsive practices in middle schools was "less than sufficient" (p. xxi). In other words, they were concerned middle school practices on the whole do not emphasize differentiation. According to their view, it is incumbent for middle level educators use developmental practices that meet these needs. Selecting a middle school context to collect data may help to provide additional information on middle school teachers' beliefs and practice that could assist middle level educators in helping students succeed.

Community context. TMS is located in the Pacific Northwest, primarily serving twin towns (Towns A and B) and three additional smaller farming communities. Town A is a small town with many families who have been in the area for generations as well as families new to the area. Town B is also home to a midsize university with approximately 6,000 undergraduate students. Students from the university often interact with middle school students in several ways. First, TMS has a mentoring program with the university as well as an after school program. Physical education majors often assist the faculty at TMS with their in-class kinesthetic activities, called "brain breaks" by the faculty. Second, teacher candidates from the university frequently complete their student teaching experiences at TMS or the larger school district. Lastly, a number of graduating teacher candidates eventually wind up working at TMS. 
The two towns share similar ethnic demographics. According to the U.S. Census Bureau website (2016), Town A has a population of approximately 8,700 people and is predominately White (73.3\%) and Latino (35.3\%). By comparison, Town B is slightly larger with 9,700 residents and has similar population groups predominately White $(82.8 \%)$ and Latino (13.4\%). Students from three elementary schools located across the two towns merge into TMS when they graduate from the fifth grade.

District and school context. To begin, according to Plano Clark and Creswell (2010), purposeful sampling is where "researchers intentionally select sites and individuals to learn about or understand the central phenomenon" (p. 253). Using purposeful sampling I chose the school site, which I named Typical Middle School (TMS), for several reasons.

TMS is part of a larger school district covering just over 154 square miles and serving over 2,900 students. According to the state 2016 Educator Equity Report, student ethnicity in the district is split evenly between 50\% White and 50\% students of color. Just over 3\% of teachers in the district were of color (Chief Education Office, 2016). The district has an average of 31.5\% students identified as English Language Learners (ODE, 2106). Further, the school district has an average of 55\% economically disadvantaged students. This percentage is slightly higher than state averages (51\%) for the reported year (ODE, 2016). The next section provides the context for TMS and my rationale for selecting the school as the site of my study.

First, TMS could be considered a "typical" public middle school in the northwest region of the United States. Like many other public middle schools in the state, TMS 
serves sixth through eighth graders. According to the school website, TMS offers a full curriculum of classes and electives, including science, social studies, math, language arts, choir, band, art, yearbook, health, physical education, Lego robotics, French, service learning and leadership classes. TMS also featured an after school program available for students wanting help with homework, tutoring, or other enrichment opportunities. Finally, several clubs and athletic programs operated in the building under the supervision of TMS staff and community volunteers. According to a scan of the web pages of ten other similarly-sized middle schools, TMS's course and extra-curricular offerings fell in line with other institutions.

Second, student demographics at TMS were similar to district percentages: according to figures provided by the building principal, the racial makeup of students at TMS in 2015 included White (49.5\%), Latino (44.1\%), with other ethnicities making up the remaining $(4.1 \%)$. At the time of this study, the racial composition of the certified TMS staff was reported by the state department of education (and confirmed by my observations) to be entirely White.

Expanding further outwards, most of the demographic data at TMS were generally comparable with state averages, including class size, socio-economics, and student ethnicity. During 2015-16 when I conducted this study, 735 students had enrolled at TMS. The average class size for core curriculum (language arts, mathematics, science, and social studies) classes were generally in line with state averages. According to the 2015-16 report card, median class sizes at TMS were 28 students, slightly higher than the state average of 25 students per class (ODE, 2016). 
The numbers of students on free and reduced-price lunches, (often used as proxy figure for approximating the socio-economic levels of students), was also slightly above state averages, $61 \%$ at TMS compared to $51 \%$ of middle school students statewide (ODE, 2016).

TMS had a slightly higher percentage of Latino students $(43 \%)$ than from across the state, perhaps due to the dominance of local agricultural jobs that traditionally employed high numbers of Latino workers. Statewide, according to the Chief Education Office (2016) approximately $37 \%$ of students identified as culturally and linguistically diverse. The report indicated this percentage was slight increase from the previous year. Finally, as mentioned previously, the ethnic composition of the full-time faculty at TMS was entirely White. In rural areas (similar to where TMS is located) $88 \%$ of teachers identified themselves as White (ODE, 2016). The ethnic disparity between faculty and students is common to many schools in the area; statewide only about $8 \%$ of teachers identified themselves as teachers of color (Chief Education Office, 2016). As I wished to understand teachers' beliefs about classroom diversity (including cultural diversity) and their influence on differentiated instruction, the significant disparity between faculty and student diversity made TMS an attractive location to select participants. Besides the attractive demographic characteristics of TMS, the particular location of this school offered additional opportunities for my study. I describe these opportunities in the next section.

From my perspective as a researcher, I am familiar with the wider context of the TMS community and school through my work there as a university supervisor of student 
teachers. This supervisor experience provided me with an introduction to the culture of TMS and the larger school district. Though I am less knowledgeable about the beliefs and practices of individual teachers in the school, I am familiar with many of the cultural nuances of the school, its faculty and staff, the students, and its instructional and organizational practices.

Subsequently, having been an extended visitor at TMS for over a year, as well as a member of the community in which TMS is located, I believe the administration, staff, and students were familiar and comfortable with my presence. Therefore, the choice of setting also reflects some elements of convenience sampling techniques, which Vogt et al. (2012) described as a method of selecting phenomena based upon "what is easy for the researcher" (p.339). As I needed to spend a significant amount of time collecting data, I saw this as an advantage.

To address the concerns raised by Vogt et al. (2012), I maintain the time I spent at TMS prior to this study and the relationships formed with those at TMS might enable me to access information researchers considered "outsiders" might not be privy to. Further, the TMS faculty and staff are aware of my former professional status as a middle level educator, which should help the perception of me "fitting in" with the culture of the school, which is one reason why I believe I was allowed access to TMS in a researcher role and why the faculty and staff may have felt more comfortable talking with me and answering my questions honestly. The advantages and disadvantages of the familiarity regarding data collection will be addressed in the section on the role of the researcher. 
Participants. For this study, the TMS Principal made recommendations for six teachers across content areas and grade levels who could serve as study participants. The TMS principal based his selection on those teachers whom he considered skilled at employing differentiated instructional practices in their classrooms. Using multiple participants allowed for a level of comparison enabling me to establish emerging patterns, trends, or outliers. Of the six teachers the principal recommended, four agreed to participate in this study.

Plano Clark and Creswell (2010) included typical sampling as one type of purposeful sampling strategy where the researcher intends to describe cases that are typical or average. Ultimately, my TMS participants were considered "typical" teachers considered by their principal to be proficient at differentiated instruction. How did I define "typical?"

The recommended participants were considered veteran teachers with at least 10 years classroom experience and come from varying grade levels and content areas, but sharing similar demographic, socio-economic, and cultural characteristics. They were all female, similar to $76 \%$ of teachers nationwide (U.S. DOE, 2013). They considered themselves to be part of the middle class. Like $90 \%$ of the other teachers in the state, these middle class, female teachers identified themselves as White (Chief Education Office, 2016). These characteristics placed them squarely in line with state and national averages.

Further, like four out of five teachers currently practicing in the US, the participants have similar teaching credentials earned through traditional teacher 
preparation programs (OPE, 2013). Additionally, they attended many of the same professional development sessions on teaching and differentiated practices. In other words, both their in-service and pre-service training could be considered "typical" for teachers operating in this area. The following section discusses procedures used in this case study, including a timeline for data collection and data analysis procedures.

\section{Procedures}

Upon receiving IRB approval to conduct my study, I contacted the teacher participants via email and phone to arrange face-to-face meetings to review participation details and obtain signed consent forms. Data collection commenced in mid-September and continued biweekly through mid-December 2015. Some member checking and clarification of interviews continued into February 2016.

To explore the research questions and to produce systematic, rich descriptions of the cases, I used multiple data collection methods, including three semi-structured interviews, bi-weekly classroom observations, and artifact analysis. I selected these methods to "add rigor, breadth, complexity, richness, and depth" to my study (Denzin \& Lincoln, 2000, p. 5). All data collection took place on TMS grounds, occurring before, during, and after the normal school day. All data collected from this study will be kept in a locked drawer in my home office for a minimum of three years after the completion of this study.

Further, my methods were intended to "serve to clarify meaning by identifying different ways the phenomenon is being seen" (Stake, 1995, p. 444). Classroom observations may reveal inconsistencies or incongruities with interview data. The data 
collection methods are the most fitting for this type of study and for the participants involved because exploring and describing the complex relationship between beliefs and practices requires multiple sources of evidence collected over time (Plano Clark \& Creswell, 2010).

\section{Instruments and Measures}

In Table 2, I review the four instruments I used in this study and the constructs each instrument measures. Following the table is a rationale for the selection and format of these instruments.

Table 2

Qualitative Instruments Selected and Constructs Measured

Instrument

Semi-structured interviews (2 per participant)

Likert survey

Participant observations (6 per participant)

Physical artifacts (as available)
Construct Measured

General teacher teaching and learning beliefs, self-efficacy

Classroom diversity beliefs

Differentiated instructional beliefs

Adaptive Teaching Competency, Classroom diversity, Differentiated instructional practices, and Classroom environment

Adaptive Teaching Competency, Differentiated instructional practices
Time Administered

mid-September 2015

October 2015

December 2015

Bi-weekly beginning mid-September to December 2015

mid-September to December 2015

The first data collection instrument consisted of semi-structured teacher interviews. According to Seidman (2013), the purpose of interviewing is not to test a 
hypothesis, but to express an interest in "the lived experience of other people and the meaning they make of that experience" (p. 9). I scheduled two semi-structured interviews with each teacher participant at the beginning and end points of the observation period. These interviews were semi-structured using predominantly openended questions to allow participants the freedom to discuss their beliefs at length. I employed a semi-structured approach to gain what Thomas (2011) called "the best of both worlds," which is a compromise between the efficiency of a structured interview and the rich conversational potential of an unstructured interview (p. 163). To ensure a reasonable time commitment for the participants, interviews were scheduled for approximately 30-45 minutes each. Brief follow-up conversations were needed to occur after interviews for clarification. These conversations took place intermittently through February 2016.

The first set of semi-structured interview questions (see Appendix A) consisted of items adapted from three sources. Self-efficacy items were modified from TschannenMoran and Hoy's (2001) Teacher Sense of Self-efficacy Scale (TSES) and Gibson and Dembo's (1984) Teacher Efficacy Scale (TES). I selected the TSES and TES because both align with Bandura's (1986) social cognitive theory and are both widely used to measure teacher efficacy and teacher beliefs. Additionally, while not as widely used, a few items from the TSES and TES can measure differentiated instructional practices.

I modified these instruments from their original Likert questionnaire responses to allow participants the opportunity to expand and elaborate upon their responses in an interview format. Interview questions about curriculum, instruction, and assessment 
came from Savasci and Berlin (2012). These questions were included as they are associated with beliefs about general teaching and learning and fit well with the study's first research question: What are middle school educators' beliefs about differentiated teaching and learning in diverse classes?

The second set of semi-structured interview questions (See Appendix C) consists of items adapted from Savasci and Berlin (2012) exploring beliefs about teaching and learning. These items were chosen to align with the study's conceptual framework exploring the study's first and third research questions: (a) how do middle school teachers implement their beliefs about differentiated teaching and learning?, and (b) what factors influence middle school teachers' adoption of differentiated instruction in their classrooms?

For my next data collection instrument, I gathered data from observations of the participants' classroom teaching using a differentiated instruction observation tool (see Appendix D). I adapted the tool from the Differentiated Classroom Observation Scale (DCOS) developed by Cassady et al. (2004.) The purpose of these observations was to gain a "here-and-now experience in depth" (Lincoln \& Guba, 1985, p. 273). In other words, I wanted to see how teachers used or did not use differentiated instruction in their classrooms. Data from observations can also support or counter participant's comments made during interviews.

While the DCOS was originally created to examine differentiated instructional activities and experiences of talented and gifted students in regular classroom settings, Cassady et al. (2004) surmised that the tool also could be used for other groups of 
students as well. The tool includes the range of differentiated instructional activities that could occur in the classroom, making it an attractive choice to more formally explore the second research question: how do middle school teachers implement their beliefs about differentiated teaching and learning?

I observed participants bi-weekly throughout the term, during which time I shadowed my participants for their half of their school day. TMS ran on a six period day. Each period lasted one hour, beginning at 8:10 a.m. Students had a 5 minute passing period between classes and a 30 minute lunch break. The final bell to dismiss students rang at 3:15, with the exception of Wednesdays when students were dismissed an hour early so teachers could attend their meetings with their professional learning communities. For morning observations, I would arrive a few minutes early before the students entered the room at 8:10 a.m. and stay with the teacher until her lunch period. Afternoon observations began with the teacher during their lunch break, which some participants ate in their classrooms, others in the staff lounge. I usually left with the students at 3:15 p.m., although on two occasions I accompanied the participant to her after school supervision of bus students. I alternated between morning and afternoon observations to gather enough data to provide what Stake (1995) called incontestable description for further analysis, interpretation, and reporting (p. 62). During these observations, I recorded my field notes on my laptop describing what occurred, as well as writing immediate reflections on the meanings of those descriptions (themes, speculations, patterns, issues). In one case where I could not type field notes immediately due to an iPad error, I wrote notes in a paper journal. Finally, in cases 
where I had neither my laptop nor journal, I took mental notes that were transcribed at the earliest opportunity using Notability software in my iPad.

The third set of study data (see Appendix B) was designed to help triangulate teachers' beliefs about classroom diversity. With permission, I used the Teacher Cultural Beliefs Scale (TCBS) developed by Hachfeld et al., (2011). The TCBS uses a Likert scale to measure teacher multicultural and egalitarian beliefs about diversity, making it a useful tool to explore my third research question: What factors influence teachers' adoption of differentiated instruction in their classrooms?

My fourth data collection method included teacher, classroom, and school artifacts, including lesson plans, written feedback, and teacher resources collected from the participants in electronic and print formats. Yin (2003) maintained physical artifacts have less potential relevance for data collection than direct observation and interview methods. While I somewhat agree with Yin (2003), I still maintain data from artifacts can lead to a more precise understanding of the instructional practices used by the participants in their classrooms and thus were worth including in this study by allowing one more data point to explore. Artifact data could help to explore all three of the research questions, depending on the relevance and usefulness of the artifact.

\section{Data Collection and Analysis}

According to Goetz and LeCompte (1984) data collection and analysis is a simultaneous process that distinguishes qualitative designs from more positivistic research. This means the data I collect and the avenues of analysis that I chose to employ largely determined the final product of my case study. While analysis also occurred in 
tandem with data collection, a more thorough analysis took place after all data are collected. Further, data analysis is a highly iterative "complex process that involves moving back and forth" between concrete data and abstract concepts, inductive and deductive logic, or descriptive and interpretive elements (Merriam, 1998, p. 147). In other words, the process of attaching meaning to collected bits of data involves a certain level of researcher intuition. These definitions are useful to understanding the process of data analysis used in this study.

Yin (2003) recommended relying upon theoretical propositions that support my original intentions and design of the case study, as these propositions are reflected in my research questions, literature review, and new hypothesis. Use of my original theoretical propositions allowed me to focus on certain data while excluding other data. This analytical strategy used thematic networks to analyze interview, observation, and artifact data. Attride-Stirling (2001) defined thematic networks as web-like illustrations (networks) that summarize the main themes constituting a piece of text (p. 386). Thematic networks serve two purposes: a) to understand the themes on different levels, and b) to organize and display the connections between themes (Attride-Stirling, 2001). I created these thematic networks over the course of my data analysis; they also served useful visual pathways during the data analysis period. I illustrated these steps to create these thematic networks in Figure 6. 


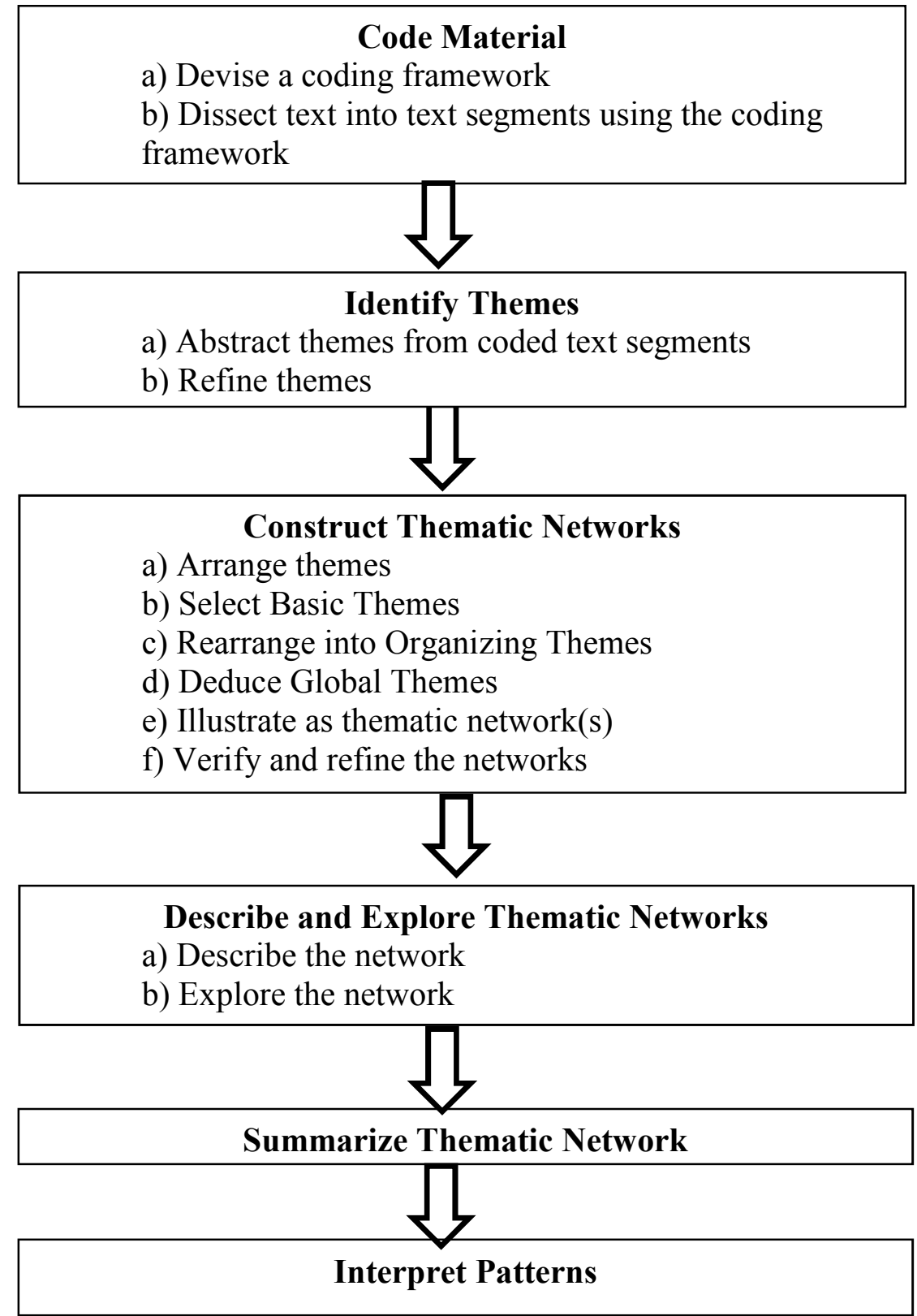

Figure 6. Steps in analysis employing thematic networks. Adapted from Attride-Stirling,

J. (2001). Thematic networks: An analytic tool for qualitative research, Qualitative

Research, 1(3), p. 391

Attride-Stirling (2001) provided six analytic steps for using thematic networks analysis, as shown in Figure 6. Step one involves devising a coding framework based on the 
number of theoretical interests (i.e., Bandura's triadic reciprocal determinism) and using the coding framework to dissect the text into pieces. In step two, researchers identify the themes from the text segments and further refine these themes into specific and broad categories. Attride-Stirling (2001) said these themes must be specific enough to "pertain to one idea," yet also be "broad enough to find incarnations in various different text segments" (p. 392). Step three involves creating the networks based in the identified themes. Fourth, researchers take each network and describe its contents and support the description with selected text segments. During this process of description, the researchers explore and note patterns they detect. Once the thematic network has been fully described and explored, researchers present a summary of main themes and characterizing patterns. Finally, researchers bring together the deductions and summaries of the networks "to explore the significant themes, concepts, patterns, and structures that arose in the text" (Attride-Stirling, 2001, p. 394). More accurately, the researchers' interpretations allow the themes, concepts, pattern, and structures to emerge from the text after returning to the original theoretical interests and research questions.

Ultimately, I did everything to ensure my analysis was of high quality. In a review of 29 case studies, Olafson, Grandy, and Owens (2015) noted more than half of the researchers failed to describe their methodology in more than a general manner, clouding efforts to understand their data analyses. To demonstrate my commitment to transparency, my analysis will show I "attended to all the evidence," addressed "all major rival interpretations," reported on "the most significant aspect of the case study," and used my own "prior, expert knowledge of the case" (Yin, 2003, p. 137). Moreover, I 
added in the review of a seasoned qualitative researcher to check my personal biases and push me for deeper analysis and understanding. In the next section, I present my methods to address Stake's (1995) question, "Do we have it right?” (p. 107).

\section{Trustworthiness and Researcher Bias}

Qualitative researchers use terms like trustworthiness, credibility, and dependability to describe validity, reliability, and researcher bias issues (Stake, 1995; Yin, 2003). It would seem one of the defining characteristics of qualitative research (as opposed to quantitative studies) is a continual engagement with these issues. Maxwell (2013) defined validity as the "correctness or credibility of a description, conclusion, explanation, interpretation, or other account" (p. 122). Ontologically, I am not seeking the existence of an objective truth, but rather to establish some grounds for credibility and deal with potential validity threats.

Merriam (1998) suggested using multiple strategies like triangulation, member checks, extended data collection, and explicitly stating researcher bias to enhance a study's internal validity. Internal validity refers to my ability to establish a causal relationship where one set of conditions leads to another set of conditions (Yin, 2003). I address the steps I took for internal validity in the next section.

First, I used triangulation to address questions of internal validity. Patton (2005) discussed four types of triangulation; this study is designed to use three of them: (a) data triangulation, (b) theory triangulation, and (c) methodological triangulation. I propose to use includes multiple participants and multiple sources of data, as well as using multiple perspectives to clarify the meanings of the data. 
Second, I used member checks during and after data collection and analysis. Guba and Lincoln (1989) suggested member checking occur continuously throughout data collection and analysis. Each participant had multiple opportunities to review and comment on the data and check for accuracy of the interview transcript. However, Guba and Lincoln caution that member checking does not certify that all errors will be discovered, so I will also employ another strategy.

Another way to increase the internal validity of my study is through long-term data collection. My participant observation period was scheduled to last as long as I can feasibly maintain it for almost half of the school year. Further, I remained in contact with my participants after data collection for clarification and data collection.

\section{Limitations}

A case study design was well suited to the nature of the research questions posed in this study. However, this particular study also suffered from many of the common limitations posed by case study research including: (a) experience of the investigator, (b) the length of the data collection and analysis period, and (c) small sampling size. Finally, as all research is affected by bias, I limited the influence of my bias by acknowledging and addressing it. Bogdan and Bilken (2007) asserted that the task of the researcher is to objectively study the subjective states of the participants. They explained:

While the idea that researchers can transcend some of their own biases may be difficult to accept at the beginning, the methods researchers use aid this process. For one thing, qualitative studies are not impressionistic essays after a quick visit to as setting or after some conversations with a few subjects. The researcher 
spends a considerable time in the empirical world laboriously collecting and reviewing piles of data. The data must bear the weight of any interpretation, so the researcher must constantly confront his or her own opinions and prejudices with the data (pp. 33-34).

In other words my own assumptions and worldviews have been rooted in a lifetime of classroom experiences with diverse students. I was a classroom teacher at the middle and high school level for 15 years and already possess beliefs about diverse classrooms, differentiated instruction, and my own teacher efficacy. Further, I am currently a teacher educator and university supervisor of new teacher candidates. These experiences could have created my own set of preconceived notions. While my own biases might be similar to the participants' perspectives, my biases could limit my interpretation of the participant data. In other words, though having similar experiences as my participants can provide a frame of reference, my own experiences could limit how I interpret my data. To address this possible limitation, I employed multiple readings of the data and followed the systematic process recommended by Attride-Stirling (2001).

Further, as I was familiar with the TMS environment and many of the faculty, I tried to recognize the potential to overlook, downplay, or omit elements of culture and important details that did not reflect positively of the site and participants. Also, while I did not have an authoritative role over the participants, my own previous work in the building as a college supervisor reminded me to be mindful of the positionality that my job has fostered in the minds of the participants. Ultimately, I needed to remember that there are trade-offs between participant access and overlooking important data. I 
operationalized this by being mindful of my own biases, empathetic to my participants' experiences and perceptions, and open to conflicting interpretations in this qualitative case study.

To begin, my research period lasted approximately three months during the fall semester at TMS. During this time, teacher observations were interrupted by holidays, a long absence by one of the participants, and school testing which drastically influenced the classroom practices used by the four teacher participants. More importantly, the length of time it took to write up the participants' interviews, classroom observations, and artifacts and then could analyze the data could hamper the usability of this study. Further, this dissertation could be too lengthy or focus on too many unnecessary data to be useful to policy makers interested in understanding teachers' beliefs about classroom diversity and differentiated instruction.

The potential limitation of collecting too much data could possibly have led to more serious implications, including the skill and experience of the researcher and author of this study. I was the sole collector and analyzer of the data, as well as the only author of the subsequent study. While I attempted to collect data in an ethical manner, using interviewing and observation techniques approved by my institutions' Internal Review Board and research classes, this study was largely guided by my own instincts and capabilities. These instincts and capabilities determined what interview quotes I used, as well as the observations I recorded. Flyvbjerg (2006) argued that experts "operate on the bases of intimate knowledge of several thousand concrete cases in their area of expertise" (p. 222). As a doctoral student, my research acumen was not based on such a deep and 
rich knowledge base of similar cases. Ultimately, this study was a product of my own creation, which could influence subsequent reliability, validity, and transferability.

Finally, this case study studied only four all-female participants $(n=4)$, which could be seen as a potential limitation. However, Patton (2005) said the logic of using a small sampling size is different for qualitative research. While quantitative research depends on a large random sampling for validity and generalizability, qualitative research is more concerned with focusing in depth on a single issue. Studying the typical, claimed Schofield (2002), on the basis of an overall fit with "the common or ordinary" is more important to case study design than a large sample size (p. 227).

\section{Summary}

To answer my three research questions, I chose to employ a qualitative case study to explore teacher beliefs about differentiated instruction in a culturally diverse, rural middle school. To gain a greater understanding of the complete relationship between teacher beliefs and practices, I used interviews, observations, a survey, and artifact analysis. Once data collection was completed, I began a thorough data analysis using the methodology provided by Attride-Stirling (2001). Finally, I discussed potential limitations to my data collection due to my bias as a former middle school teacher. In the next chapter will introduce and present the data I collected. 


\section{Chapter Four: Results and Analysis}

The purpose of this study was to explore teacher beliefs about differentiated instruction in a culturally diverse, rural middle school. In this chapter I organize and summarize relevant findings about the differentiation beliefs of four veteran teachers from a culturally diverse, rural middle school in the Pacific Northwest of the United States. Each teacher shared beliefs and practices related to working in a middle school and trying to help their students succeed despite daily challenges. This chapter contains the following sections: analysis of data, presentation of data, interpretation of data, and the limitations of the study.

\section{Analysis of Data}

As I used a constructivist narrative inquiry and life history approach to frame each case study, I included numerous direct quotations from the participants and let their "narratives carry traces of human lives that we want to understand" (Andrews et al., 2008, p. 2). In other words, adopting this method allowed the teachers' own words to drive this story. These teacher words came in the form of two semi-structured interviews which were primarily used to explore two research questions: (a) what are middle school educators' beliefs about differentiated teaching and learning in diverse classes? (b) what factors influence middle school teachers' adoption of differentiated instruction in their classrooms?

However, as Yin (2003) suggested, using multiple sources of evidence helps with the development of converging lines of inquiry, I did not rely on interviews alone. To 
help with this triangulation, I also used a combination of classroom observations and a teacher survey to complement the teacher stories described above.

I used classroom observations to help answer my second research question: What factors influence middle school teachers' adoption of differentiated instruction in their classrooms? Following the advice of Yin (2003), I developed an observation protocol (See Appendix D) to add a layer of formality to my direct observations. To record these classroom observations, I employed an iPad using Notability software to type my classroom observations and accompanying field notes. My observations and field notes were not shared with participants for review. These observations and field notes were then handled with the same analysis protocols as the interview transcripts described in the next section.

Prior to the beginning data analysis process, all interview data were transferred from my recorder to a Microsoft Word document utilizing Express Scribe digital transcription software. I transcribed the interviews myself because I wished to have "another point of transition between data collection and analysis as part of data management and preparation" (Patton, 2005, p. 441). After the eight interview transcripts were complete, I sent them to each of the participants via email for member checking (Lincoln \& Guba, 1985). In the email, I asked participants to make any needed corrections or additions that might further explain their beliefs about differentiated teaching and learning. Each of the participants corrected small transcription errors before agreeing that the data were correct. 
Then I moved into data analysis. In keeping with the spirit of Goetz and LeCompte (1984), some data analysis took place alongside data collection. However, the bulk of the analysis took place over a period of several months after data collection had ended.

First I printed hard copies of the transcripts and classroom observations in order to read them more easily. These transcripts and observations were stored in a large threering binder. I read each transcript a minimum of three times before I began formal data analysis. To analyze the data collected through this research project, I divided the analysis into five phases: (a) coding material, (b) identifying themes, (c) constructing thematic networks, (d) describing, exploring, and summarizing the thematic networks, and (e) interpreting patterns (Attride-Stirling, 2001).

Beginning with the first phase, I devised an initial coding framework based on my theoretical frameworks, including Bandura's (2012) reciprocal determinism (personal, behavioral, and environmental factors) and Adaptive Teacher Competencies. Then I coded the data using a highlighter on any relevant phrases and text segments I noticed. I did nothing with the data for several days, before repeating the highlighting process on a fresh set of transcripts, looking for themes and commonalities between the text segments. As a result of this process, I was able to create themes connecting related text segments together. To assist the process of identifying themes, I used small color-coded sticky notes placed on the transcript pages.

To construct thematic networks, I used Coggle.it, a password protected online graphic organizer to enter text segments and coding frameworks. Using Coggle.it 
allowed me to easily move text segments and themes around, but also to maintain the chain of evidence from my initial data collection through the description of my thematic networks. Yin (2003) said that maintaining a chain of evidence "helps to increase the reliability of the information in a case study" (p. 105). I wished to allow any external observer the ability to trace my analysis steps backwards or forwards from my research questions to my conclusions. Using a graphic organizer allowed me to demonstrate the first three steps from Attride-Stirling's (2001) data analysis protocol.

\section{Presentation of Data}

Once I established my thematic networks, I began to write my results. In the next section I present the data followed by an interpretation of the thematic networks and patterns that emerged as a result of the data analysis. In an effort to introduce each participant, I provide background information to shed light on the teacher as a person and as an educator. Pseudonyms provided anonymity for the participants, particularly because teachers were sharing personal and professional beliefs about their students and themselves. After I present each participant's background, I share their beliefs about teaching and learning, differentiated instruction, and their classroom diversity. Each teacher's case ends with an observation of the participant's teaching. I then conclude this chapter with a description of the major themes and networks from the teacher's beliefs and practices (Attride-Stirling, 2001).

Case One: Margarita. Margarita was born and raised in rural agricultural community located within an interior region of the state. While the region is also known for its outdoor recreational opportunities and rich history, many inhabitants of 
Margarita's hometown struggle with high unemployment, homelessness, and drug addiction. She claimed the dropout rates at her high school are consistently some of the highest in the state. Growing up a "country girl," as she called herself, Margarita admitted to leading a double life in school: cheerleader, athlete, and honor student by day and reckless thrill seeker and troublemaker by night. She recalled her family's relief when she was accepted to attend a small, liberal arts college located many hours away: she had "made it out."

While attending college, she joined the softball team, which proved to be a transformative moment for her. The team went on to win a record 12 straight district championships and provided Margarita with a strong sense of identity. Evidence of this identity still abounds in her classroom. A red and purple pendant from her alma mater dangles on the rear wall of the classroom. Several old team pictures sit on her desk. Her pen bears a Wildcat logo, the school mascot. She still maintains close ties to several of her teammates and admits to occasionally using social media on her work computer to connect with them. That Margarita's identity was rooted in her early participation in team sports helped define her interactions with her students. Frequently during my time with her, she encouraged her students to participate in the extra-curricular offerings through TMS. She also shared positive anecdotes with her students from her time in college.

The sum of these youthful experiences has given Margarita a strong sense of discipline, reliability, and empathy, personal characteristics that can better help support her students. To illustrate, Margarita has spent her entire eight-year career teaching math 
and science at TMS, working under the same building principal who originally hired her. She was fiercely loyal to her principal, volunteered on several building committees and had a reputation for accepting students to help with scheduling issues. This informal policy of taking "all the naughties" as well as Margarita's assertive demeanor had led to a reputation among the students and faculty for strong classroom management. She has strong relations with her faculty colleagues; when asked several of them characterized Margarita as an "excellent teacher." In their definition, an "excellent teacher" demonstrated strong classroom management and effective student engagement.

Besides her classroom environment, Margarita prided herself on her ability to positively interact with her students. "I always wanted to make sure that my kids always felt like they had a safe place to be and that someone knows something about them." In other words, Margarita put her focus on student affect as a way to increase student achievement.

Margarita currently teaches two blocks of sixth grade Mathematics and STEM ( science, technology, engineering, and math) courses each day. Her classes average between 25 and 30 students a period. "I like what I teach," she explained, although she admits to occasional reservations with some of her STEM courses due to a perceived lack of her science content knowledge. Overall, she enjoyed teaching at TMS, although her daily 45-minute commute to work each way had her looking at teaching positions closer to her home and family.

Margarita was easy to talk to and possessed a quick wit. During our interviews it was common for us to get off-track and dive into topics unrelated to teaching, learning, 
and differentiated instruction. However, her focus and our conversation always returned to her students and how she attempted to meet their learning needs.

Margarita's beliefs about teaching and learning. During the initial interview, Margarita tied her feelings about her own teaching strengths to her beliefs about her students. She noted, "I think some teachers just go in and expect kids to automatically understand that they [the students] need to be here and learn, but you know a lot of them come from places where no one respects education." Because of this belief, Margarita sought to provide relevant learning activities for her students' cognitive engagement, but also gain social/emotional knowledge and skills.

Her own learning needs as a student back in middle school were different than her current students' requirements. In order to reach this particular set of students, she has prioritized "changing her instructional strategies to fit and to make the kids more engaged." She repeated this theme of engagement throughout our time together. Her efforts to use more student-centered pedagogy connected student engagement, student enjoyment, and academic outcomes together, "so all of them are enjoying what they are doing. So I think that what I've done more than just, you know, giving notes and then assigning homework." For her, teaching is more than content delivery and formal assessments.

The learning objectives she has for her students are formal and informal. As a teacher, Margarita has an "official goal" for students to improve at least one level on the proficiency scale out of 4." This was a common goal among several teachers at TMS. Yet, Margarita has an unofficial goal that seems to be more important to her. While she 
described the TMS proficiency scales quickly, she spent much more time explaining how student motivation is important to her, saying:

I want my students to just like education and want to be here and want to learn. I mean, that's more important to me, and I think at the sixth-grade level that's more important to me than to be capable to do all their fractions perfectly. If they want to be at school and want to learn math and they are interested and they try, that is more important to me than how high their scores are at this point, because if they can keep that drive for learning as they progress through their education that will catch up in those other areas: academic goals or whatever.

A significant part of Margarita's professional role is student success. However, to support this goal, she knows it is very important to keep students motivated to attend and perform successfully at TMS. In her view, middle school teachers need to be able to connect with their students in order for this motivation piece to occur. Margarita admits it is "really hard to put a quantifiable measure on motivation." Further, what motivates one student may not motivate others. She explained:

I don't know if it is something that I learned from watching other people or it is just who I am that I want my kids to want to be here. I think it's important you make relationships with every kid, even if that goofball in the back left corner that is totally off in never-never land. You gotta find a way to go over... and you touch his shoulder and let him know that this is what you should be doing or make some connection about God knows what videogame he is playing, or who knows what, but they all need to want to be here to be able to do anything. 
In other words, what Margarita believes is the centrality of positive classroom studentteacher interactions towards supporting student academic success. She measured her success as a teacher by the quality of the relationships she had with her students.

Margarita was a proponent of Pride Bucks. TMS used a schoolwide academic and behavioral management rewards system for students who needed additional extrinsic motivators. Students had the opportunity to earn Pride Bucks for completing assignments on time, not having any disciplinary referrals, or any number of a list of identified actions. Margarita frequently supervised the small store in the back hallway where students can trade in their earnings for candy, school supplies, and other small trinkets. She said the Pride Bucks system is particularly effective with "those low kids." For her, the "low kids" are defined by their lack of motivation.

Margarita's beliefs about differentiated instruction. In addition to increasing and maintaining engagement so students experience academic success, Margarita recognized the value and need for differentiated instruction. How did she define and employ differentiated instruction in her classroom?

While differentiated instruction is important, Margarita, like many of the teachers I spoke with at TMS, began with a backwards planning design according to students' mandated curricular targets. Teachers at TMS do the majority of this planning collaboratively; goals are prescribed by the school district administration, and teacher committees unpack the curricular standards supporting those goals. Teachers also collaborate upon common assessments, both formative and summative, to measure 
students' proficiency reaching those goals. Margarita noted differentiated instruction is generally not an immediate priority for these teacher committees.

The lack of a schoolwide emphasis on differentiated instruction disappointed Margarita. She recalled previous years when the TMS budget allowed for additional professional development for differentiated instruction. For several years prior to Margarita's arrival, content area teams of TMS faculty met and spent the entire day planning and implementing lessons rich in differentiated instructional practices. During her first year teaching at TMS, Margarita was assigned to the Science Differentiated Instructional Team. She reported:

One person who was facilitating brought a sample of a DI lesson and then we could then spend half the day tailoring that lesson to us, to our classroom, and then researching more DI lessons to share with the group, which was amazing. Some of the best things that we've ever created came out of that one meeting, but then they cut the funding (and we've asked) that was one of the staff priorities is to get that back, but that wasn't really like a professional person training us. It was us training ourselves, but it awesome.

Margarita revealed a heightened sense of self-efficacy resulting from her perceived increase in adaptive teaching competencies. She took great pride in the bottom-up approach to professional development used in the past by TMS; Margarita's motivation was rooted in the personal and professional autonomy she felt she had.

Unfortunately, the funding for the differentiated instructional training was cut at the end of Margarita's first year. Outside of one class taken in college (“...it might have 
been a workshop. I can't really remember to be honest") these two experiences comprised the sum of Margarita's professional development focused on differentiated instruction. As a result, she occasionally doubted her knowledge and ability to differentiate instruction which left her feeling frustrated as she knew there was likely more she could have done to help each student.

Observations of Margarita's teaching. At 8:03am, the first of 25 middle schoolers entered Margarita's classroom: a roughly equal mix of Latino and White adolescents gradually shuffled in. A bulletin board with TMS news greeted students by the door. As they moved to their seats, a few students stopped to examine the student artwork lining the back wall of Margarita's room. To foster classroom community, Margarita liked to have students share drawings highlighting personal hobbies, prized possessions, and favorite movies.

Margarita considered herself to be an excellent classroom manager. A large bulletin board at the front of the room highlighted desired student dispositions: integrity, safety, respect, and responsibility. After a few minutes, and after all students arrived and took their seats, Margarita moved to the front of the room, and said "If you can hear my voice, clap once. If you are quiet, clap twice." All students immediately stopped what they were doing, and clapped twice. It was obvious Margarita had established an effective behavioral routine.

The day's activity was called "partner math" where pairs of students completed a decimal division worksheet together. Students began the worksheet the day before; today Margarita gave brief instructions and then quickly turned the students loose to complete 
the rest of the assignment. The majority of students began almost immediately, while a few struggled to find their assignments in their folders. Margarita quickly started to circulate around the room, offering praise for students already working, and assisting those students that needed it. "Nice job! That was hard."

About 15 minutes into the lesson, Margarita stopped the activity briefly to use whole class instruction on the board in response to a particularly challenging problem. As Margarita was circulating, she noticed several students were having trouble dividing the number 56.16 by 8.64 . She worked through the steps of the problem on the board before calling on students by name, asking them to share answers while refraining from critiquing each other. "Let's check- don't disagree yet." Students seemed very eager to share with Margarita, who exclaimed "touchdown" to students who provided the correct answer. After this brief problem modeling, Margarita again directed the class to work with their partners and returned to circulating around the room offering praise and encouragement.

She felt this classroom circulation was necessary to her understanding of students learning. Further, she saw this personal attention as differentiating instruction. In this way she could motivate her students:

I usually go around to each table, and I've told my kids I'll pick a different group. I'll sit at a new table and I'll do the work with them. So I'm watching what they are doing while I'm doing it and they can also say 'look at, she's working with us' and I feel like they enjoy that when I'm doing their homework with them. 
What Margarita advocated was the importance of attention in the definition of student engagement. During the lesson, she paid less attention to other facets of student engagement, including student curiosity, interest, or optimism.

Towards the end of the lesson, I noticed one student, "Nathan," busy copying answers from his partner's worksheet. While Nathan did not seem too interested, his partner was also describing the steps to solving the problem. "See, you put the decimal right there to hold the place value," the partner advised. This peer tutoring arrangement appeared to be commonplace for this room; Margarita looked over at the two students frequently but did not intervene. This scene seems to support Margarita's belief in student-directed learning, "...learning from peers is a good thing because they are making connections with their peers in ways that sometimes adults can't connect with them." When another student attempted to turn in her paper alone, Margarita asks her, "Is your partner done? That's what matters."

Students took a short break between math and STEM class, most leaving their seats after math class to leave the classroom to talk with friends in the hallway before returning for STEM. After a five-minutes break, the bell rang to introduce STEM class, which (for the majority of today's 45-minute period) involved students watching a Bill Nye science video that Margarita downloaded from YouTube which discussed atoms and molecules. Bill Nye was a popular science educator and television personality who had children's science show during the 1990s. As these were the same students from the previous math class, Margarita used a different strategy to start class, deciding not use her clapping strategy to check for student attention. 
This time, as students reentered the room at the start of the period, Margarita turned on her Smart Board. Displayed on the screen were several pictures of common items like a jelly jar, a hammer, and a helium balloon. Standing at the back of the room, Margarita specified certain molecular properties. Then she asked students to select items on the screen that possessed those properties; several students came forward to tap the screen to reveal the correct answers. A vocabulary quiz was imminent; Margarita used the transition to redirect students' attention. She did not like to waste time transitioning between activities. "While you are amazed, what should you be doing? Getting your paper out." Once students were seated and quiet, Margarita finished the Smart Board activity with a quick five-question quiz students completed at their desks.

After the quiz was over, Margarita gave instructions to the students to view the science video and complete their worksheet. Margarita returned to her desk and graded worksheets from the previous math period while the video played. After 10 minutes, some children's attention began to wander. Margarita looked up and noticed the off-track students. "If you missed one of the answers, ask a partner the whole question. Ask for the question." This video and worksheet comprised the total of the STEM instruction for the period.

At the end of the period she handed the math papers back to the students before class expired. When the bell rang again to indicate the end of the period, the students pushed in their chairs and left. While Margarita employed engaging strategies during math, her STEM instruction missed opportunities for differentiated instruction, such as the tiered assignments she used in her math class, to increase student engagement. 
Case Two: Jane. Jane was in her $10^{\text {th }}$ year of teaching social studies at TMS. Her career had an inauspicious beginning: her teacher candidacy practicum was "not the best experience." When she graduated with her MAT degree from a large university in the Pacific Northwest, Jane "was not enthusiastic" about teaching middle school and desired to work with older students at the high school level. Finding no available positions, Jane substitute taught for a year while holding a second job at Nordstrom's Department Store. In the spring, the former principal at TMS happened to see her resume online, gave her a call, and invited her to interview for a social studies vacancy. She accepted the teaching position and has been at TMS ever since.

Most days, Jane dressed like she had just come from an expensive department store, wearing clothing seemingly more fitting a corporate board room than a middle school classroom. Her attire differed significantly from other TMS teachers who opted for more casual clothing like jeans and polo shirts. Professional appearance and demeanor were important to Jane. She radiated a more formal version of professionalism than her peers (particularly her co-teacher) throughout her time with me as evidenced by her interactions with students and her careful choice of words in response to my questions. Jane has taught a variety of courses in her career; currently she combined two sections of eighth grade U.S. history co-taught with another teacher, Mr. Darb. He sported tattoos on his legs (which could be seen frequently as he often wore shorts to class) and carried himself with the informal confidence of a veteran teacher.

One visible manifestation of their classroom context was their average class size; together Jane and Mr. Darb had upwards of 65 students per class period. While Jane 
admitted it occasionally took longer to move through content with so many students, she appreciated the extra set of eyes and ears a co-teacher brought to the classroom. She also pointed out the flexibility of having both genders represented in the authority role, saying "we have the male/female role, and we've put that to use, good cop/bad cop..." This full-time collaborative teaching assignment was unique at TMS; theirs was the only cotaught class in the school.

Jane took three years to progress to full co-teaching with Mr. Darb. When she was first hired, both the building principal and Mr. Darb wanted her to have a solo year in her own classroom to develop her own teaching style without Mr. Darb's presence. The second year both teachers co-taught an honors section of U.S. history, "just to kind of experiment a little bit," before moving into full-time co-teaching at the beginning of the third year. Jane explained how Mr. Darb took the lead during their first year together, but over the past seven years together they learned to use their different teaching styles to their mutual advantage.

Their current co-teaching model was an evolution of seven years of pedagogical compromises. Jane and Mr. Darb followed a co-teaching strategy similar to Beninghof's (2012) Duet Model. Using this method, both teachers shared the curricular, instructional and assessment planning and practices. While each teacher brought their own skills and talents, their co-teaching model reflected a sense that both levels of students were "ours," rather than "yours" and "mine." The model also effectively doubled the number of students for Jane, increasing the challenges and opportunities to diagnose students' needs and form productive relationships. 
Jane's beliefs about teaching and learning. Jane explained her personal preference was towards social learning and group-oriented instructional strategies as a way to foster learning. Yet, Jane said her "goal is to always see them independently complete whatever task we are asking them to do." On the other hand, she claimed Mr. Darb is "much more direct instruction," a combination of lecture, worksheets, and guided activities. She compared their collaborative planning approach to the understanding learning by design approach championed by Wiggins and McTighe (2005). "We kind of do a backwards approach, so what is it that we need to see and then what we do to break it down and say what would be the best strategy for us to teach that and then give them opportunities to practice it." This statement means final summative assessments drove instructional planning, with scaffolding decision-making during the lesson occurring later. This backward approach was widely used at TMS.

Next, Jane also shared challenges with whole group goal setting and being able to recognize individual learning as it occurs with large classroom diversity:

Sometimes I think what is hard, especially with the diverse group of kids we have and the large population is that [learning] happens at different times with different kids. With some kids, it's the first time they try it. They get it right away. For other kids it's right before the assessment, or they did the assessment and that's the first time that they got it.

Jane does not mention how students who may require more time to demonstrate proficiency on an assessment are able to do so when the rest of the class has moved on with the curriculum. 
Jane described the shifting measures of social studies learning outcomes, and generally agreed with current trends highlighting analysis and interpretation skills. TMS followed the Common Core State Standards, and recently the faculty and administration decided to use the English Language Arts Standards for reading and writing to guide social studies instruction. This new focus was a departure from an older social studies program emphasizing content recognition and recall. Jane acknowledged "the reality is that reading and writing are going to be lifelong skills that they basically need, so that we kind of shift the focus. We use the content to teach those skills." With the new shift in emphasis, Jane felt she was primarily a reading teacher. In particular, she was proud of their work clarifying reciprocal teaching: questioning, clarifying, summarizing and predicting, academic skills usually emphasized in other content areas.

Jane's beliefs about differentiated instruction. As a veteran teacher, Jane was well-versed using the language of differentiated instruction. When asked what differentiated instruction meant, she quickly answered, "It is providing multiple opportunities, but also multiple ways that students can obtain the skill or content knowledge." For her, differentiated instruction was about instructional planning moves selecting the right set of instructional strategies based on her diagnosis of the academic needs of the class. In particular, Jane felt scaffolding strategies helped to meet these needs. She recalled asking herself constantly, "Is there a different way I can present it or use different information to present it to help that student that time to flip the switch and get it?" In short, differentiated instruction was best fostered through purposeful planning. 
When asked about what kinds of students she had in mind when planning differentiated instruction, Jane described students who "can't get it the first time." For example, Jane worried about the abilities of English Language Development (ELD) students in her class to acquire new vocabulary during reading instruction. Like all classroom teachers at TMS, both she and Mr. Darb delivered their instruction in English, and Jane knew this might influence the academic success of her non-native English speakers.

Her concern about one subpopulation of her classroom population quickly led to more general classroom applications. She compared the needs of her ELD students (who were overwhelmingly Latino) to other White students who also required additional reading remediation.

...this is kind of tricky because we didn't have them last year when we were teaching this. What I struggle with personally when I look at that population it's not so much... I have just as many kids who are not ELD. Let's say that they are White: -they have the same reading level and have the same reading issues, so the reality is that they need that instruction too. You could put them in an ELD class and they would have just as much benefit ....they need that instruction too, but because they are White and English is their primary language, they are not getting that instruction, either.

Jane recognized the potential of ELD strategies to help White and Latino students equally. Her egalitarian worldview saw culturally responsive teaching as "just good 
teaching." Jane further expressed the belief some of her Latino students took advantage of their labelled status to disengage from the curriculum. She explained:

Unfortunately that group of kids (especially by middle school) has identified and labelled as ELD since they've probably been in kindergarten, and that's a long time to be stuck with a label. At this point in eighth grade if they are still stuck with that label then there's already that sense of 'I'm not going to get it. I don't get it; and I don't care." So it becomes more of a behavior and attitude and motivation issue than a skill issue. A lot of them do have the skill if they really want to have it, and we have the same issue trying to motivate those kids that are lower readers anyways.

Jane recognized the importance of addressing student motivation, but revealed a lack of efficacy to approach students who felt disengaged from the curriculum.

Overall, Jane felt "like we do a good job at it [differentiated instruction]. However, she noted the fading emphasis on differentiated instruction at TMS since she began teaching a decade ago. "At the time the nationwide focus was on, when I was going to school to become a teacher, that differentiation was the big buzzword. Now I think it's a little more about the proficiency line.” At TMS, Jane felt like proficiency grading, not differentiated instruction, was on the minds of faculty members. Observations made following her to faculty meetings and hasty teachers' lounge lunches confirmed Jane and her fellow teachers talked frequently about proficiency grading issues. They were concerned with their students' learning objectives, and the types of 
summative assessments students would need to demonstrate to show their mastery of the content.

Jane critiqued differentiated instructional practices for potentially diminishing cognitive rigor, particularly towards product outcomes, where students demonstrated their understanding of the content knowledge. Jane was skeptical of too much student autonomy in this area, believing student choice incompatible with high academic standards.

I do think that there's probably more ways we would teach that, but yeah, at the same time there's that balance of what's manageable too, you know? I think that one of the things I didn't like when the big DI rush and everyone was all about student choice. I like that idea about student choice but sometime you have to, sometimes when you give students that much and you give up quality control, too. And I would rather have a little more control and make sure that I'm getting the quality and the rigor of the work that I want.

Jane demonstrated the ability to hold multiple contradictory beliefs. While she made statements consistent with differentiated instructional philosophies, she also espoused the belief in expository instruction, equating teacher-directed instruction with academic rigor.

Observations of Jane's teaching. Jane spent her day on the lower tier of a large classroom she shared with Mr. Darb. A row of bookcases divided the room in half. Most of the shelves on her side were empty; a few American history text books and general reference books lingered. On the other side of the classroom, a set of black and white 
photos of U.S. Presidents lined one wall. The most recent photo was of Lyndon Johnson, who left office in 1969.

Elsewhere on the walls were worksheets with missing student names tacked up, waiting on their owners to claim them. The front of the room was dominated by a large classroom management poster. On the left side was a list of teacher "communications," like ringing a bell, two or 10 finger taps, or a brain tap. The right side of the poster listed the "norms," or what actions students should take when hearing or seeing the teacher's communications. For example, a 10-finger tap by the teacher meant students should talk with their group. During my time observing, both teachers used the communications listed on the chart frequently, and students responded accordingly.

At the start of class, 22 students sat in the upper section, while 28 moved to the room below. I was struck by the overall number of middle schoolers gathered in one room. For management and pedagogical reasons, Jane and Mr. Darb placed all of their student desks into groups of four. However, even with the desks placed together, floor space on the two levels was limited and students did not have a lot of room to maneuver. This lack of room influenced how the teachers grouped students together for activities. Proximity, rather than readiness, interest, or learning profile dictated the composition of most peer groupings.

On one particular morning, Jane and Mr. Darb had students prepare for their upcoming parent-teacher conferences. Students were brainstorming and listing their personal and academic goals for the year. Mr. Darb stood in front of their darkened room hovering over a bright overhead projector and demonstrated how students were to fill out 
their goal sheets. Meanwhile, Jane circulated in her bottom level monitoring her own students work individually at their seats. Because the room is so large, both teachers used a voice amplification system hooked up to speakers in the room; their voices projected well above the background cacophony of 60 middle school students working. They switched roles every 10 minutes, Jane demonstrating to the class from the projector while Mr. Darb moved about his students.

Both teachers emphasized the importance of students completing their goal sheets. Their teacher-created sheet used SMART goals, which they defined as "1) Specific, 2) Measurable, 3) Achievable, 4) Realistic, and 5) Timely.” Jane and Mr. Darb emphasized repeatedly, “The SMART learning targets will help you to organize your thoughts for the first conference." Several times during the lesson, the two teachers selected students to share their learning goals by drawing Popsicle sticks with student names on them.

The SMART activity did not take the whole period. With 15 minutes left, Jane turned on an episode of Liberty's Kids for the students. Liberty's Kids is a PBS produced cartoon highlighting the American Revolutionary Period. Jane liked using this cartoon because it "hits all the content" and students "remember all the vocabulary we've talked about in class because the video is visual." Jane reminded the students to remain quiet while watching the cartoon.

Student attention started to wander shortly after the Jane turned the room lights out and the video on. Many students watched the cartoon for short 1-2-minute segments and then turned their attention to other activities. I noticed several students fidgeting, 
playing with three-ringed binders, or writing notes to each other. Meanwhile, Jane and Mr. Darb worked at their desks during the video. When I look over the shoulder of Jane, I saw she was answering email.

Case Three: Carol. Carol was a veteran of 28 years' experience in the classroom who firmly believes "I still have a passion for it." She was a leader in the building and often hosted teacher candidates from the local university. Former students often came by to tell her how much they enjoyed her class. Her dedication to teaching was easy to recognize. Originally, however, a career in education was not her first choice. Coming from a family of teachers, Carol was instead focused on athletics and had little interest in teaching. While in high school she earned a volleyball scholarship to a major university far from her home.

Unfortunately, in a transformative event Carol said "was meant to be" on the night before she was due to leave for college an automobile accident with a drunken driver left her with serious injuries and unable to play sports. Months of physical recovery and soul searching eventually led her to eventually embrace the family business. "You know, I do love teaching and it's in my blood." She graduated from the local college with a teaching degree and had been in middle schools ever since.

She had been a language arts teacher at TMS for the past 10 years. During our initial interview, I noted ample evidence of her veteran status. On her feet, Carol wore thick-soled shoes, a practical choice for a profession that requires standing long hours. On top of a warm black sweater she displayed a large button supporting her local teachers 
union. She chewed gum during our interview. She said the gum helped her to keep her saliva flowing and voice fresh.

Further evidence manifested in her choice of classroom décor. Her room was somewhat funnel-shaped and was only accessed by proceeding down a long ramp to her door. Her walls were filled with large, paper cut-outs of people autographed with language arts vocabulary terms. Posters and signs instructing students how to be academically successful in her classroom dotted the open spaces. This was the room of a veteran teacher.

When I remarked about her classroom decorations, Carol recalled her first impressions of the room and how much work it needed to bring it up to her standards. "There were 112 spit wads on the ceiling. I counted every time I flipped them down, because I was crying... and the room was baby poop color, like mustardy yellow." Over time, however, she made significant improvements to the décor and in the resources she made available to the students. Each student had access to a Chromebook. She had plans to acquire several iPads or Kindle Fires to replace her old stash of library books, as she noticed that "kids weren't accessing them in here." She wound up donating most of her library books back to the TMS library where "people can use them."

Carol's beliefs about teaching and learning. Carol was a believer in teachers' autonomy to control their own managerial and instructional decisions. Yet, much of what Carol did over the course of the day was supposedly influenced by her administrators' priorities and how her colleagues operationalized them. For example, the language arts teachers at TMS used the same district-adopted curriculum. Further, according to TMS 
policy, all language arts teachers used common formative and summative assessments. However, Carol chose to stray from this curriculum when she feels her students' needs are not being met. "I do follow that [Springboard], but if I feel like there is something that kids need to explore, then I'm gonna go there and take a little bird walk off the straight path and then we come back to that path." In short, Carol recognized the need to address student interest in her lesson planning.

She expressed the importance of lesson planning to allow her students to be engaged in their learning and have fun in the process. Sticking solely to the curriculum, in Carol's belief, was “just brain changing, and that's not learning." In other words, Carol believed differentiated instruction should include a curriculum that incorporated students' interests into daily lessons.

Ultimately, Carol hoped her students left her class with the ability to consume content critically and communicate clearly. She did not see her primary role as a contentdeliverer. Carol viewed her role as a conduit for students to build their skills. "I don't want to tell them what the right answer is. I want them to be able to go on their own and come up with their own answer." Much of Carol's conversation focused around this pedagogical belief of hers: student learning outcomes should reflect skills-based targets grounded in motivational theory. She did not measure her effectiveness through student academic achievement alone.

Carol's beliefs about differentiated instruction. Carol talked candidly about her DI beliefs. When asked, at first, she said "I don't differentiate." Soon, however, she opened up and explained this statement. Carol admitted to struggling with differentiated 
instruction. The realities of inadequate planning time, class sizes numbering 30 students or more a term, and a lack of professional development all hindered Carol's ability to meet the needs of all of her students. She summed up her efficacy beliefs, saying, "I feel like my ability is higher than what I actually have time to do...frustrating. I hate to say it. I wish I could say it's higher." In other words, Carol had high expectations for her personal capacity to differentiate instruction, but was tempered by a lack of resources.

Carol continued, sharing a common sentiment among TMS faculty. Selfassessing her ability to use differentiated instruction, she said "I think I'm good at differentiating between classes, but individual differentiating for my special needs kids... I wish I could say I was more proficient, more proficient than that." The difference between the expectations and the realities of implementing differentiated instruction seemed to weigh on her mind. "It's really, really difficult to do when it's not the focus of our school. It used to be the focus of the school." Carol's beliefs in her individual ability to differentiate instruction were influenced by the broader collective efficacy of TMS. As she saw it, implementation of differentiated instruction required communal effort among faculty as well as long-term institutional support (e.g., work time, supportive scheduling, and additional training). That focus no longer existed. What happened?

Carol described how the emphasis on differentiation has waned over the years, as well as her efforts to keep it going. ...we had time to design those kinds of lessons and we really could differentiate the content in our rooms and it was a good thing, but then the district moved away from that and towards proficiency. Now we are all supposed to march together 
and do the little packet things which I kind of passively/aggressively rebel against. I'm at the end of my career so I feel like I have more freedom to do that rather than just people who are just starting out.

She had been teaching long enough to witness many different educational initiatives, each purporting to improve student learning outcomes. Carol's beliefs in her own abilities to meet the needs of her students led her to resist some TMS curricular mandates.

As a language arts teacher tasked with the goal for each student to read, write, and converse effectively, the variety of student variance presented challenges to Carol. When asked about the academic performance of students in her classes, she responded:

It's overwhelming. The range of abilities [in her fifth and sixth period classes] in there. Fourteen IEPs or 504s and then there are 11 English language learners and then three have passed the SBAC. So we have non-reading to $10^{\text {th }}$ grade reading level in there, so that's a very, very big challenge.

In spite of the challenges, Carol remained opposed to tracking as a means of addressing the broad spectrum of academic needs. "I don't know in the long run if that is good for kids." At the time, TMS tracked students based on one data point: a standardized test linked to the Common Core State Standards. In Carol's opinion, this led to inaccurate placements for students that followed them through the remainder of their school careers. She further noted, “Our scores have gone down since we've started tracking kids.” In short, Carol saw tracking as harmful to all of her students. 
According to her, tracking led to "those bubble kids who could rise up are not, because they don't have the exposure to that higher level thinking that they need to push them." In Carol's view, academic success for lower achieving students depended upon placement in heterogeneous classroom compositions. Conversely, Carol felt students at the upper reaches of academic performance "solidified their learning" when they had to "slow down and teach someone else." She believed in the peer mentoring process to help students at both ends of the scale.

Observation of Carol's teaching. Carol had students engaged in a computerbased lesson to co-create a PowerPoint on symbolism. The room was filled with the usual noise of seventh graders engaged in group work. Twenty-six students huddled over Chromebooks and were busily working away. Carol constantly circulated around the room checking in with students; she was a strong classroom manager. Carol often sat down beside her students when she worked with them. She also touched several students on the shoulder when she wanted to connect with them; I observed several high-five slaps with students as well.

Occasionally she rang a small bell, and the students stopped talking while she modeled how to work through a portion of the assignment. Sometimes she provided unusual guidance to students for using their Chromebooks properly, but generally she pushed students to problem-solve technical issues on their own. "I know you know how to do it. I'm old; you're young. Figure it out." Generally, it seemed students who received Carol's technical non-support did figure it out. 
Carol ended class several minutes early to allow students to return their Chromebooks to the supply cart in the back of the room. This procedure did not take all of the planned class time, so Carol improvised. "Ok, back to your seats. You read my mind...you guys have superpowers and you didn't even know it." To fill the remainder of the time, she displayed a short poem by Robert Frost on the overhead projector for the students to read. This poem ended with the line "Nothing gold can stay," popularized in the S.E. Hinton novel The Outsiders. Carol had one student read the short poem out loud to the class. Next, Carol asked the students to tell each other what they thought the poem meant. The bell rang to let the class go, but she did not immediately dismiss the class, preferring to wait until one student answered her question "What does this poem mean?" Finally, one student responded with "Be brave." The answer satisfied Carol, who then released the students to their next class.

Case Four: Lisa. Lisa has taught for over a decade, but was not sure of the exact number. She sheepishly admitted, 'It's one of those things where I've been teaching long enough I don't really know if it's my twelfth or thirteenth year." Her route into the middle school classroom was circuitous: after spending 4 years at a community college investigating a variety of occupations, including firefighting, forensic pathology, and physical therapy, she still was unsure of a career choice. Job shadowing experiences soured her on those occupations, yet the reasons for her switch to education were difficult for her to recall during the interview. "Honestly, I don't really know what it was that finally made me realize teaching is what I wanted to pursue." 
Eventually, she transferred colleges and graduated with her teaching certification. She has been a sixth grade teacher ever since. She began teaching for 3 years in a selfcontained elementary classroom covering all content areas. When TMS expanded 8 years ago building a new wing to include sixth graders, Lisa was given the option to teach a lower grade or transfer to TMS and focus on math. The choice was easy. Lisa "knew right away that I wanted to come here and do math... which is funny because I struggled with math all through high school."

She recognized the irony of her statement, but claimed it gave her insight into “those students who have big holes and those students whose math isn't their favorite and they struggle." According to Lisa, students have not changed much over the years. “There are just kids that get it, and some don't." Lisa felt her beliefs gave her an advantage with her more recalcitrant students.

Typically, Lisa arrived at school by the mandated contract time (7:30am) accompanied by her 5 year old son, the older of her two children. He stayed with her until it was time for him to catch his bus to attend a nearby elementary school. Before children, Lisa often arrived earlier, but balancing her personal and professional life caused her to make some compromises with the time she spent at TMS. However, Lisa saw a silver lining with having a family, as she now felt like she was more "patient and empathic" towards the families of her students. Her maternal perspective was reflected in her social media postings, which were rife with pictures of her children and their family outings. 
Lisa's beliefs about teaching and learning. When I asked Lisa about her goals for student learning, she pointed to her wall. Two large pieces of poster board festooned with colored circles dominated one side. Lisa listed her students' names down the y-axis of the chart and labelled her math and science learning targets horizontally across the top. Round stickers indicated the academic progress of each student. Some students had as many as five; others had none at all. "We've started doing sticker charts for their learning targets... and I love it because you know those are my goals." Lisa believed the charts reinforced to her students the importance of learning specific skills, providing a constant reminder of the goals students should meet by the end of the year. While these goals were established collaboratively with the rest of the sixth grade math faculty, Lisa's unofficial goal for the year was to reduce the number of math "holes" students possessed before they moved on to seventh grade. "That chart sums it up, you know."

The goals on Lisa's wall chart were based on the Common Core State Standards. The order in which the sixth grade math faculty addressed those goals were based on the team's assessment of the academic needs of their students combined with the requirements of the Smarter Balanced Assessments (2014). Like many of her TMS colleagues, Lisa expressed a belief in backwards planning design. "We need to write the assessment first, so definitely like that is our base. We look at standards; what learning targets we have from that. We write the assessment based on that and then we figure out what do we need to do to make sure that we are touching on all these pieces." The language of the backward planning model, common among other teachers at TMS, had come from multiple professional development sessions and university trainings. 
Over the years, Lisa refined her philosophy of education down to a succinct “...if you were working harder than your students, you were doing something wrong." She shared her preference for teaching in the latter half of the school year, as she felt students became accustomed to her policies and procedures. They were, Lisa believed, much better able to operate independently, which allowed her to focus on building relationships with her students. She thought springtime was when she was best able to stray occasionally from strict content coverage to "have fun" for a few minutes.

Further explaining her beliefs about teaching, Lisa saw her primary role as a facilitator to students. "I'm here to assist you and that sort of thing, but trying to help them grow their own wings, you know. That's my role is to support them, I guess. Give them what they need and support them." Her beliefs were grounded in constructivism and she used the language of differentiation when describing her role in the classroom.

I honestly don't care who they are getting it from as long as it's correct. I'm kind of sitting back ... I've loosened up a little about how they say things, because as long as its correct, it might sound weird (the way they are saying it), but as long as its correct, I'm like 'that's their language' and that's what is going to click for someone else possibly.

Lisa's response to differentiation focused on content differentiation, allowing different "inputs" for students. She did not believe in adapting what she taught as much as she was willing to modify how she gave students access to those concepts.

On the other hand, what did she see the student role in learning? "So their job is to seize the day." When I asked Lisa to explain what she meant by that, she elaborated, 
"It's not just their grades and that sort of thing. It's their life skills you know." Lisa expressed belief in students learning competencies beyond mere academic achievement. She felt her planning responsibilities included the affective domain outcomes like intrinsic motivation and self-regulation.

Lisa's beliefs about differentiated instruction. When I asked Lisa about differentiated instruction, she brought up the cancelled professional development TMS once supported. "When I first started here, the first couple of years they had differentiated instructional teams and we got to have a couple days throughout the year. We had training and it was fabulous. At that point this whole differentiated instruction learning and instruction sounded wonderful, but at that point when it was introduced to me, I was expected to start doing it, and I was like, 'Are you kidding me? I have to do all these different things for all these different students?"' Lisa's original definition of differentiated instruction was rooted in a common misconception of differentiated instruction. This mistaken belief thought teachers should create individualized lesson plans for each student, a daunting if not impossible task given large class sizes and heterogeneous classroom diversity.

With experience, Lisa's fears about differentiated instruction eventually waned. "It's really not like as scary and big as it seemed at first, you know, and then there are simple ways to do it there's and then once I stopped and thought about it I was already doing it in some ways and I just didn't realize that's what it was." In particular, she saw her fading apprehensions linked to her efforts to differentiate process and content. 
What did differentiated instruction look like in Lisa's room? According to her, "If there is something that the majority of the class is getting then we approach them in different ways so like a little shorter time frame. Those kids that aren't getting it are working on it and the other kids are working on a project or extension that goes with it." This belief allowed students to create their own timelines for their "sense-making activities." This response demonstrated a belief in process differentiation. Lisa continued her explanation, shifting towards content differentiation. "I mean sometimes it comes down to teach and what not to teach, but I mean it basically boils down to these are the standards and learning targets we need to reach and we need to address but how we address them for each kid might look different."

Observations of Lisa's teaching. Students started to arrive in her room shortly after 8:03. Within a few minutes, 30 students drifted in from the hallway and sat down at their assigned seats. Lisa grouped her classroom desks into sections of six students each. As the students were chatting quietly, the dean of students at TMS entered the room and asked Lisa if he could briefly speak to her students. He then reminded students of the schools' discipline policy, emphasizing the word "respect" as a code for hallway behavior and excessive talking. It was quickly apparent the dean of this school had the respect of Lisa's students, as they all gave him their undivided attention for several minutes while he spoke to them.

Lisa jumped into action immediately after the dean left. Moving to the front of the room, she began the day by reading the list of student pairings for a collaborative math activity. The topic was on multiplying decimals; students needed to finish a 
worksheet. Lisa used a form of ability grouping to determine who was matched up, partnering low and high together, dividing students into "tutors" and "learners." She then instructed her students to match up with an appropriate partner and begin the activity. As the students self-selected into their groups, I scanned the walls of Lisa's classroom, each painted light blue, mustard green, or cream color. Like Margarita, she displayed her behavioral expectations on a large bulletin board by the door. Emphasized in large gold letters are the words purpose, respect, integrity, determination, and empathy. A large whiteboard fills the front of the room, which Lisa and her students used frequently. Running along the top of adjacent wall was a row of tan cabinets, upon which sat several unopened brown boxes. A glow-in-the-dark Halloween skeleton dangled off the end of one of the boxes. The entire back wall is filled with "pride paws," studentcreated biographical artwork they made at the beginning of the year as part of an introductory activity.

Students sat in pairs at their desks in Lisa's room. She grouped her desks by fours, with plastic chairs that the students could easily move. I see that the "tutors" were mostly the students who have already finished their worksheets, and were now engaged with helping the "students" out. Lisa moved to her desk, frequently asking students who approached her, "What are you working on?"

For the next 30 minutes, students completed their worksheets, bringing them to Lisa at her desk. "What are you working on?" she repeated frequently, as she checked their work for accuracy. She asked several students about their missing math work. If they met her level of proficiency, Lisa gave them a Pride Buck. At the end of the period, 
Lisa stood at her desk and addressed the students "Most of you took advantage of your time... some of you wasted your time, which was a bummer. You will have to work on it during study hall and turn it in tomorrow." There did not seem to be a penalty for offtask behaviors or tardy worksheets beyond this admonition to work on math outside of the class time.

Her students went on break for five minutes. Most students left the room to socialize in the hallway. When they returned to Lisa's room after the break, the students were met by nine physical education majors from the local university and their professor, an energetic sort. The professor told the class that they were there to help them with a "brain booster" and that all students needed to stand. Next, she informed them that they will play "Giant Rock-Paper-Scissors" with a partner. Her kinesthetic creation involved whole-body movement as opposed to the more sedate, traditional model played with hands only. Over the next 10 minutes, Lisa's room was filled with lots of laughter, noise, and movement as students jumped and flailed their arms to indicate their selections.

After the physical education students left the room, Lisa called attendance before the start of STEM class. One at a time, she entered their names into the computer attendance program. When she finished, Lisa brought up the class' behavioral incentive. Classes that earned more than 50 points could attend a "movie party" at the end of the week. A few students indicated that they were not interested in attending the reward party. These students would instead go to a study hall, a move Lisa attempted to discourage, trying to steer them towards attending the party saying "the study hall won't be fun or anything." Further, Lisa has enhanced the incentive by stipulating students can 
roll over any points in excess of the needed amount to the next reward party. At this new information, some students became very eager to discuss the movie party, while Lisa attempted to pivot the conversation to the STEM assignment for the day.

“Ok, today you are finishing your natural resource posters. Your task is to create posters of natural resources; the expectations for your posters are on the front board..." Lisa wanted students to read paragraphs from a textbook provided by a statewide energy non-profit organization and paraphrase the book descriptions of natural resources. The non-profit donated the textbooks and small resource kits to students with the purpose of encouraging low-cost renewable energy options. The kit included fluorescent bulbs, fact sheets, and energy inventories. Lisa assigned the take-home work from the kit as an optional assignment for students. Those students who wished to take the kits home and use them could earn additional Pride Bucks in Lisa's class.

Lisa distributed sheets of $8 \times 14$ inch construction paper to her students. Then, with a last-minute reminder to students to use "lots of color" on their posters, she gave students the performance goal to be "mostly done" by the end of the period. Once they have their colored paper, students moved about the room. Some chose to work at their desks; others sprawled out on the floor to draw their posters.

The quality and quantity of the student work varied widely. Some students copied their posters verbatim from their source material; others attempted to have conversations with nearby students to figure out their own wording for the textual component of the assignment. Further, several students spent the majority of their time working on their 
drawings, saving their narrative writing for the end. During this time, Lisa worked at her desk helping students who approached with questions or to just show their posters.

At the end of the period, Lisa informed students to clean up their workspaces, turn in their posters regardless of completion, and get ready to leave. Once the bell rang, students quickly departed Lisa's room. After students left, Lisa quickly thumbed through the stack of posters looking for exemplars to share with the class. "I also like to keep tabs on who will need additional time to finish them," she shared. In doing this, Lisa demonstrated a form of differentiation called tiered assignments where the content is the same, but the process is varied according to the level of skill attained.

\section{Interpretation of Findings}

I designed this study to explore the beliefs of veteran teachers about differentiated instruction in a culturally diverse middle school. At the heart of this study was the task of discovering themes, which Ryan and Bernard (2003) called "abstract (and often fuzzy) constructs linking expressions." This means there are many approaches to link expressions to theoretical constructs to create themes, including inductive (from the data) and a priori (my previous understandings) approaches. Using the analysis strategies recommended by Attride-Stirling (2001), I looked for repetitions, metaphors or analogies, and similarities or differences in the participants' interviews and observations. As I sorted through my field notes and interview transcripts, I discovered four themes among the differentiated instructional beliefs and practices of these four veteran, white, female middle school teachers which include: a) differentiated instruction is believed essential in creating effective classrooms, b) each teacher's particular definition of diversity used can 
influence teachers' implementation of differentiated instructional strategies, c) professional development sessions can influence differentiated instructional practices, and d) the ability to create classroom environments conducive to learning influences teacher efficacy.

\section{Theme 1: Differentiated Instruction is Essential for Effective Classrooms}

All participants believed differentiated instruction was an essential approach to meeting student needs. Sharing its importance, Margarita responded, “I don’t feel like you can teach effectively without doing that, because if you are not doing differentiated instruction that means you don't know your kids, and I don't feel like you can be a good teacher without knowing your kids." In other words, Margarita strongly identified with the part of differentiated instruction that calls for strong diagnostic knowledge of student readiness, interests, learning styles. In short, effective teachers "know your kids."

Other teachers shared Margarita's belief in pre-assessment. Lisa explained before each new topic she tries "to do some preassessment...to get a good idea where they are." In other words, she looks for student readiness. Carol agreed, but added a management component, "You have to figure out what works for each class, and it's not going to look exactly the same in each class and that's just the way it is." Even Jane (who admittedly was the most skeptical of the four participants about differentiated instruction) shared, "I do think that's where differentiation is important... I do think it needs a variety." In this case, "it" refers to student learning styles. While Jane supported the use of proficiency standards, she admitted, “...how we address them for each kid might look different.” In sum, while each participant might have defined differentiation differently, they all shared 
the similar view that differentiated instruction was important to meeting the unique and varied learning needs of their students. Further, all of these teachers discussed the importance of "figuring out" what worked for each kid. When teachers understand what a student needs and how to support student learning, teachers can purposefully create a more effective environment and learning activities which can increase students' opportunities for success.

\section{Theme 2: Diversity Definitions Influence Implementation}

A second theme that I developed from the data was that one's individually held definition of a term or concept can impact a person's attitude and behavior. Milner (2010) defined student diversity as including, but not limited to, aspects of "race, ethnicity, gender, sexual orientation, language, religion, ability, and socio-economic background" (p. 5). Each teacher in this study had her own definition of diversity grounded in egalitarian worldviews and in turn so did her beliefs and practices related to supporting student needs through differentiated instruction.

Egalitarianism. Each of the participants expressed egalitarian beliefs about their classroom diversity. Generally speaking, proponents of egalitarianism favor equality of some sort among people (Hachfeld et al., 2011). When Margarita said "It would be immoral if you didn't treat every kid the same," she provided a succinct definition of egalitarianism. Over the course of data analysis, I noticed text segments from the other participants expressing similar beliefs to Margarita's, including Jane's concern for White students' lack of access to reading remediation courses, whose spaces were reserved for ELD students. She believed her ELD students could increase their learning outcomes if 
they wanted, "a lot of them do have the skill if they really want to have it." In Jane's diagnosis, a lack of motivation united her "lower readers," White and ELD students, alike.

Further, the results from the Teacher Cultural Beliefs Scale (See Appendix B) distinguishing multicultural and egalitarian viewpoints support stronger egalitarian orientations by the four participants. Table 3 provides the raw data from the survey for the four veteran teacher participants. While each teacher reported agreement with both multicultural approaches to classroom diversity, their unanimous responses strongly supported egalitarian viewpoints.

Results lend support to the interpretation that teachers in this study believed treating students differently based on cultural diversity was wrong. To sum up the results from Table 3, all participants felt strongly that student similarities should be stressed and fostered over their differences. These results echoed the teachers' sentiments about valuing sameness or communalities and beliefs about treating students in the same way. However, the teachers' responses about multicultural beliefs illustrate their recognition of the need to be responsive to cultural differences. 
Table 3

Results from the Teacher Cultural Belief Scale

\begin{tabular}{|c|c|c|c|c|c|}
\hline Multicultural Beliefs & $\begin{array}{l}\text { Strongly } \\
\text { Agree }\end{array}$ & Agree & $\begin{array}{c}\text { No } \\
\text { opinion }\end{array}$ & Disagree & $\begin{array}{l}\text { Strongly } \\
\text { Disagree }\end{array}$ \\
\hline $\begin{array}{l}\text { 1. In the classroom, it is important to be } \\
\text { responsive to differences between cultures. }\end{array}$ & 1 & 3 & 0 & 0 & 0 \\
\hline $\begin{array}{l}\text { 2. It is important for children to learn that } \\
\text { people from other cultures can have different } \\
\text { values. }\end{array}$ & 4 & 0 & 0 & 0 & 0 \\
\hline $\begin{array}{l}\text { 3. Respecting other cultures is something that } \\
\text { children should learn as early as possible. }\end{array}$ & 4 & 0 & 0 & 0 & 0 \\
\hline $\begin{array}{l}\text { 4. When counseling parents who have a } \\
\text { different cultural background than I do, I try to } \\
\text { be considerate of cultural particularities. }\end{array}$ & 2 & 2 & 0 & 0 & 0 \\
\hline $\begin{array}{l}\text { 5. When meeting with parents of different } \\
\text { cultural backgrounds, I spend more time trying } \\
\text { to understand and empathize with their } \\
\text { perspective. }\end{array}$ & 1 & 3 & 0 & 0 & 0 \\
\hline $\begin{array}{l}\text { 6. Dealing with cultural diversity should be } \\
\text { taught in teacher training courses. }\end{array}$ & 4 & 0 & 0 & 0 & 0 \\
\hline Egalitarian Beliefs & $\begin{array}{l}\text { Strongly } \\
\text { Agree }\end{array}$ & Agree & $\begin{array}{c}\text { No } \\
\text { opinion }\end{array}$ & Disagree & $\begin{array}{l}\text { Strongly } \\
\text { Disagree }\end{array}$ \\
\hline $\begin{array}{l}\text { 7. Schools should aim to foster and support the } \\
\text { similarities between students from different } \\
\text { cultural backgrounds. }\end{array}$ & 4 & 0 & 0 & 0 & 0 \\
\hline $\begin{array}{l}\text { 8. In the classroom, it is important that students } \\
\text { of different origins recognize the similarities } \\
\text { that exist between them. }\end{array}$ & 4 & 0 & 0 & 0 & 0 \\
\hline $\begin{array}{l}\text { 9. When there are conflicts between students of } \\
\text { different origins, they should be encouraged to } \\
\text { resolve the argument by finding common } \\
\text { ground. }\end{array}$ & 4 & 0 & 0 & 0 & 0 \\
\hline $\begin{array}{l}\text { 10. Children should learn that people of } \\
\text { different cultural origins often have a lot in } \\
\text { common. }\end{array}$ & 4 & 0 & 0 & 0 & 0 \\
\hline
\end{tabular}

In educational settings, teachers holding egalitarian beliefs tend to emphasize the importance of treating students similarly while downplaying any cultural differences that might manifest themselves in the classroom. Egalitarian teachers are less likely to include cultural differences in lesson planning, teacher expectations, and their definitions of student learning (Hachfeld et al., 2011). As a consequence, the teachers tend to 
support common curricula, create similar educational experiences, and hold communal expectations for their students.

It is important to note the different definition of egalitarianism held by the veteran teacher participants from the naive egalitarianism noted in a study of teacher candidates' beliefs (Causey et al., 2000). Naive egalitarianists attempt to create a color-blind classroom in an effort to create equitable opportunities for all students, regardless of need and context. In other words, by pretending that cultural differences do not exist, teachers believe students can overcome any obstacles to their future success through a combination of effort and confidence. Yet, as opposed to the naïve egalitarianists, the veteran participants recognized the student diversity in their classrooms, but chose not to address it. Margarita explained, “...diversity is a huge issue here. Not only like cultural diversity but also the level of kids the diversity affects." Margarita was aware of cultural diversity, but downplayed that component of diversity to focus on what she considered more immediate pedagogical concerns.

While teachers in this study certainly recognized the importance of all these components, according to their stated beliefs and responses on the Teacher Cultural Beliefs Survey, they chose to concentrate their instructional efforts on just one component: student ability. Like the other teacher participants, Margarita acknowledged the presence of diversity in the student in her classes but her instructional practices generally addressed academic variance, not cultural diversity.

Other teacher participants responded similarly regarding the needs of subgroups of students in their classrooms, particularly with their Latino students. For example, in 
Jane's lesson on the causes of the American Revolution, both she and Mr. Darb would often draw the names of students to share their responses in front of the room. While teachers were able to use the classroom audio system to project their voices, students were not able to use this tool. Instead, students would have to speak loudly on their own. Several Latino students appeared uncertain or hesitant with vocalizing their responses in front of the entire class when asked to do so. Often, these students would need to be prompted by the teachers to participate or helped with articulating their answers in both an audible and coherent manner. I observed the Latino students' reluctance to participate in class discussions in all of the participants' classrooms.

With this cultural subgroup, Jane believed their needs were rooted in "more of a behavior and attitude and motivation issue than a skill issue because a lot of them do have the skill if they really want it." Jane attributed the source of her Latino students' lack of willingness to participate or academic "holes" to personal decisions made by each student, rather than acknowledging their lack of participation might be rooted in language or cultural differences. Therefore, Jane was missing an opportunity to assist her students' academic growth, increase engagement, and illustrate her belief in the value of students' cultural capital.

Compared to the color-blind orientations expressed by the naïve egalitarian preservice teachers, the veteran teachers in this study seemed more aware of the heterogeneous compositions of their students, yet still believed it was necessary to treat all students equally. So, while they might have expressed strong egalitarian views, they also chose to be selective in their definitions of diversity: sometimes they distinguished 
between whole classes, but more frequently between individual students. Illustrating a whole class perspective, Carol shared, "You have to figure out what works with each class and it's not going to look exactly the same for each class and that's just the way it is." Carol prided herself on differentiating formative assessments for individual students to "give kids lots of different experiences headed to that goal." Yet, during a classroom discussion involving a room full of Latino students, Carol admonished them, "One thing you guys really stink at is listening to each other." Similar to other participants, Carol realized the individual diversity present in her classroom, yet generally chose to employ whole class strategies to address diversity, which she and the other teachers in this study defined along cognitive abilities. Primarily, teachers used one differentiated instructional strategy to address classroom diversity — mixed ability grouping, which is described in the next section.

Mixed ability grouping. Margarita, Jane, Carol, and Lisa did not emphasize cultural diversity in their definitions of classroom grouping. Yet, they freely acknowledged the range of academic learners in their classrooms. As Lisa noted, "there are some that get it; some don't." Included in her "don't" group were students who demonstrate deficiencies of academic knowledge and skills and are often below grade level. The teachers commonly used words like "holes" to describe the gaps in the academic proficiencies of their students. Carol, too, shared that within her classes, there is a broad spectrum of student knowledge and ability often referred to as "levels." Carol explained, "We go from kids who are non-readers in one classroom to kids who are reading at college levels." This means that to have an effective classroom and learning 
environment, teachers must know each student's academic needs, and be able to plan for and facilitate learning opportunities for the varying ability levels or groups. However, knowing this needs to happen did not reduce the challenges to doing this well and consistently. Carol elaborated that it is a challenge to plan language arts instruction with the range of diverse needs.

Mixed ability grouping is the practice of putting students with varying cognitive levels and knowledge in small groups for teaching and learning Margarita shared she plans on "purposely having different levels talking to each other and different levels of kids working on problems together." Lisa liked to seat "students at a high and a low together and changing their seats every six weeks...getting them to talk to each other." Jane was more succinct, stating "Within the classroom we might do some ability grouping together." These three examples illustrate a commonly used practice by these teachers and that these teachers only seem to use mixed ability grouping to address cognition despite a large number of other differences present in the students in their classroom. Further, teachers saw mixed ability grouping as a motivator for students with less cognitive ability. Carol explained the motivational importance that ability grouping provides lower and mid- level students. Carol said, “... without it the bubble kids who could rise up are not because they don't have the exposure to that higher level thinking that they need to push them." She believed the interaction between students of mixed abilities was an important motivational component to her differentiated instructional practices. 
Rather than selecting differentiated instructional practices based on cultural differences, the teachers in this study chose to use motivation as their primary approach to improve the academic output of their diverse student populations. Through the use of mixed ability grouping and increased student motivation, these teachers believed their students would feel encouraged to be successful learners in their classrooms. Thus, their perceived ability to use personal encouragement is another way teachers in this study measure their effectiveness in the classroom.

\section{Theme 3: Classroom Environment Influences Teacher Self-efficacy}

There is a wide variety of factors that influence student and teachers beliefs that they are able to be successful in the classroom. Common factors include, but are not limited to students' past educational experiences, parent and family involvement, teacher knowledge and competence, positive relationships between teachers and students, positive relationships between students and students, a safe and encouraging environment, and students being engaged and motivated to learn (Axelson \& Flick, 2011; Blatchford et al., 2011; Brighton, 2003; Hardre \& Sullivan, 2008; Hattie, 2013; RubieDavies, 2010; Rubie-Davies et al., 2012). To increase student success in classes, teachers use multiple approaches collectively referenced as adaptive teaching competencies. These adaptive teaching competencies included their content knowledge, diagnostic knowledge, classroom management styles, and teaching methods (Bruhwiler \& Blatchford, 2011).

The teachers in this study exhibited a range of adaptive teaching competencies. All of the teachers demonstrated strengths in these areas and were highly regarded by their administrators and peers for their professional competence. The TMS principal 
recommended all of the teachers in this study. His belief was seconded by the participants' faculty peers: one teacher shared an observation about Margarita's content knowledge, "She knows her stuff." These adaptive teaching competencies are used to create and maintain a learning environment that fosters feelings and attitudes in students that they "can do this."

Yet, all the participants believed their success in the classroom came through one major competency: their personal ability to motivate students. While school proficiency targets served as the formal means of their classroom effectiveness, all of the teachers in this study indicated they placed more importance on fostering their students' positive feelings toward their education. Bandura (1986) claimed one of the sources of selfefficacy was verbal persuasion. Encouraging and convincing students they are able to perform their classroom tasks, the teacher participants all strove to develop their students' own self-efficacy beliefs. Their goals for their students reflected this belief. Jane summarized this view with her statement "I want them to feel confident and like their own personal growth." What she was saying is students needed to have feelings of selfefficacy. Bandura (1997) described self-efficacy as “beliefs in one’s capabilities to organize and execute the sources of action required to produce given attainments" (p. 3). In short, students needed to believe they can do well in order to actually do well. Jane explained why student self-efficacy was important, particularly to increase learning outcomes for students identified with those academic "holes." Jane said, "If they can keep that drive for learning as they progress through their education that will catch up in those other areas." Ultimately, the teachers in this study primarily defined their 
success in the classroom through their students' affective domain competencies (e.g. social, emotional, and problem-solving competencies). If the teachers believe their students have high levels of self-efficacy, then they felt successful as educators.

In this case study, the students' levels of self-efficacy were reciprocated back onto the teachers' own feelings of effectiveness in the classroom. "I wish I could say I was more proficient in that," Carol said. She felt she could always do more to meet the learning needs of her students, but believed she was limited by contextual factors outside of her control, such as time, resources, and range of student variance present in her classes. Ultimately, the quality and quantity of mastery experiences teachers felt they had persuading students of the importance of their education contributed significantly to own their efficacy levels.

Bandura (1997) hypothesized "people avoid activities and environments they believe exceed their capabilities, but they readily undertake activities and pick social environments they judge themselves capable of handling" (p. 160). For example, the teachers in this study, all White, were uncomfortable with addressing cultural diversity, so they generally shied away from any planning, instructional, or managerial moves that highlighted cultural diversity. This practice is reinforced by participants' responses to the egalitarian belief statements on the Teachers Cultural Beliefs Scale. However, all of the teachers felt they were excellent motivators and spent a great deal of time and effort coaxing, encouraging, and otherwise influencing their students into feeling successful.

The teachers beliefs in their motivational abilities were reflected in their goals for student learning explained at length during their interviews. Lisa wanted her students by 
the end of the term to be "feeling successful... and then feeling like this was their class and their spot for the year." Margarita wanted her students to believe "there are possibilities for their own lives." Carol wanted students to "feel confident." The extent to which the teachers were able to foster these feelings of confidence, competence, and self-worth in their students loomed large in the participants' self-assessment of their teaching effectiveness and ability to create and maintain a classroom environment conducive to supporting the whole child. Effectiveness was not measured by these teachers based on school proficiency targets. Carol explained, "This data collection is overrated because some teachers who don't know their kids and know what their kids are capable of use it as a crutch." In other words, she accused some teachers of using proficiency targets as an imprecise shorthand measurement of student performance. While providing one measure of cognitive ability, targets did not accommodate for the range of student backgrounds, interests, and abilities (i.e., student diversity). Instead, teachers measured their students' efficacy using their perceptions of the students' active participation and engagement levels in the classroom.

Thus, teachers in this study took pride in their ability to create learning environments that, according to Jane, "optimized student learning." When these teachers believed that the environments they created maximized students opportunities for success academically and social-emotionally, they felt proud and in turn had increased teacher efficacy levels. Margarita explained, "My classroom environment I would say was my number one priority." Carol elaborated on this focus with a question she believed guided her efforts as a teacher. She said, "In the back of your brain, you are always thinking and 
asking how I can make my classroom a better place to be so that kids are excited to be here so they want to learn and engage with the material?" Carol's question neatly encompassed the reciprocal nature of teacher's classroom practices influencing student learning outcomes. The teachers observed that their students' engagement and motivational levels in class were linked to the teachers' ability to success create effective classroom environments. Conversely, teachers believed their success at creating effective classroom environments was linked to the engagement and motivational levels of their students.

Each teacher had slightly different ways of operationalizing this belief about the primacy of the learning environment which meshed with their statements about their teacher roles and their backgrounds. Margarita, the college athlete, described her role as "coaching kids along," and while Carol, the veteran teacher with grown children of her own, defined her role in her middle school classroom environment as a "nurturer at this age." Jane saw herself as "the orchestrator of the whole learning process...to create an environment." Finally, Lisa wanted her students to be working harder in her room than she, believing if students weren't, "she was doing something wrong." While each teacher defined an effective learning environment differently, they all saw their role in creating the classroom environment as their primary role.

Using their learning environment as a means to address classroom diversity was the key factor of teacher efficacy. Because modifying learning environment is a major way teachers in this study chose to differentiate instruction, the next section looks at the 
way teachers chose, and did not choose, to implement differentiated instructional practices in their classroom.

Theme 4: Professional Development Can Support Differentiated Instruction Guskey (1986) believed teachers' beliefs could be shaped by having them engage in certain practices or actions. Commonly these practices or actions include professional development. Recent studies suggest professional development be ongoing to effectively support teachers' differentiated instructional beliefs (Dixon et al., 2014). Untimely, sporadic, or incomplete professional development can influence the degree to which teachers' beliefs are affected.

Critiques of preservice training. Each of the veteran teachers in this study had a minimum of 10 years teaching experience; Carol had nearly three decades in the classroom. All participants were generally unimpressed with the quality of their preservice differentiated instructional training. Jane explained, "Where I went to school didn't prepare me for that, like I was knowledgeable about it. What I was missing was the practical side of implementing it." Margarita offered her opinion about the one class she claimed she took during her teacher training "It's so hard to remember a differentiated instruction class at the beginning, because you don't know what you are doing."

Participants claimed their lack of practical experiences with differentiated instruction led to misconceptions that negatively influenced their early implementation efforts. Jane shared, "If I think about what I would originally have started off with 10 years ago thinking what differentiation should be, then no. I don't think I probably did as 
well." Lisa added, "Once I stopped and thought about it, I was already doing it in some ways and I just didn't realize that what it was." With experience, her efficacy to differentiate increased. "It's definitely changed and gotten more comfortable." This means Lisa did not believe her initial training prepared her for her initial differentiated experiences. However, over time she was able to adjust her beliefs to suit her new definition of differentiated instruction.

Positive Beliefs towards Inservice Training. Compared to their mediocre reviews of their preservice training, all teachers in this study exhibited strong beliefs for the value of their in-service professional development to foster differentiated instruction in the classroom. Each teacher referenced differentiated instructional "teams" that used to meet at TMS regularly ten years earlier when Jane, Lisa, and Margarita were newer teachers. Lisa shared her recollection of the teams. "When I first started here the first couple of years they had differentiated instructional teams. We got to meet a couple of days throughout the year we had training and it was fabulous." Carol elaborated on the purpose of the teams. "We had time to design those kinds of lessons and we could really differentiate the content in our rooms and it was a good thing." Margarita also expressed positive sentiments. "We were able to research more differentiated instructional lessons to share with the group which was like amazing." While sometimes TMS would hire differentiated instructional experts to come in and help facilitate team meetings, mostly the teachers drove the work on the differentiated instructional teams. Margarita described one session's details at length but summed up the teaming experience having control over how they used their time to collaboratively plan for meeting their students' 
needs in the classroom. "Some of the best things that we've ever created came out of that one meeting." In other words, she favorably viewed the autonomy and practicality of the training. These favorable views of their professional development translated over into the implementation of differentiated instructional practices in their classrooms.

Cautious Implementation. Each of the participants described a reduced emphasis on differentiated instruction over the years at TMS including how the decreased differentiated instruction focus impacted their current implementation of differentiated instructional practices. Carol illustrated her current approach to differentiation in her classroom with a story about her father, who had recently taken up beekeeping. "Always approach the hive from the back," he told her. "If you approach it from the front they'll attack you." She believed in taking a cautious posture towards implementing differentiated instruction, explaining, "You need to have calm about you." She said she gave up trying to differentiate content, where teachers adapt what the student needs to learn or how the student accesses the information, "because it was way too difficult." Instead Carol shared her focus on differentiating processes because "of course, every teacher does that." In her view, differentiating for process did not mean varying the classroom activity to meet student variance. Instead, process differentiation meant varying her expectations for students' demonstration of their knowledge and skills. In her view, Carol felt most successful with her efforts to differentiate formative assessments to meet individual learning needs.

The other participants expressed similar sentiments revealing caution and a diminished urgency. While Jane supported differentiated instruction, she also strove for 
“a balance of what's manageable, too." Further, though Margarita talked about the importance of differentiated instructional practices, her classroom emphasis was on interacting with each of her students over consistently seeking ways to support student individual academic or classroom needs. Margarita used her personality rather than her planning to increase student learning outcomes. Of the four participants, only Lisa displayed any significant content and process differentiation, once allowing her students the opportunity to select their creations for a STEM project she had assigned. She was proud of the lesson and made sure I was present on that day to observe it.

\section{Summary}

In sum, teacher professional development is a process, not an event.

Differentiated instructional practices require constant attention and refinement. In the absence of regular professional development for differentiated instruction, teachers resort to their own definitions and implementations of differentiated instruction. If building, grade level, or content area teams do not emphasize and support differentiated instruction, it is possible teachers may also downplay their implementation efforts in the classroom as well. 


\section{Chapter 5: Discussion/Conclusions}

A considerable amount of research reports that a large percentage of teachers believes differentiated instruction is challenging to implement (Farkas \& Duffet, 2010; Rochkind et al., 2007; Tomlinson, 2014). This belief may lead teachers to downplay differentiated approaches in favor of more uniform pedagogical approaches. Findings from these studies have stimulated growth in interest in teachers' beliefs about students and differentiated instruction, particularly in light of growing ethnic and cultural diversity in U.S. classrooms. The purpose of this qualitative study was to explore the beliefs of veteran middle school teachers about using differentiated instructional practices in large, diverse classes. The research questions guiding this study included:

1. What are middle school educators' beliefs about differentiated teaching and learning in diverse classes?

2. How do teachers implement their beliefs about differentiated teaching and learning?

3. What factors influence teachers' adoption of differentiated instruction in their classrooms?

I previously discussed why understanding teachers' beliefs about teaching and learning in large diverse classes is important to the successful implementation of differentiated instructional practices. I examined the literature surrounding teachers' beliefs and practices, particularly as they apply to adaptive teaching competencies, classroom diversity, and differentiated instruction. This concluding chapter briefly 
synthesizes the findings before situating them with the larger context of education in the U.S. and discusses their implications.

\section{Synthesis of Findings}

This synthesis section aims to briefly and concisely discuss the major findings from this study and then link them to an appropriate set of conclusions. The task of defining what is (and what is not) appropriate can be a subjective enterprise for case study scholarship. This study was invariably influenced by my own experiences, background, and beliefs. However, as maintained by Yin (2003), I made every effort to present evidence in a neutral manner, supply enough evidence to convince readers of my knowledge of the subject, and attended to the validity of my evidence. Thus, the appropriateness of the conclusions drawn here and in the implications should present a case study that is "complete," a characteristic Yin attributed to exemplary case studies (p. 162).

Beliefs about differentiating instruction. First, teachers in this study indicated strong beliefs about the value of differentiating instruction to address classroom diversity. These teachers were veterans; they were familiar with the term differentiated instruction and they were well versed in its potential to meet individual student needs. Further, as experienced educators, each teacher believed she was aware of the range of physical, intellectual, moral/ethical, emotional/psychological, and social development levels each student possessed in their classroom (Anfara et al., 2007). Their beliefs were supported by their building administrator's perceptions: each participant was rated highly by the TMS principal in their ability to meet the needs of their students. Thus, in spite of 
different classroom management strategies and teaching methods, each participant was confident about her own adaptive teaching competencies and spoke positively about the value of differentiated instruction.

This finding supports Wormelli's (2007) precondition for successful differentiation: each teacher seemingly possessed the necessary supportive "mind-set." During interviews, each teacher expressed statements supporting the value of differentiated instruction. However, as described below, this study did not find a direct association between their stated supportive beliefs and implemented differentiated instructional practices. In other words, positive sentiments alone did not guarantee teachers would implement differentiated instructional practices in the classroom.

Differentiated instruction is more than a specific strategy or checklist of options; it is a way of thinking about teaching and learning in diverse classrooms. While ability grouping, tiered learning activities, or varied reading assignments are helpful tactics, differentiation is more a philosophy than a pedagogical toolbox. Differentiation beliefs include the realization learning is an internal process, rather than something that happens externally to students. Further, supportive differentiation beliefs reflect and refine the ideas around each student as an individual and also as a member of the larger classroom. Rather than identifying ways to develop a wide variety of strengths each student possessed, the teachers in this study considered differentiated instruction necessary for highlighting mostly cognitive commonalities their students shared.

Definitions influence practices. Second, this study illustrates teachers' personal and professional definitions of classroom diversity influenced their differentiated 
instructional implementation. Classroom diversity has numerous characterizations, each with its own meanings and implications. While each teacher was aware of the different meanings given to classroom diversity by scholars (Calderon et al., 2011; Causey et al., 2000; Milner, 2010), the findings of this study indicate teachers downplayed most aspects of diversity to concentrate upon just one: the cognitive abilities of the class.

Further, the findings suggest egalitarian beliefs were as least partially responsible for this singular focus on academic variance over other forms of classroom diversity. Egalitarian teachers tend to create one set of educational experiences in their classroom and generally focus on emphasizing commonalities among their students rather than celebrating differences (Hachfeld, et al., 2011). While the larger implications of egalitarian worldviews are presented later in this chapter, an immediate result from the teachers' egalitarianism was their preferred differentiated instructional approach used in their classrooms. This favored approach minimized addressing or celebrating students' cultural capital or needs.

In educational settings, teachers holding egalitarian beliefs tend to emphasize the importance of treating students similarly while downplaying cultural differences that might manifest themselves in the classroom. Egalitarian teachers are less likely to include cultural differences in lesson planning, teacher expectations, and their definitions of student learning (Hachfeld et al., 2011). As a consequence, egalitarian teachers tend to support common curricula, create similar educational experiences, and hold communal expectations for their students. 
It is important to note the different definition of egalitarianism held by the veteran teacher participants from the naive egalitarianism noted in a study of teacher candidates' beliefs (Causey et al., 2000). Naive egalitarianists attempt to create a color-blind classroom in an effort to create equitable opportunities for all students, regardless of need and context. In other words, by pretending that cultural differences do not exist, teachers believe students can overcome any obstacles to their future success through a combination of effort and confidence. Yet, as opposed to the naïve egalitarianists, the veteran participants recognized the student diversity in their classrooms, but chose not to address it. Margarita explained, “...diversity is a huge issue here. Not only like cultural diversity but also the level of kids the diversity affects." Margarita was aware of cultural diversity, but downplayed that component of diversity to focus on what she considered more immediate pedagogical concerns.

The teachers in this study chose to employ mixed-ability grouping as their preferred differentiation strategy. This strategy allowed them to create common goals and hold similar expectations for all of their students, while accommodating the academic variance found in each of their classrooms. McIntyre (1997) suggested White teachers often overlook ethnic diversity in their classroom as a result of a privileged social position and a fear of making mistakes with diversity issues. None of the teacher participants felt their ethnic backgrounds were an impediment to addressing classroom diversity, and did not include any ethnic considerations when grouping students by ability in their classrooms. 
More tellingly, due to the mandates put forth by national, state, and local education policies, each of the teachers in this study felt compelled to try to have each of their students (regardless of ethnic or cultural background) reach a certain standard of proficiency. This proficiency level (which each student was expected to meet or exceed) impelled teachers to address academic variance, while allowing them the privilege to ignore other components of diversity. The teachers in this study generally indicated their disagreement with instructional or managerial strategies that would have them treat students differently based on ethnic, linguistic, or economic differences.

Further, the school climate of TMS heavily favored egalitarianism in the classroom and beyond. TMS combined three different elementary schools from a wide geographic area with different ethnic compositions; their focus was on creating a unified, common school culture. Their frequent use of extrinsic motivators like Pride Bucks, schoolwide "parties" rewarding appropriate behaviors, and numerous extra-curricular activities were designed to create an inclusive school environment with common values, expectations, and beliefs for teachers and students alike. Less importance was given to employing culturally responsive pedagogies to address and celebrate ethnic diversity. While TMS posted signs to wash hands in Spanish and English, all academic instruction was delivered in English only. Further, there were no Latino full-time licensed classroom teachers, yet over $44 \%$ of TMS students were Latino. Tyler et al. (2006) suggested "the value teachers assign to academic success should not be understood in the absence of cultural considerations." In other words, teachers' perceptions of student motivation and achievement should be mediated by aspects of culture. However, students' cultural needs 
were rarely considered in planning instruction and learning environments. Yet, all of the participants rated their abilities as teachers primarily on their ability to create a classroom environment that supported their expectations for student learning. In sum, the teachers' narrow definition of diversity led them to employ differentiated instructional practices that only addressed cognitive variance.

Classroom environments and teachers have a reciprocal relationship. Third, this study strengthens the idea of a reciprocal relationship between classroom environment and teachers' self-efficacy. Rubie-Davies (2010) described how teacher beliefs (e.g. mastery goals, differentiation, expectations) influence the instructional and socio-emotional climate of their classrooms. This study found all participants held strong efficacy beliefs about their ability to design and lead instruction to a diverse group of students. This efficacy was rooted in their beliefs in their ability to create effective working relationships with their students in their classrooms.

\section{Professional development influences differentiated instructional practices.}

The fourth finding from this case study indicated teachers had strong beliefs in the usefulness of in-service professional development to support differentiated instructional implementation. At one time, schoolwide professional development efforts led to increased teacher efficaciousness towards their ability to differentiate instruction. Over time, the lack of unified schoolwide emphasis led teachers to adopt their own means of differentiating instruction, primarily through ability grouping and creating classroom environments emphasizing student motivation and engagement. 
All of the teachers expressed some level of remorse that their professional development no longer emphasized differentiated instruction and felt this contributed to their incomplete approaches to meet classroom diversity. Some chose to use classroom management strategies. Others used schoolwide behavioral incentive programs. However, all participants similarly underscored the importance of their students' affective domains (i.e. motivation and engagement) towards increasing learning outcomes.

\section{Situated in Larger Context}

Many educational studies have investigated the growing cultural, linguistic, ethnic, and economic diversity in US classrooms (Capps et al., 2005; Miller, 2011; National Center for Education Statistics, 2014). Awareness of the issues, challenges, and opportunities stemming from classroom diversity while also meeting academic performance benchmarks set by local, state, and federal mandates may help teachers to be more successful at increasing student learning outcomes. Further, a considerable amount of research purports the beliefs that teachers hold about their students influence their instructional and managerial decisions in the classroom.

Qualitative research in general is interested in "what is, what may be, and what could be" (Schofield, 2002, p. 209). Case studies are not meant to be generalizable, but can be used to enhance their implications for the understanding of other situations. Schofield (2002) argued for a reconceptualization of generalizability that emphasizes analyzing the degree to which the situation investigated matches other situations in which the researcher is interested. This is a study of "what is," or studying a typical, common, 
or ordinary context. TMS was selected because of its typicality, which is more likely to help understand similar kinds of institutions.

Typicality helps to understand the prevailing national teacher-student

demographic mismatch. Across the United States, White teachers make up over $80 \%$ of the workforce. Increasingly, teachers do not look like their students: by 2024 only $46 \%$ of students are predicted to be white (Chief Education Office, 2016). The TMS student body was $44 \%$ Latino, yet all faculty members were White. National education reports have drawn attention to the disparities in learning outcomes between White students and other ethnic groups (NAEP, 2013). In an educational system that is supposed to celebrate diversity and promote democratic values, students of all cultures need minority role models (Darling-Hammond \& Sclan, 1996). As a result, recent educational scholarship is turning attention to the implications of this ethnic and cultural mismatch between students and teachers (Gay, 2015; Milner, 2012). All of the participants in this study valued their relationships with their students, yet this mismatch stood in the way of effective classroom differentiation. Situated within the larger context of this scholarship, the findings of this study suggest this body of scholarship pursue exploring beliefs of veteran teachers about student diversity.

\section{Recommendations}

The discussion of the data highlighted some of the complex and sophisticated beliefs held by teachers and their subsequent classroom practices. I have presented their words and observations of their teaching not to answers how to differentiate instruction, but rather as insights how experienced middle school teachers attempt to define and 
implement teaching and learning in diverse classrooms. Drawing from these discussions, several recommendations for practice can implied from this study which may assist preservice and veteran teachers, as well as administrators, scholars, and teacher educators. A willingness to engage with these issues and challenges may increase learning outcomes for students.

First, I suggest it is important for teachers to have both the skills and opportunities to reflect on their own beliefs and practices with classroom diversity and differentiated instruction. As noted in Chapter 1, policy and demographic realities require teachers plan and work with diverse student populations. Like other working professionals, teachers protect their professional reputations and are cautious divulging beliefs or practices that may portray them in a negative light. Teachers know they need to address classroom diversity with differentiated instruction, yet may be hindered from doing so by a lack of skills, beliefs, and resources. Additionally, they may be reluctant to share their professional shortcomings with "outsiders" such as building or district administrators, unfamiliar faculty members, or university researchers. This resistance to scrutiny may help to explain why there is an overall lack of scholarship examining veteran teachers' beliefs.

Teachers should regularly and collaboratively have opportunities to reflect with their peers as part of their continuing professional development. Regular, consistent, and deliberative reflections on what practices are working and what is not with groups of students will ensure that teachers can review and improve their professional skills when working with diverse student populations. While it is true that for many veteran teachers, 
reflective practice is an instinctive skill, the process of collaborative reflection may help these veterans to understand their beliefs more comprehensively by challenging one other's beliefs, reflect on their own mistakes, and develop classroom practices more in line with the philosophes of differentiated instruction. When teachers work together to ask troubling questions and challenge each other's beliefs concerning classroom diversity, they demonstrate their willingness to take risks and learn from each other. This can only be good for their students. Ultimately, awareness of the issues and challenges with implementing differentiated instructional practices may increase teachers' ability to meet the needs of all of their students. More research would be helpful to understanding how veteran teachers reflect on their practices and their efficacy in the classroom.

Second, the results of this study indicate teachers are not immune to the wider stereotypes that persist in our society. These stereotypes can manifest themselves in the beliefs veteran teachers hold about their students, particularly with those students from outside of the cultural, ethnic, or socio-economic circles teachers may be most familiar with. The mismatch between teacher and student may result in expectations and practices that do not adequately meet the needs of all students. While reducing this mismatch is increasingly being noted at the policy level with efforts to attract more teachers of color to the classroom, the current demographic realities of teacher and student populations indicate this issue will be present for some time to come.

The veteran teachers in this study expressed a strong belief in the appropriateness of egalitarian worldviews as a means to address classroom diversity. Egalitarianism tries to find the similarities and commonalities existing in diverse populations while 
downplaying cultural differences. Yet, Gay (2015) and Milner (2010) have both cautioned against egalitarian orientations. Opportunities are lost, they claim, from working in a pluralistic institution which can result in students becoming "disengaged, disinterested, and disconnected from lessons and lesson opportunities" (Milner, 2010, p. 6). In other words, when students see themselves reflected in the curricula they may perform more successfully than when they do not.

This implication has potential ramifications for future research. While teacher candidate beliefs have been extensively explored, scholars have largely overlooked the voices of veteran teachers regarding their cultural worldviews. It would be interesting for researchers to explore the impact of egalitarian versus multicultural worldviews and teachers' subsequent classroom practices. As the vast majority of public schoolteachers in the United States are White, further scholarship could also explore the impact of White cultural and ethnic identity in the classroom.

Third, while each of the teachers in this study expressed the importance of differentiating instruction, the lack of ongoing professional development resulted in the decay of necessary skills and beliefs to adequately do so. In general, therefore, it seems shifting the curricular focus away from differentiation can result in incomplete and disjointed classroom implementation.

These results led teachers to question their efficacy to differentiate instruction. These uncomfortable questions may lead teachers to redefine differentiated instruction to fit their previous classroom practices in order to protect their professional self-esteem. Yet, reducing the numbers of disengaged or unmotivated students can improve teaching 
efficacy with corresponding improvement in the learning environment. In particular, the findings of this study implied the participants' reliance on mixed-ability grouping as a way to differentiate instruction neglected the needs of their talented and gifted (TAG) students. Future scholarship could assess the impact of teacher beliefs on students with high cognitive functioning capabilities, particularly when those TAG students are part of a diverse classroom mix.

\section{Summary}

Teacher beliefs serve as powerful predictors of classroom practices. As classroom diversity continues to rise across the United States, teachers will need to increase their differentiated instructional practices to meet the needs of all of their students. School administrators should provide continual, ongoing professional development to help their faculty. Effective teaching, the kind of teaching that increases student achievement across ethnic, cultural, socio-economic, or cognitive boundaries, thrives in an environment where teachers can individually and collaboratively reflect on their beliefs and practices. 
References

Apple, M. (2006). Educating the "right" way: Markets, standards, God, and inequality (2nd ed.). New York: NY: Routledge.

Andrews, M., Squire, C., \& Tamboukou, M. (2008). Doing narrative research (2 ${ }^{\text {nd }}$ ed.). Los Angeles, CA: Sage.

Anfara, V. A., Jr., Mertens, S. B., \& Caskey, M. M. (2007). Introduction. In S. B. Mertens, V. A. Anfara, Jr., \& M. M. Caskey (Eds.), The young adolescent and the middle school (pp. ix-xxxiii). Charlotte, NC: Information Age.

Antonio, A., Chang, M., Hakuta, K., Kenny, D., Levin, S., \& Milem, J. (2004). Effects of racial diversity on complex thinking in college students. Psychological Science, 15(8), 507-510.

Anunah, J., \& Hodge, S. (2005). Secondary physical education teachers' beliefs and practices in teaching students with severe disabilities: A descriptive analysis. The High School Journal, 89(2), 40-54.

Archambault, F., Westberg, K., Brown, S., Hallmark, B., Emmons, C., \& Zhang, W. (1993). Regular classroom practices with gifted students: Results of a national survey of classroom teachers. Research Monograph 93102. University of Connecticut, The National Research Center on the Gifted and Talented.

Atjonen, P., Korkeakoski, E., \& Mehtalainen, J. (2011). Key pedagogical principles and their major obstacles as perceived by comprehensive school teachers. Teachers and Teaching: Theory and Practice, 17(3), 273-288. 
Attride-Stirling, J. (2001). Thematic networks: An analytic tool for qualitative research. Qualitative Research, 1(3), 385-405.

Axelson, R., \& Flick, A. (2011). Defining student engagement. Change, 43(1), 38-43.

Balfanz, R., Herzog, L., \& Mac Iver, D. (2007). Preventing student disengagement and keeping students on the graduation path in urban middle grades schools: Early identification and effective interventions. Educational Psychologist, 42(4), 223235.

Bandura, A. (1986). The explanatory and predictive scope of self-efficacy theory. Journal of Social and Clinical Psychology, 4(3), 191.

Bandura, A. (1997). Self-efficacy: The exercise of control. New York, NY: W.H. Freeman and Company.

Bandura, A. (2012). On the functional properties of perceived self-efficacy revisited. Journal of Management, 38(1), 9-44.

Bender, W. (2012). Differentiated instruction for students with learning disabilities: New practices for general and special educators ( $3^{\text {rd }}$ ed.). Thousand Oaks, CA: Corwin.

Beninghof, A. (2013). Co-teaching that works: Structures and strategies for maximizing student learning. San Francisco, CA: Jossey Bass,

Berliner, D., \& Biddle, B. (1995). The manufactured crises: Myths, fraud, and the attack on America's public schools. White Plains, NY: Longman.

Blatchford, P., Bassett, P., \& Brown, P. (2011). Examining the effect of class size on classroom engagement and teacher-pupil interaction: differences in relation to 
pupil prior attainment and primary vs. secondary schools. Learning and Instruction, 21(6), 715-730.

Blozowich, D. (2001). Differentiated instruction in heterogeneously grouped sixth grade classrooms. (Doctoral dissertation). Available from ProQuest Dissertations \& Theses Global. (304789162). Retrieved from http://stats.lib.pdx.edu/proxy.php?url=/docview/304789162?accountid=13265

Bogdan, R., \& Bilken, S. (2007). Qualitative research methods (5 $5^{\text {th }}$ ed). Boston, MA: Allyn \& Bacon.

Brante, G. (2009). Multitasking and synchronous work: Complexities in teacher work. Teaching and Teacher Education, 25(3), 430-436.

Brighton, C. (2003). The effects of middle school teachers' beliefs on classroom practices. Journal for the Education of the Gifted, 27(2/3), 177-206.

Bronfenbrenner, U. (1986). Ecology of the family as a context for human development: Research perspectives. Developmental Psychology, 22(6), 723-742.

Bruhwiler, C., \& Blatchford, P. (2011). Effects of class size and adaptive teaching competency on classroom processes and academic outcomes. Learning and Instruction, 21(1), 95-108.

Buehl, M., \& Beck, J. (2015).The relationship between teachers' beliefs and teachers' practices. In H. Fives \& M. Gill (Eds.), International handbook of research on teacher beliefs (pp. 66-84). New York, NY: Routledge. 
Calderhead, J. (1996). Teachers: Beliefs and knowledge. In D. C. Berliner \& R. C. Calfee (Eds.), Handbook of educational psychology (pp.709-725). New York, NY: Macmillan.

Calderón, M., Slavin, R., \& Sánchez. (2011). Effective instruction for English learners. The Future of Children, 21(1), 103-127.

Capps, R., Fix, M., Murray, J., Ost, J., Passel, J., \& Herwantoro, S. (2005). The new demography of America's schools: Immigration and the No Child Left Behind Act. Washington, DC: Urban Institute.

Caprara, G., Barbaranelli, C., Steca, P., and Malone, P. (2006). Teachers'self-efficacy beliefs as determinants of job satisfaction and students academic achievement: A study at the school level. Journal of School Psychology, 44(6), 473-490.

Cassady, J., Neumeister, K., Adams, C., Cross, T., Dixon, F., \& Pierce, R. (2004). The differentiated classroom observation scale. Roeper Review, 26(3), 139-146.

Causey, V., Thomas, C., \& Armento, B. (2000). Cultural diversity is basically a foreign term to me: the challenges of diversity for preservice teacher education. Teaching and Teacher Education, 16(1), 33-45.

Chamberlin, M., \& Powers, R. (2010). The promise of differentiated instruction for enhancing the mathematical understandings of college students. Teaching Mathematics and Its Applications, 29(3), 113-139.

Chan, D. (2008). Dimensions of teacher self-efficacy among Chinese secondary school teachers in Hong Kong. Educational Psychology, 28(2), 181-194. 
Chief Education Office. (2016). 2016 Oregon Educator Equity Report. Retrieved fromhttp://tspc.oregon.gov/publications/EducatorEquityReport_CEdO_July_2016 .pdf

Chingos, M. (2011). The false promise of class size reduction. Retrieved from https://cdn.americanprogress.org/wpcontent/uploads/issues/2011/04/pdf/class_size.pdf/

Clandinin, D., \& Connelly, F. (2000). Narrative inquiry: Experience and story in qualitative research. San Francisco, CA: Jossey-Bass.

Common Core State Standards Initiative. (2012). Common Core State Standards. Retrieved from http://www.corestandards.org/read-the-standards/.

Cook, W., Leeds, C., \& Callis, R. (1951). Minnesota Teacher Attitude Inventory. Oxford, England: Psychological Corp.

Corbin, J., \& Strauss, A. (2008). Basics of qualitative research: Techniques and procedures for developing grounded theory ( $3^{\text {rd }}$ ed.). Thousand Oaks, CA: Sage. Counts, G. (1932). Dare the school build a new social order? New York, NY: John Day. Cuban, L. (1983). How did teachers teach, 1890-1980. Theory into Practice, 22(2), 159165.

Damico, S., \& Sparks, C. (1986). Cross-group contact opportunities: Impact on interpersonal relationships in desegregated middle schools. Sociology of Education, 59(2), 113-123.

Darling-Hammond, L. (2007). Race, inequality, and educational accountability: The irony of 'No Child Left Behind.' Race Ethnicity and Education, 10(3), 245-260. 
Darling-Hammond, L., \& Sclan, E. M. (1996). Who teaches and why: Dilemmas of building a profession for 21st century schools. In J. Sikula, T. J. Buttery, \& E. Guyton (Eds.), Handbook of research on teacher education (2nd ed., pp. 67-101). New York, NY: Macmillan.

Dee, T., \& West, M. (2011). The non-cognitive returns to class size. Educational Evaluation and Policy Analysis, 33(1), 23-46.

Dembo, M., \& Gibson, S. (1984). Teacher efficacy: A construct validation. Journal of Educational Psychology, 76(4), 569-582.

Denzin, N., \& Lincoln, Y. (2000). Introduction: The discipline and practice of qualitative research. In N. Denzin \& Y. Lincoln (Eds.), Handbook of qualitative research (pp.1-32). Thousand Oaks, CA: Sage.

Dixon, F., Yssel, N., McConnell, J., \& Hardin, T. (2014). Differentiated instruction, professional development, and teacher efficacy. Journal for the Education of the Gifted, 37(2), 111-127.

Eccles, J., \& Midgley, C. (1989). Stage-environment fit: Developmentally appropriate classrooms for young adolescents. In C. Ames \& R. Ames (Eds.), Research on motivation in education: Vol. 3. Goals and cognitions (pp. 13-44). New York, NY: Academic Press.

Englehart, J. (2006). Teacher perceptions of student behavior as a function of class size. Social Psychology of Education, 9(3), 245-272.

Englehart, J. (2011). Why class size effects cannot stand alone: Insights from a qualitative exploration. Learning Environments Research, 14(2), 109-121. 
Enyedy, N. (2014). Personalized instruction: New interest, old rhetoric, limited results, and the need for a new direction for computer-mediated learning. National Education Policy Center. Boulder, CO. Retrieved from http://nepc.colorado.edu/publication/personalized-instruction

Ernst, C., \& Rogers, M. (2009). Development of the inclusion attitude scale for high school teachers. Journal of Applied School Psychology, 25(3), 305-322.

Fairbanks, C., Duffy, G., Faircloth, B., He, Y., Levin, B., Rohr, J., \& Stein, C. (2009). Beyond knowledge: Exploring why some teachers are more thoughtfully adaptive than others. Journal of Teacher Education, 61(1), 161-171.

Farkas, S., Johnson, J., \& Foleno, T. (2000). A sense of calling: Who teaches and why. New York, NY: Public Agenda. Retrieved from http://www.publicagenda.org/files/pdf/sense_of_calling.pdf

Figlio, D., \& Loeb, S. (2011). School accountability. In E. Hanushek, S. Machin, \& L. Woessman (Eds.), Handbooks in economics of education, Vol.3 (pp. 383-421). Amsterdam, North Holland: Elsevier.

Fives, H., \& Buehl, M. (2012). Spring cleaning for the "messy" construct of teacher's beliefs: What are they? Which have been examined? What can they tell us? In K.R. Harris, S. Graham, \& T. Urdan (Eds.), APA educational psychology handbook: Volume 2 individual differences and cultural and contextual factors (pp. 471-499). Washington, DC: American Psychological Association.

Fives, H., \& Buehl, M. (2015). The functions of beliefs: Teachers' personal epistemology on the pinning block. In G. Scraw, J. Brownless, L. Olafson, \& M. Van der Veldt 
(Eds.). Teachers' personal epistemologies: Evolving models for transforming practice. (pp. 178-235). New York, NY: Springer Publishing Company.

Flyvbjerg, B. (2006). Five misunderstandings about case-study research. Qualitative Inquiry, 12(2), 219-245.

Friedman, I., \& Farber, B. (1992). Professional self-concept as a predictor of teacher burnout. The Journal of Educational Research, 86(1), 28-35.

Frome, P., Lasater, B., \& Cooney, S. (2005). Well-qualified teachers and high quality teaching: Are they the same? (Research Brief). Atlanta, GA: Southern Regional Education Board.

Gage, N. (1963). Handbook of research on teaching. Chicago, IL: Rand McNally.

Gamoran, A., Nystrand, M., Berends, M., \& LePore, P. (1995). An organizational analysis of the effects of ability grouping. American Educational Research Journal, 32(4), 687-715.

Gardner, H. (1983). Frames of mind: The theory of multiple intelligences. New York, NY: Basic Books.

Gay, G. (2004). The importance of multicultural education. Educational Leadership, 61(4), 30-35.

Gay, G. (2015). Teachers' beliefs about cultural diversity: Problems and possibilities. In H. Fives \& M. Gill (Eds.), International handbook of research on teachers' beliefs (pp. 436-452). New York, NY: Routledge.

George, P. (2010). A rationale for differentiating instruction in the regular classroom. Theory into Practice, 44(3), 185-193. 
Getzels, J., \& Jackson, P. (1963). The teacher's personality and characteristics. In N. L. Gage (Ed.), Handbook of research on teaching (pp. 507-582). Chicago, IL: Rand McNally.

Gibson, S., \& Dembo, M. (1984). Teacher efficacy: A construct validation. Journal of Educational Psychology, 76(4), 569-582.

Giroux, H. (2012). Education and the crises of public values: Challenging the assault on teachers, students, \& public education. New York, NY: Peter Lang.

Goddard, R., Hoy, W., \& Hoy, A. (2000). Collective teacher efficacy: Its meaning, measure, and impact on student achievement. American Educational Research Journal, 37(2), 479-507.

Goetz, J., \& LeCompte, M. (1984). Ethnography and qualitative design in educational research (Vol. 19). Orlando, FL: Academic Press.

Good, T., \& Brophy, J. (1997). Looking into classrooms. New York, NY: Longman.

Grimaldi, E. (2010). Neoliberalism and the marginalization of social justice: The making of an education policy to combat social exclusion. International Journal of Inclusive Education, 16(11), 1131-1154.

Grittner, F. (1975). Individualized instruction: An historical perspective. The Modern Language Journal, 59(7), 323-333.

Guba, E., \& Lincoln, Y. (1985). Fourth generation evaluation. Newbury Park, CA: Sage.

Guba, E., \& Lincoln, Y. (1994). Introduction: Entering the field of qualitative research. In N.K. Denzin \& Y.S. Lincoln (Eds.), Handbook of qualitative research (pp. 1-17). 
Thousand Oaks, CA: Sage. Retrieved from http://www.gdufs.biz/10-

guba_lincoln_94.pdf

Gurin, P., Nagda, B., \& Lopez, G. (2004). The benefits of diversity in education for democratic citizenship. Journal of Social Issues, 60(1), 17-34.

Guskey, T. (1986). Staff development and the process of teacher change. Educational Researcher, 15(5), 5-12.

Gutek, G. (1986). Education in the United States: An historical perspective. Englewood Cliffs, NJ: Prentice-Hall.

Hachfeld, A., Hahn, A., Schroeder, S., Anders, Y., Stanat, P., \& Kunter, M. (2011). Assessing teachers' multicultural and egalitarian beliefs: The Teacher Cultural Beliefs Scale. Teaching and Teacher Education, 27(6), 986-996.

Hall, G. (1904). Adolescence: Its psychology and its relations to physiology, anthropology, sociology, sex, crime, religion, and education (Vols. I \& II). New York, NY: D. Appleton \& Co.

Hanushek, E. (2011). The economic value of higher teacher quality. Economics of Education Review, 30(3), 466-479.

Harris, D., \& Sass, T. (2011). Teacher training, teacher quality and student achievement. Journal of Public Economics, 95(7-8), 798-812.

Hardré, P., \& Sullivan, D. (2008). Student differences and environment perceptions: How they contribute to student motivation in rural high schools. Learning and Individual Differences, 18(4), 471-485. 
Hattie, J. (2013). Visible learning: A synthesis of over 800 meta-analyses relating to achievement. New York, NY: Routledge.

He, Y., \& Levin, B. (2008). Match or mismatch: How congruent are the beliefs of teacher candidates, teacher educators, and cooperating teachers? Teacher Education Quarterly, 35(4), 37-55.

Hernandez, D. J. (2011). Double jeopardy: How third-grade reading skills and poverty influence high school graduation. Baltimore, MD: The Annie E. Casey Foundation. Retrieved from http://www.gradelevelreading.net/wordpress/wpcontent/uploads/2010/10/DoubleJ eopardyReport040511FINAL.pdf

Hoffman, B., \& Seidel, K. (2015). Measuring teachers' beliefs: For what purpose? In H. Fives \& M. Gill (Eds.), International handbook of research on teachers' beliefs (pp. 106-127). New York, NY: Routledge.

Holas, I., \& Huston, A. (2012). Are middle schools harmful? The role of transition timing, classroom quality, and school characteristics. Journal of Youth and Adolescence, 41(3), 333-345.

Hood, O. (2012). Differentiated instruction in developmental mathematics classes and achievement of ethnic minority students. (Doctoral dissertation). Available from Proquest Dissertations and Thesis database (UMI No. 3495148)

Jordan, A., \& Stanovich, P. (2003). Teachers' personal epistemological beliefs about students with disabilities as indicators of effective teaching practices. Journal of Research in Special Educational Needs, 3(1), 1-14. 
Joseph, S. (2013). Differentiating instruction: Experiences of pre-service and in-service trained teachers. Caribbean Curriculum, 20(1), 31-51.

Juvonen, J., Nishina, A., \& Graham, S. (2006). Ethnic diversity and perceptions of safety in urban middle schools. Psychological Science, 17(5), 393-400.

Kagan, D. (1992). Implications of research on teacher belief. Educational Psychologist, 27(1), 65-90.

Kardan, S., \& Conati, C. (2013). Comparing and combining eye gaze and interface actions for determining user learning with an interactive simulation. In International User Modeling, Adaptation, and Personalization (pp. 215-227). Berlin, Germany: Springer Berlin Heidelberg.

Kiely, M., Brownell, M., Lauterbach, A., \& Benedict, A. (2015). Teachers' beliefs about special needs and inclusion. In H. Fives \& M. Gill (Eds.), International handbook of research on teachers' beliefs (pp. 475-488). New York, NY: Routledge.

Kim, T., \& Axelrod, S. (2005). Direct instruction: An educators' guide and a plea for action. The Behavior Analyst Today, 6(2), 111-120.

Kliebard, H. (2004). The struggle for the American curriculum. New York, NY: Routledge.

Klein, J. \& Rice, C. (2012). U.S. education reform and national security. (Independent Task Force Report No. 68). New York, NY: Council on Foreign Relations.

Kohn, A. (2000). The case against standardized testing: raising the scores, ruining the schools. Portsmouth, NH: Heinemann. 
Kozol, J. (1991). Savage inequalities: Children in America's schools. New York, NY: Crown.

Kunter, M., Klusmann, U., Baumert, J., Richter, D., Voss, T., \& Hachfeld, A. (2012). Professional competence of teachers: Effects on instructional quality and student development. Journal of Educational Psychology, 105(3), 805-820.

Ladson-Billings, G. (2011). Is meeting the diverse needs of all students possible? Kappa Delta Pi Record, 47(1), 13-15.

Lalvani, P. (2013). Privilege, compromise, or social justice: Teachers' conceptualizations of inclusive education. Disability \& Society, 28(1), 14-27.

Lee, C., \& Picanco, K., (2013). Accommodating diversity by analyzing practices of teaching (ADAPT). Teacher Education and Special Education, 36(2), 132-144.

Levin, B. (2014). The development of teachers' beliefs. In H. Fives \& M. Gill (Eds.), International handbook of research on teachers' beliefs (pp. 48-65). New York, NY: Routledge.

Levin, B., He, Y., \& Allen, M. (2013). Teacher beliefs in action: A cross sectional, longitudinal, follow-up study of teachers' personal practical theories. Teacher Educator, 48(3), 1-17.

Lincoln, Y. S., \& Guba, E. G. (1985). Naturalistic inquiry. Thousand Oaks, CA: Sage.

Little, C., McCoach, B., \& Reis, S. (2014). Effects of differentiated reading instruction on student achievement in middle school. Journal of Advanced Academics 25(4), 384-402. 
Liu, S. (2011). Factors related to pedagogical beliefs of teachers and technology integration. Computers and Education, 56(4), 1012-1022.

Lucas, T., Villegas, A., \& Martin, A. (2015). Teachers' beliefs about English language learners. In H. Fives and M. Gill (Eds.), International handbook of research on teachers' beliefs (pp. 453-474). New York, NY: Routledge.

Luke, A. (2010). Documenting reproduction and inequality: Revisiting Jean Anyon's “social class and school knowledge.” Curriculum Inquiry, 40(1), 167-182.

Lumby, J. (2013). Leading for equality in a changing Europe. In A. Kollias (Ed.), Critical factors in the discourse on SL from the perspective of equity and learning. (pp. 81-86). Southhampton, UK: European Policy Network on School Leadership. Retrieved from http://eprints.soton.ac.uk/364141/2/Leading\%20for\%20Equality $\% 20 \mathrm{in} \% 20 \mathrm{a} \% 20$ Changing\%20Europe\%20EPNoSL\%20pdf\%20version.pdf

MacFarlane, K., \& Woolfson, L. (2013). Teacher attitudes and behavior toward the inclusion of children with social, emotional, and behavioral difficulties in mainstream schools: An application of the theory of planned behavior. Teaching and Teacher Education, 29(1), 46-52. doi:10.1016/j.tate.2012.08.006

Maxwell, J. (2013). Qualitative research design: An interactive approach ( $\left.{ }^{\text {rd }} \mathrm{ed}.\right)$. Thousand Oaks, CA: Sage.

McAdamis, S. (2001). Teachers tailor their instruction to meet a variety of student needs. Journal of Staff Development, 22(2), 1-5. 
McIntyre, A. (1997). Making meaning of whiteness: Exploring racial identity with White teachers. Albany, NY: State University of New York Press.

McCroskey, L., Richmond, V., \& McCroskey, J. (2002). The scholarship of teaching and learning: Contributions from the discipline of communication. Communication Education, 51(4), 383-391.

McInerney, P. (2007). From naïve optimism to robust hope: Sustaining a commitment to social justice in schools and teacher education in neoliberal times. Asia-Pacific Journal of Teacher Education, 35(3), 257-272.

McTighe, J., \& Brown, J. (2010). Differentiated instruction and educational standards: Is détente possible? Theory into Practice, 44(3), 234-244.

Merriam, S. (1988). Case study research in education. San Francisco, CA: Jossey-Bass. Midgley, C., Maehr, M., Hruda, L., Anderman, E., Anderman, K., Gheen, M.,...Urdan, T. (2000). Manual for the patterns of adaptive learning scales. Ann Arbor: MI, 1001, 48109-1259

Milem, J., \& Umbach, P. (2003). The influence of precollege factors on students' predispositions regarding diversity activities in college. Journal of College Student Development, 44(5), 611-624.

Miles, M., \& Huberman, M. (1994). Qualitative data analysis: An expanded sourcebook. Newbury Park, CA: Sage.

Milesi, C., \& Gamoran, A. (2006). Effects of class size and instruction on kindergarten achievement. Educational Evaluation and Policy Analysis, 28(4), 287-313. 
Miller, P. (2011). A critical analysis of the research on student homelessness. Review of Educational Research, 81(3), 308-337.

Milner, H. R. (2006). Preservice teachers' learning about cultural and racial diversity: Implications for urban education. Urban Education, 41(4), 343-375.

Milner, H. R. (2010). Start where you are, but don't stay there: Understanding diversity, opportunity gaps, and teaching in today's classrooms. Cambridge, MA: Harvard Education Press.

Moon, T., Tomlinson, C., \& Callahan, C. (1995). Academic diversity in the middle school: Results of a national survey of middle school administrators and teachers. (Research Monograph No. 95124). Storrs, CT: National Research Center on the Gifted and Talented.

Morgan, H. (2014). Maximizing student success with differentiated learning. The Clearing House: A Journal of Educational Strategies, Issues, and Ideas, 87(1), 34-38.

Muis, K. (2004). Personal epistemology and mathematics: A critical review and synthesis of research. Review of Educational Research, 74(3), 317-377.

National Center for Education Statistics (2013). The Nation's Report Card: A First Look: 2013 Mathematics and Reading (NCES 2014-451). Institute of Education Sciences, U.S. Department of Education, Washington, D.C.

National Commission on Excellence in Education. (1983). A nation at risk: The imperative for educational reform. The Elementary School Journal, 84(2), 112130. 
National Council for Accreditation of Teacher Education. (2014). NCATE unit standards. Retrieved from http://www.ncate.org/Standards/tabid/107/Default.aspx National Middle School Association. (1995). This we believe: Developmentally responsive middle schools. Columbus, $\mathrm{OH}$ : Author.

National Middle School Association. (2010). This we believe: Keys to educating young adolescents. Westerville, $\mathrm{OH}$ : Author.

Nespor, J. (1987). The role of beliefs in the practice of teaching. Journal of Curriculum Studies, 19(4), 317-328.

Nuthall, G. (2005). The cultural myths and realities of classroom teaching and learning: A personal journey. The Teachers College Record, 107(5), 895-934.

Olafson, L., Grandy, C., \& Owens, M. (2015). Qualitative approaches to studying teachers' beliefs. In H. Fives \& M. Gill (Eds.), International handbook of research on teachers' beliefs (pp. 128-149). New York, NY: Routledge.

Oleson, A., \& Hora, M. (2014). Teaching the way they were taught? Revisiting the sources of teaching knowledge and the role of prior experience in shaping faculty teaching practices. Higher Education 68(1), 29-45.

Oregon Department of Education (2016). Statewide report card, 2015-2016. Retrieved from http://www.oregon.gov/ode/schools-anddistricts/reportcards/Documents/rptcard2016.pdf

Osgood, R. L. (2005). The history of inclusion in the United States. Washington, DC: Gallaudet University Press. 
Pajares, M. (1992). Teachers' beliefs and educational research: Cleaning up a messy construct. Review of Educational Research, 62(3), 307-332.

Parker, C. (2011). An investigation of differentiated instruction: Closing the achievement gap for elementary English language learners. (Doctoral dissertation). Available from ProQuest Dissertations and Theses database. (UMI No. 3438868).

Patton, M. (2005). Qualitative research. Hoboken, NJ: John Wiley \& Sons.

Plano Clark, V., \& Creswell, J. (2010). Understanding research: A consumer's guide. Upper Saddle River, NJ: Pearson.

Reis, S., Gentry, M., \& Maxfield, L. (1998). The application of gifted education pedagogy to teachers' classroom practices. Journal for the Education of the Gifted 21(3), 310-334.

Reis, S., Gubbins, E., Briggs, C., Schreber, F., Richards, S., Jacobs, J., \& Renzulli, J. (2004). Reading instruction for talented readers: Case studies documenting few opportunities for continuous progress. Gifted Child Quarterly, 48(4), 309-338.

Richardson, V. (1996). The role of attitudes and beliefs in learning to teach. In J. Sikula (Ed.), Handbook of research on teacher education (pp.102-119). New York, NY: Simon \& Schuster.

Richardson, V. (2003). Pre-service teachers' beliefs. In J. Raths \& A. McAninch (Eds.), Teacher beliefs and teacher education: Advances in teacher education (pp.1-22). Greenwich, CT: Information Age.

Rivkin, S., Hanushek, E., \& Kain, J. (2005). Teachers, schools, and academic achievement. Econometrica, 73(2), 417-458. 
Robinson, L., Maldonado, N., \& Whaley, J. (2014, November). Perceptions about implementation of differentiated instruction. Paper presented at the Annual MidSouth Educational Research (MSERA) conference, Knoxville, TN.

Rochkind, J., Ott, A., Immerwahr, J., Doble, J., \& Johnson, J. (2007). Lessons learned: new teachers talk about their jobs, challenges and long-range plans. Issue no. 2: Working without a net: How new teachers from three prominent alternate route programs describe their first year on the job. Washington, DC: National Comprehensive Center for Teacher Quality \& Public Agenda. Retrieved from http://files.eric.ed.gov/fulltext/ED499415.pdf

Roeser, R., \& Eccles, J. (1998). Adolescents' perceptions of middle school: Relation to longitudinal changes in academic and psychological adjustment. Journal of Research on Adolescence, 8(1), 123-158.

Rohrer, D \& Pashler, H. (2012). Learning styles: Where's the evidence? Medical Education 46(1), 34-35.

Rosenthal, R., \& Jacobson, L. (1968). Pygmalion in the classroom: Teacher expectation and pupils' intellectual development. New York, NY: Holt, Rinehart \& Winston.

Rubie-Davies, C. (2007). Classroom interactions: Exploring the practices of high- and low-expectation teachers. British Journal of Educational Psychology, 77(2), 289306.

Rubie-Davies, C. (2010). Teacher expectations and perceptions of student attributes: Is there a relationship? British Journal of Educational Psychology, 80(1), 121-135. 
Rubie-Davies, C., Flint, A., \& McDonald, L. (2012). Teacher beliefs, teacher characteristics and school contextual factors: What are the relationships? British Journal of Educational Psychology, 82(2), 270-288.

Rubin, B. (2006). Tracking and detracking: Debates, evidence, and best practices for a heterogeneous world. Theory into Practice, 45(1), 4-14.

Ryan, G., \& Bernard, H.R. (2003). Techniques to identify themes. Field Methods, 15(1), 85-109.

Ryan, K., \& Cooper, J. (2007). Those who can, teach. Boston: MA Wadsworth Cenage Learning.

Salend, S., \& Duhaney, G. (1999). The impact on inclusion on students with and without disabilities and their educators. Remedial and Special Education, 20(2), 114-126.

Santangelo, T., \& Tomlinson, C. (2012). Teacher educators' perceptions and use of differentiated instruction practices: an exploratory investigation. Action in Teacher Education, 34(4), 309-327.

Santamaria, L. (2009). Culturally responsive differentiated instruction: Narrowing gaps between best pedagogical practices benefitting all learners. Teachers College Record, 111(1), 214-247.

Savasci, F., \& Berlin, D. (2012). Science teacher beliefs and classroom practice related to constructivism in different school settings. Journal of Science Teacher Education, $23(1), 65-86$. 
Schofield, J. A. (2010). The colorblind perspective in school: Causes and consequences. In J.A. Banks and C.A.M. Banks (Eds.), Multicultural education: Issues and perspectives ( $7^{\text {th }}$ ed., pp. 259.283). Hoboken, NJ: Wiley.

Schofield, J. W. (2002). Increasing the generalizability of qualitative research. The qualitative researcher's companion, 171-203.

Seidman, I. (2013). Interviewing as qualitative research: A guide for researchers in the education and the social sciences. New York, NY: Teachers College Press.

Sharma, U., Loreman, T., \& Forlin, C. (2012). Measuring teacher efficacy to implement inclusive practices. Journal of Research in Special Education Needs, 12(1), 1221.

Sherman, S. (2009). Haven't we seen this before? Sustaining a vision in teacher education for progressive teaching practice. Teacher Education Quarterly, 36(4), 41-60.

Shulman, L. (1986). Those who understand: Knowledge growth in teaching. Educational Researcher, 15(2), 4-14.

Shulman, L. (1987). Knowledge and teaching: Foundations of the new reform. Harvard Educational Review, 57(1), 1-22.

Slavin, R. E., Madden, N. A., \& Leavey, M. (1984). Effects of team assisted individualization on the mathematics achievement of academically handicapped and nonhandicapped students. Journal of Educational Psychology, 76(5), 813819.

Smarter Balanced Assessment Consortium. (2014). Technology. Retrieved from http://www.smarterbalanced.org/smarter-balanced-assessments/technology/ 
Smit, R., \& Humpert, W. (2012). Differentiated instruction in small schools. Teaching and Teacher Education, 28(8), 1152-1162.

Soodak, L., Podell, D., \& Lehman, L. (1998). Teacher, student, and school attributes as predictors of teachers' responses to inclusion. The Journal of Special Education, 31(4), 480-497.

Stake, R. (1995). The art of case study research. Thousand Oaks, CA: Sage.

Subban, P. (2006). Differentiated instruction: A research basis. International Education Journal, 7(7), 935-947.

Sullivan, A., Klingbeil, D., \& Van Norman, E. (2013). Beyond behavior: Multilevel analysis of the influence of sociodemographics and school characteristics on students' risk of suspension. School Psychology Review, 42(1), 99-114.

Taylor, E. W., \& Snyder M. J. (2012). A critical review of research on transformative learning theory, 2006-2010. In E. W. Taylor, \& P. Cranton (Eds.), The handbook of transformative learning: Theory, research, and practice (pp. 37-55). San Francisco, CA: Jossey-Bass.

Thomas, G. (2012). How to do your case study: A guide for students and researchers. Thousand Oaks, CA: Sage.

Thoonen, E., Sleegers, P., Oort, F., Peetsma, T., \& Geijsel, F. (2011). How to improve teaching practices: The role of teacher motivation, organizational factors, and leadership practices. Educational Administration Quarterly, 47(3), 496-536. 
Thurlow, M., Moen, R., \& Altman, J. (2006). Annual performance reports: 2003-2004 state assessment. Minneapolis: University of Minnesota, National Center on Educational Outcomes.

Tomlinson, C. (1995). Deciding to differentiate instruction in middle school: One school's journey. Gifted Child Quarterly, 39(2), 77-87.

Tomlinson, C. (2006). Teaching beyond the book. Educational Leadership, 64(1), 16-21.

Tomlinson, C. (2014). The differentiated classroom: Responding to the needs of all learners. Alexandria, VA: Association for Supervision and Curriculum Development.

Tomlinson, C., Brighton, C., Hertberg, H., Callahan, C., Moon, T., Brimijoin, K., ... Reynolds, T. (2003). Differentiated instruction in response to student readiness, interest, and learning profile in academically diverse classrooms: A review of literature. Journal for the Education of the Gifted, 27 (2/3), 119-145.

Tomlinson, C., \& Imbeau, M. (2010). Leading and managing a differentiated classroom. Alexandria, VA: Association for Supervision and Curriculum Development.

Trent, S., Kea, C., \& Oh, K. (2008). Preparing preservice educators for cultural diversity: How far have we come. Exceptional Children, 74(3), 328-350.

Tschannen-Moran, M., \& Hoy, A.W. (2001). Teacher efficacy: capturing an elusive construct. Teaching and Teacher Education, 17(7), 783-805

Turner, R., Hewstone, M., \& Voci, A. (2007). Reducing explicit and implicit outgroup prejudice via direct and extended contact: The mediating role of self-disclosure 
and intergroup anxiety. Journal of Personality and Social Psychology, 93(3), 369388.

Tyler, K., Boykin, A., \& Walson, T. (2006). Cultural considerations in teachers' perceptions of student classroom behavior and achievement. Teaching and Teacher Education, 22(8), 998-1005.

Ullucci, K. (2007). The myths that blind: The role of beliefs in school change. Journal of Educational Controversy, 2(1), 1-7.

U.S. Census Bureau (2016). Quickfacts. Retrieved from https://www.census.gov/quickfacts/table/PST045216/41

U.S. Department of Education. (2002). No child left behind: Executive summary. Retrieved from www.ed.gov/nclb/overview/intro/execsumm.html

U.S. Department of Education, National Center for Education Statistics. (2013). Characteristics of Public and Private Elementary and Secondary School Teachers in the United States: Results from the 2011-12 Schools and Staffing Survey (NCES 2013-314). Washington, DC: National Center for Education Statistics, Institute of Education Sciences, U.S. Department of Education. Retrieved from https://nces.ed.gov/fastfacts/display.asp?id=55

U.S. Department of Education, National Center for Education Statistics. (2014). The Condition of Education 2014 (NCES 2014-083). Washington, DC: National Center for Education Statistics, Institute of Education Sciences, U.S. Department of Education. Retrieved from https://nces.ed.gov/programs/digest/d13/tables/dt13_203.60.asp?current=yes 
Van den Bergh, L., Denessen, E., Hornstra, L., Voeten, M., \& Holland, R. (2010). The implicit prejudiced attitudes of teachers: Relations to teacher expectations and the ethnic achievement gap. American Educational Research Journal, 47(2), 497527.

Villegas, A. (2007). Dispositions in teacher education: A look at social justice. Journal of Teacher Education, 58(5), 370-380.

Vogt, P., Gardner, D., \& Haeffele, L. (2012). When to use what research design. New York, NY: Guilford Press

Vogt, F., \& Rogalla, M. (2009). Developing adaptive teaching competency through coaching. Teaching and Teacher Education, 25(8), 1051-1060.

Vygotsky, L. (1978). Mind in society. Cambridge, MA: Harvard University Press.

Wang, M. (1980). Adaptive instruction: Building on diversity. Theory into Practice, 19(2), 122-128.

Washburne, C. (1925). Adapting the schools to individual differences. Bloomington, IL: Public School Publishing Company.

Weaver, M. (2006). Do students value feedback? Student perceptions of tutors' written responses. Assessment \& Evaluation in Higher Education, 31(3), 379-394.

Wenzel, A., \& Roberts, J. (2014). Coaching teacher dispositions: Research summary. Association for Middle Level Education. Retrieved from http://www.amle.org/BrowsebyTopic/WhatsNew/WNDet/TabId/270/ArtMID/888 /ArticleID/442/Coaching-Teacher-Dispositions.aspx

White, E. (2011). Whiteness and teacher education. Hoboken, NJ: Taylor and Francis. 
Wiggins, G., \& McTighe, J. (2005). Understanding by Design (2 ${ }^{\text {nd }}$ ed.). Alexandria, VA: Association for Supervision and Curriculum Development.

Woolfolk-Hoy, A., Davis, H., \& Pape, S. (2006). Teacher knowledge and beliefs. In P. A. Alenader \& P. H. Winne (Eds.), Handbook of educational psychology (2 ${ }^{\text {nd }}$ ed.) (pp. 715-737). Mahwah, NJ: Erlbaum.

Wormelli, R. (2007). Differentiation from planning to practice grades 6-12. Portland, ME: Stenhouse.

Yin, R. (2003). Case study research: Design and methods ( $3^{\text {rd }}$ ed.). Thousand Oaks, CA: Sage.

Zeichner, K., \& Melnick, S. (1996). The role of community field experiences in prepareing teachers for cultural diversity. In K. Zeichner, S. Melnick, \& M.L. Gomez (Eds.), Currents of reform in preservice teacher education (pp. 176-198). New York: Teachers College Press. 
Appendix A

Semi-Structured Interview 1 Questions \& Research Questions Addressed (in parentheses)

1. How do you define teaching?

2. How do you define learning?

3. How do you think students' best learn your content?

4. What are your goals for student learning?

5. How do you plan for your instruction? $(1,2)$

6. How do you decide what you teach and what not to teach? How do you decide when to move from one concept to another?

7. Tell me about the characteristics of your ideal learning environment.

8. On a scale of 1 (low) to 5 (high) rate how successful you feel adjusting your lessons for individual students. Why did you give yourself that rating? $\quad(1,3)$

9. Tell me about/ How well can you implement alternative strategies in your classroom? $(1,3)$

10. What are the different assessment methods you use? To what extent do you feel you can use a variety of assessment strategies? $\quad(1,3)$

11. To what extent do you feel can you provide an alternative explanation or example when students are confused? $(1,3)$

12. How do you know if students are learning? (1)

13. How well can you provide appropriate challenges for very capable students? $(1,3)$ 
Appendix B

Teacher Cultural Beliefs Scale

Please rate each of these statements on a scale from 1-5:

1 (strongly disagree), 2(disagree), 3(no opinion), 4(agree), 5(strongly agree)

If you wish to add any additional comments, please add them belwo the appropriate statement.

1. In the classroom, it is important to be responsive to differences between cultures.

2. It is important for children to learn that people from other cultures can have different values.

3. Respecting other cultures is something that children should learn as early as possible.

4. When counseling parents who have a different cultural background than I do, I try to be considerate of cultural particularities.

5. When meeting with parents of different cultural backgrounds, I spend more time trying to understand and empathize with their perspective.

6. Dealing with cultural diversity should be taught in teacher training courses.

7. Schools should aim to foster and support the similarities between students from different cultural backgrounds.

8. In the classroom, it is important that students of different origins recognize the similarities that exist between them.

9. When there are conflicts between students of different origins, they should be encouraged to resolve the argument by finding common ground.

10. Children should learn that people of different cultural origins often have a lot in common. 


\section{Appendix C}

Semi-Structured Interview 2 Questions \& Research Questions Addressed (in parentheses)

1. What are your goals for student learning?

2. How do you plan your lessons according to these goals?

3. How would you define differentiated instruction? What is your understanding of differentiated instruction? $\quad(1,3)$

4. How do you feel about differentiated learning (DI)? Do you feel that you implement DI in your classroom? Can you give an example? $(1,3)$

5. How do you view your role as a teacher?

6. What is the student role in the classroom?

7. How do you feel about your curriculum?

8. What are the most important factors that affect the way you teach?

9. What are other factors that influence the way you teach? Tell me about them. (3)

10. How do you want your students to view your class by the end of the school year? 
Appendix D

\section{Differentiated Instruction Observation Codes (Addresses Research Question 2)}

\begin{tabular}{|c|c|c|}
\hline Instructional Activity & Code & Description \\
\hline Lecture & $\mathrm{L}$ & Teacher lecturing to a group of students \\
\hline Lecture with Discussion & LD & $\begin{array}{l}\text { Teacher-led lecture, with periodic student discussion } \\
\text { (recitation) }\end{array}$ \\
\hline Class Discussion & $\mathrm{CD}$ & Discussion in class, students are primary discussants \\
\hline Small Group Discussion & GD & Discussion in class, but in small group, not whole group \\
\hline $\begin{array}{l}\text { Problem Modelling by } \\
\text { Teacher }\end{array}$ & $\mathrm{PM}$ & $\begin{array}{l}\text { Teacher working how to execute a task (e.g. working a math } \\
\text { problem on board) }\end{array}$ \\
\hline Student Presentation & SP & $\begin{array}{l}\text { Student(s) presenting information to the class (how to diagram } \\
\text { a sentence) }\end{array}$ \\
\hline $\begin{array}{l}\text { Demonstration by } \\
\text { Teacher }\end{array}$ & $\mathrm{D}$ & Teacher demonstrating a procedure to the class \\
\hline Questioning by Teacher & Q & Teacher asking question of student(s) in group setting \\
\hline Student Responding & SR & $\begin{array}{l}\text { Student(s) answering questions posed by teacher (choral } \\
\text { response included as well) }\end{array}$ \\
\hline Manipulatives & $\mathrm{M}$ & $\begin{array}{l}\text { Student(s) working with concrete materials to illustrate } \\
\text { abstract concepts (e.g. math blocks) }\end{array}$ \\
\hline Cubing & $\mathrm{C}$ & Students working with cubing curriculum materials \\
\hline Learning Center & $\overline{\mathrm{LC}}$ & $\begin{array}{l}\text { Student(s) working at planned learning center(s) individually } \\
\text { or in small groups }\end{array}$ \\
\hline $\begin{array}{l}\text { Anchoring activity before } \\
\text { lesson }\end{array}$ & $\mathrm{AB}$ & $\begin{array}{l}\text { Use of lesson-anchoring materials prior to teacher } \\
\text { presentation of content }\end{array}$ \\
\hline
\end{tabular}




\begin{tabular}{|c|c|c|}
\hline $\begin{array}{l}\text { Anchoring activity during } \\
\text { lesson }\end{array}$ & $\mathrm{AD}$ & $\begin{array}{l}\text { Use of lesson-anchoring activity during teacher presentation } \\
\text { of content }\end{array}$ \\
\hline $\begin{array}{l}\text { Anchoring activity after } \\
\text { lesson }\end{array}$ & $\mathrm{AA}$ & $\begin{array}{l}\text { Use of lesson-anchoring activity after teacher presentation of } \\
\text { content }\end{array}$ \\
\hline Seat work- Individual & SWI & $\begin{array}{l}\text { Student(s) working at desk on academic materials } \\
\text { (independently) }\end{array}$ \\
\hline Seat work- Group based & SWG & Student(s) working at desk on academic materials (groups) \\
\hline Cooperative learning & $\mathrm{CL}$ & $\begin{array}{l}\text { Students working in a planned cooperative structure to } \\
\text { complete a task }\end{array}$ \\
\hline Role Playing & $\mathrm{RP}$ & Student(s) engaged in role play exercises \\
\hline $\begin{array}{l}\text { Teacher interacting with } \\
\text { individual student }\end{array}$ & TIS & Teacher working with/talking to/helping individual student \\
\hline $\begin{array}{l}\text { Teacher interacting with } \\
\text { small group }\end{array}$ & TIG & Teacher working with/ talking to/helping individual student \\
\hline Technology use-Students & TS & $\begin{array}{l}\text { Technology being used by students for related learning } \\
\text { activities }\end{array}$ \\
\hline Technology use-Teacher & TT & $\begin{array}{l}\text { Technology being used by the teacher for presenting } \\
\text { instructional content }\end{array}$ \\
\hline Assessment activity & A & $\begin{array}{l}\text { Student(s) engaged in a formalized assessment activity (e.g. } \\
\text { test, performance) }\end{array}$ \\
\hline $\begin{array}{l}\text { Pull-out activity, } \\
\text { individual, or group }\end{array}$ & $\mathrm{PO}$ & Student(s) removed from the room- no observation possible \\
\hline Other & $\mathrm{O}$ & List of "other" activities \\
\hline
\end{tabular}


Date Time Location

\begin{tabular}{lll}
\hline Time & Codes & Narrative
\end{tabular}

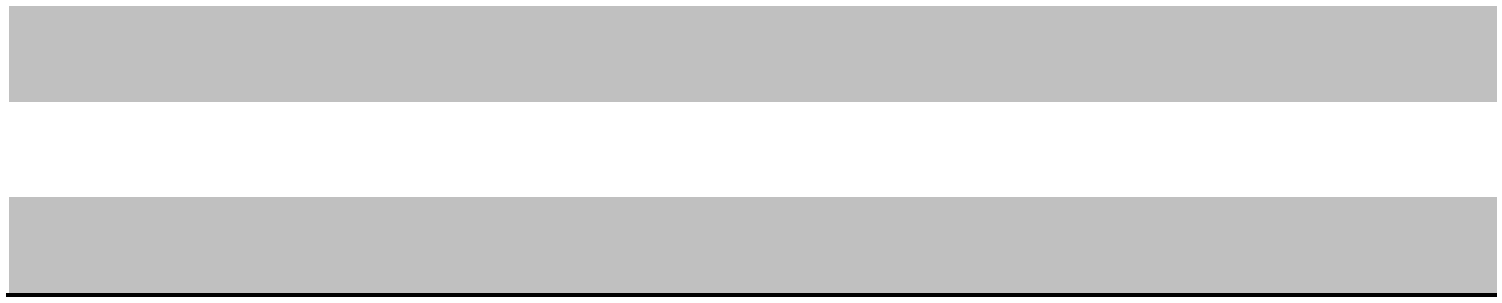

